\title{
Identification of two pathways mediating protein targeting from ER to lipid droplets
}

Jiunn Song ${ }^{1,2}$, Arda Mizrak ${ }^{1,2}$, Chia-Wei Lee ${ }^{1,2}$, Marcelo Cicconet ${ }^{1,7}$, Zon Weng Lai ${ }^{1,2,3}$, ChiehHan $\mathrm{Lu}^{1,2,8}$, Stephanie E. Mohr ${ }^{4}$, Robert V. Farese, Jr. ${ }^{1,2,5,7, *}$, Tobias C. Walther ${ }^{1,2,3,5,6,7, *}$

${ }^{1}$ Department of Cell Biology, Harvard Medical School, Boston, MA 02115, USA

${ }^{2}$ Department of Molecular Metabolism, Harvard T.H. Chan School of Public Health, Boston, MA 02115, USA

${ }^{3}$ Harvard Chan Advanced Multi-omics Platform, Harvard T.H. Chan School of Public Health, Boston, MA 02115, USA

${ }^{4}$ DRSC/TRiP Functional Genomics Resources \& DRSC-BTRR, Department of Genetics, Harvard Medical School, Boston, MA 02115, USA

${ }^{5}$ Broad Institute of Harvard and MIT, Cambridge, MA 02124, USA

${ }^{6}$ Howard Hughes Medical Institute, Boston, MA 02115, USA

${ }^{7}$ These authors contributed equally

*Correspondence: robert@hsph.harvard.edu (R.V.F.), twalther@hsph.harvard.edu (T.C.W.) 


\section{SUMMARY}

Pathways localizing proteins to their sites of action within a cell are essential for eukaryotic cell organization and function. Although mechanisms of protein targeting to many organelles have been defined, little is known about how proteins, such as key metabolic enzymes, target from the ER to cellular lipid droplets (LDs). Here, we identify two distinct pathways for ER-to-LD (ERTOLD) protein targeting: early ERTOLD, occurring during LD formation, and late ERTOLD, targeting mature LDs after their formation. By using systematic, unbiased approaches, we identified specific membrane-fusion machinery, including regulators, a tether, and SNARE proteins, that are required for late ERTOLD targeting. Components of this fusion machinery localize to LD-ER interfaces and appear to be organized at ER exit sites (ERES) to generate ERLD membrane bridges. We also identified multiple cargoes for early and late ERTOLD. Collectively, our data provide a new model for how proteins target LDs from the ER.

\section{KEY WORDS}

protein targeting, protein trafficking, membrane fusion, lipid droplet, endoplasmic reticulum, endoplasmic reticulum exit site, GPAT4, seipin, BSCL2

\section{HIGHLIGHTS}

- Proteins localize to LDs either during formation or later through ER-LD bridges

- Specific membrane fusion machinery localizes to LDs and mediates protein targeting

- Specific ER exit site proteins associate with LDs and participate in ERTOLD targeting

- Proteomic studies reveal cargoes for early and late ERTOLD targeting 


\section{INTRODUCTION}

Compartmentalization of biochemical reactions is a key feature of eukaryotic cells. To enable this compartmentalization, proteins must localize to specific sites in cells, such as the nucleus, mitochondria, or other organelles, where they carry out their functions. Although the protein targeting mechanisms for many organelles is well understood, we know relatively little about how proteins target to the surfaces of lipid droplets (LDs). Compared with other organelles, LDs are unusual since they are bounded by a monolayer of phospholipids that stabilizes their neutral lipid cores (Thiam et al., 2013a). The unusual architecture of LDs presents a challenge for cells: how do cellular proteins target specifically to the LD monolayer surface? Since LDs are ubiquitous organelles that store lipids as metabolic fuel and membrane lipid precursors (Olzmann and Carvalho, 2019; Walther and Farese, 2012; Welte, 2015), this problem is important for understanding the principles of energy storage and also is relevant to human disease. Mutations of LD proteins predispose to or cause metabolic diseases, such as non-alcoholic fatty liver disease/non-alcoholic steatohepatitis (NAFLD/NASH) [e.g., PNPLA3 (BasuRay et al., 2019; Romeo et al., 2008) and HSD17B13 (Abul-Husn et al., 2018)] and lipodystrophy [PLIN1 (Gandotra et al., 2011) and PCYT1A (Payne et al., 2014)], and some of the mutations affect localization of the proteins to LDs.

Evolution appears to have solved the problem of targeting proteins to LD surfaces with two principal pathways (Dhiman et al., 2020; Kory et al., 2016). In one, LD proteins are synthesized in the cytoplasm and directly bind LDs. In this cytoplasm to $\underline{\text { LD }}$ (CYTOLD) pathway, most commonly amphipathic helices of soluble proteins directly adsorb and bind to LD surfaces (Pataki et al., 2018; Prévost et al., 2018; Rowe et al., 2016). These protein segments bind preferentially to LDs where packing defects of phospholipids with exposed hydrophobic surfaces are likely more common, larger, and more persistent than in other membranes (Prévost et al., 2018).

The other pathway, ER-to-LD (ERTOLD) targeting, is less well understood. ERTOLD targeting is important for proteins harboring hydrophobic protein segments that are initially inserted into the ER bilayer (Kory et al., 2016; Schrul and Kopito, 2016). The few known cargoes for the ERTOLD pathway include important enzymes of lipid synthesis, such as ACSL3 [long chain acyl-CoA ligase 3] or GPAT4 [glycerol 3-phosphate acyltransferase 4] (Kassan et al., 2013; Wilfling et al., 2013). 
How proteins reach LDs from the ER is unclear. Inasmuch as LDs form in the ER, the simplest pathway is to move to the surface of a LD during its formation. Indeed, studies of a small, hydrophobic hairpin sequence derived from GPAT4, known as LiveDrop, show that it accumulates on LDs as they are forming in the ER at LD assembly complexes (LDACs), consisting of seipin and accessory proteins (Chung et al., 2019; Wang et al., 2016). The driving force for LD accumulation appears to be a conformational change that allows the protein to adopt an energetically more favorable state on the LD surface than in the ER membrane (Olarte et al., 2020). Similarly, HPos peptide, derived from ACSL3, localizes to LDs during their formation (Kassan et al., 2013).

Surprisingly, full-length GPAT4 does not utilize the same pathway to access LDs. It is excluded from LDs when they form and targets to mature LDs hours later (Wilfling et al., 2013). Light and electron microscopy studies provided evidence that late ERTOLD targeting involves physical continuities - or membrane bridges - between the ER and LDs (Cottier and Schneiter, 2022; Jacquier et al., 2011; Wilfling et al., 2013). How the bridges are formed is unknown. The Arfl/COPI vesicular trafficking machinery (Beck et al., 2009) is required for ERTOLD targeting of proteins, such as GPAT4 (Wilfling et al., 2014) and the major TG lipase ATGL (Beller et al., 2008; Ellong et al., 2011; Soni et al., 2009). Although the function of the Arf1/COPI machinery in this process is uncertain, it may promote membrane bridges forming between ER and LDs (Thiam et al., 2013b; Wilfling et al., 2014).

Here we sought to uncover the pathways of ERTOLD protein targeting. Specifically, we tested the hypothesis that there are early and late pathways of ERTOLD targeting, and we investigated the mechanism behind the formation of ER-LD membrane bridges that mediate late ERTOLD targeting. Using an unbiased screening approach, we identified the protein machinery for late ERTOLD targeting that supports heterotypic organelle fusion of the ER and LDs. This trafficking appears to occur at ERES, a subdomain of the ER important for protein export. Capitalizing on these insights, we systematically identified cargoes for the late ERTOLD targeting pathway. 


\section{RESULTS}

\section{ERTOLD cargoes access LDs at different time points during LD formation}

LiveDrop, but not full-length GPAT4, accesses LDs during their formation (Wang et al., 2016; Wilfling et al., 2013). To test whether ERTOLD targeting during LD formation is specific to LiveDrop or applies to full-length native proteins, we co-expressed fluorescently tagged GPAT4 and LD-associated hydrolase (LDAH), another known ERTOLD cargo (Thiel et al., 2013), in Drosophila cells. LDAH is a serine hydrolase implicated in the turnover of cholesterol esters in human macrophages and lipid storage in Drosophila (Goo et al., 2014; Kory et al., 2017; Thiel et al., 2013). LDAH is enriched on LDs as early as $30 \mathrm{~min}$ after induction of LD formation (by incubating cells in oleate-containing medium), but GPAT4 is enriched on LDs $\sim 3$ hours later (Figure 1A).

We also tested the targeting kinetics of several other LD proteins with hydrophobic regions that localize to the ER in the absence of LDs (Liu et al., 2018; Olzmann et al., 2013; Thul et al., 2017; Yu et al., 2018). Ubxd8, a recruitment factor for the p97 segregase, behaved comparable to LDAH and targeted LDs during formation, whereas the enzymes Ldsdh1 and HSD17B11 localized to LDs at later times, similar to GPAT4 (Figures 1B and 1C). Notably, overexpressed HSD17B11 targeted only some LDs, suggesting additional determinants of LD targeting for this protein (Figures S1A and S1B). Taken together, LD proteins appear to use different ERTOLD pathways to access LDs: some target during formation, and others later in LD biogenesis.

\section{A genome-wide screen identifies mediators of late ERTOLD targeting}

The inability of some ERTOLD proteins to access LDs during their formation raises the question of how they target mature LDs at later times. To address this, we systematically screened the genome for factors required for GPAT4 targeting to LDs (Figure 2A). Specifically, we determined the effects of RNAi-mediated protein depletions on LD targeting of stably expressed, fluorescently tagged GPAT4. Duplicate experiments were performed for the entire genome, collecting eight images for each knockdown and generating $~ 1.2$ million images in total. Automated image analysis segmented nuclei and LDs to quantify the level of GPAT4 at LDs for each cell (Figure S1C). We expressed the results as a LD targeting ratio, calculated by dividing the fluorescent signal of GPAT4 on LDs by the signal outside the LDs, and the median across all cells for each 
knockdown was reported as the final readout. Plotting the distribution of LD targeting ratios across all gene knockdowns revealed a normal distribution around a median value of 2.42 , similar to the result for negative control RNAi against LacZ (not expressed in Drosophila cells; Figures $2 B$ and 2C). As expected, depleting most gene products had no effect on GPAT4 targeting to LDs. In contrast, depleting the positive control proteins $\beta C O P$ or Arf1 (Wilfling et al., 2014) greatly decreased LD targeting of GPAT4, whereas depleting seipin increased targeting (Wang et al., 2016) (Figures 2B and S1D). These controls were reproducible, and results from replicate screens correlated well ( $\mathrm{R}=0.7645$; Figure $\mathrm{S1E})$. To make the results more accessible and allow efficient data mining, we will deposit all images and analyses at the Lipid Droplet Knowledge Portal [http://lipiddroplet.org/; (Mejhert et al., 2021)].

As a conservative cut-off for identifying screen hits, we focused on genes with a robust zscore of less than -2.5 or greater than 2.5 , indicating that the LD targeting ratio was at least 2.5 median absolute deviations from the overall median. These cutoffs yielded 896 genes that decreased and 214 genes that increased GPAT4 targeting upon knockdown (of 13,900 genes tested), excluding ribosomal, proteasomal, or spliceosomal genes. Analysis of the genes that reduced targeting revealed many genes encoding membrane-trafficking proteins. This was corroborated by gene ontology analysis (Eden et al., 2009) that showed enrichment of genes involved in Golgi apparatus vesicular transport $(\mathrm{p}=6.77 \mathrm{E}-08)$ and vesicle-mediated transport $(p=3.59 \mathrm{E}-06)$, as well as by enrichment of protein complexes (Vinayagam et al., 2013) involved in vesicle fusion and tethering (Figure S1F).

\section{Specific membrane-fusion factors are required for late ERTOLD targeting}

Among the genes required for GPAT4 targeting, we detected a Rab protein, a membrane tether, specific SNAREs, and auxiliary proteins that recycle the membrane-fusion machinery (Table S1 lists the gene nomenclature in this study).

Of the 30 Drosophila Rab GTPases, only Rab1 (robust Z-score $=-5.5$ ) was required for GPAT4 targeting to LDs in the screen (Figure 2D). To validate the specificity of this finding and the requirement of Rab1 in late ERTOLD targeting, we designed 2-3 additional dsRNAs against Rab proteins implicated in LD biology (Schroeder et al., 2015; Tan et al., 2013; Wang et al., 2012; Wu et al., 2014; Xu et al., 2018) and tested whether they are required for LD localization of 
GPAT4, fluorescently tagged at its endogenous genomic locus (Figures 3A and S2A). In agreement with the screen result, Rab1 depletion abolished GPAT4 targeting to LDs. In contrast, depleting Rab7, Rab8, Rab18, Rab32, or Rab40 had no effect on GPAT4 targeting. Expressing tagged wildtype Rab1 in cells depleted of Rab1 (with dsRNA against 5' UTR) rescued GPAT4 targeting to LDs, indicating that the effect is specific to the RNAi-mediated depletion of Rab1 (Figures S2B and S2C). Expression of the Rab1 N124I mutant, which acts as a dominant-negative to endogenous Rab1 by sequestering its activating guanine nucleotide exchange factor [GEF; (Satoh et al., 1997)], impaired endogenous GPAT4 targeting to LDs (Figures S2B and S2C).

Among membrane tethering complex components, GPAT4 targeting to LDs was reduced upon depletion of $\operatorname{Cog} 2$ (robust Z-score = -3.5), $\operatorname{Cog} 3$ (-3.2), Cog4 (-3.3), Rint1 (-4.1), Zw10 (2.8), and Trs20 (-4.9) (Figure 2D). In follow-up studies with additional dsRNA designs, depletion of $\operatorname{Cog} 2, \operatorname{Cog} 3$, and $\operatorname{Cog} 4$ led to much smaller LDs but did not impair LD targeting of GPAT4 (Figure S2A). We suspect that the apparent low targeting ratios may have resulted from small LDs and the limited resolution of the automated confocal microscope. In contrast, depletion of Trs20 and Rint 1 abolished LD targeting of tagged endogenous GPAT4 and resulted in LD targeting ratios close to 1 (Figures 3A and 3B). Yet, loss of the other components of TRAPP complexes (e.g., Trs23, Trs33, Bet5, Trs85, Trs120, or Trs130) or NRZ/NZZ complexes (e.g., Rod, Zw10, Zwilch) did not impair LD targeting of endogenous GPAT4 (Figures 3B and S2A). Depleting Vps52 and Vps53 (components of GARP complex) did not affect GPAT4 targeting to LDs (Figures 3B and S2A). Thus, of the membrane tethering factors, Trs20 and Rint1 were required for GPAT4 targeting.

In vesicular fusion, four SNARE proteins (one from each of $\mathrm{Qa}, \mathrm{Qb}, \mathrm{Qc}$, and $\mathrm{R}$ classes) localize to the vesicle and target membrane and assemble to fuse the compartments (Hong, 2005; Söllner et al., 1993). For repeated cycles, the auxiliary proteins NSF and $\alpha$ SNAP disassemble the post-fusion SNARE complex (Südhof and Rothman, 2009; Ungar and Hughson, 2003; Whiteheart et al., 1994; Zhao et al., 2015). In the screen, each known Drosophila SNARE protein was individually depleted. Depleting several Qa SNAREs (Syx5, robust Z-score = -6.7; Syx13, -3.4; Syx18, -4.5) and Qb SNAREs (membrin, -2.7; Sec20, -2.9) and a single Qc SNARE Bet1 (-6.1) and R SNARE Ykt6 (-3.9) reduced GPAT4 targeting to LDs (Figure 2D). In experiments with additional dsRNAs and endogenous GPAT4 knock-in cells, depletion of candidates reduced but did not abolish LD targeting of GPAT4 per se, except for a single SNARE of each class. 
Specifically, depletion of Syx5 (Qa), membrin (Qb), Bet1 (Qc), or Ykt6 (R) abolished GPAT4 targeting (Figures 3A, 3B, and S2A). Depleting NSF (robust Z-score = -3.3) or aSNAP (-6.4), but not NSF2, $\gamma \mathrm{SNAP} 1$, or $\gamma \mathrm{SNAP} 2$, reduced GPAT4 targeting to LDs in the screen, and these results were confirmed with additional dsRNAs in cells expressing endogenously tagged GPAT4 (Figures 3B and S2A). Finally, expressing the Syx5 1-445 truncation mutant (missing the Cterminal transmembrane segment) or the NSF-E329Q mutant (defective in ATP hydrolysis), which act as dominant-negatives to endogenous Syx5 and NSF, respectively (Dascher et al., 1994; Whiteheart et al., 1994), impaired LD targeting of endogenously tagged GPAT4 (Figures S2B and S2C).

We also examined the targeting of endogenous GPAT4 by immunoblotting lysate fractions from cells depleted of Trs20, Rab1, Rint1, Syx5 or Bet1. Endogenous GPAT4 amounts were decreased in LD fractions and increased in microsomal fractions for each of these factor knockdowns (Figures 3C and S3A).

Importantly, depletion of membrane fusion machinery specifically affected ERTOLD cargo, as depleting Trs20, Rab1, Rint1, Syx5, or Bet1 did not affect the LD delivery of CYTOLD cargoes, such as Lsd1, CGI-58, or CCT1 (Figures 3D-E and S3F-G). The targeting phenotype was further specific to the late ERTOLD pathway, as depletion of Trs20, Rab1, Rint1, Syx5, or Bet1 impaired LD targeting of Ldsdh1 (Figures 3D and 3E) and HSD17B11 (Figures S3B-E) but not of the early ERTOLD cargoes LDAH or Ubxd8 (Figures 3C-E and S3F-G).

\section{Membrane-fusion factors Rab1 and Rint1 localize to LDs}

To determine if the membrane-fusion machinery identified by the screen acts directly at LDs, we analyzed the localization of these factors in cells. Review of published data (Krahmer et al., 2018) supported localization of specific SNARE proteins at LDs; proteomic analysis of liver LDs showed that three of the four SNARE orthologs required for late ERTOLD in Drosophila cells (i.e., Stx5 (ortholog of Syx5), Bet11 (ortholog of bet1), and Ykt6) were enriched in LD fractions (Figure S4C). However, the site of SNARE protein action is difficult to analyze because these proteins act transiently in numerous membrane-fusion reactions. We therefore focused on the upstream factors, Rab1 and Rint1. To analyze their localizations, we expressed tagged versions of Rab1 or Rint1 in Drosophila cells, induced LDs by growing cells for 20 hours in oleate-containing medium, and 
analyzed their distribution by confocal microscopy. In agreement with prior reports of Rab1 enrichment in LD proteomes (Bersuker et al., 2018; Krahmer et al., 2013), mCherry-Rab1 formed ring-like intensities around LDs (Figure 3F). In comparison, EGFP-Rint1 showed a punctate localization with most of the signals adjacent to or overlapping with LDs (Figure 3F). Trs20 localized to LDs in a small fraction of cells when overexpressed (Figure S4A). When co-expressed with Rint1, both robustly localize to LDs, suggesting Trs20 is recruited to LDs by Rint1 (Figure S4B).

\section{ER exit sites are required for late ERTOLD protein targeting}

Membrane fusion in cells is often spatially organized to specific domains of organelles. It was thus noteworthy that a second category of membrane-trafficking factors required for GPAT4 targeting from the screen was genes involved in ERES organization and function (Figure S1F). ERES are special ER domains that form transport carriers with protein cargoes destined for secretion via the Golgi apparatus (Bannykh et al., 1996). Our screen identified most proteins that function at ERES as required for GPAT4 targeting to LDs, including Sec12, Sec16, Tango1, and most of COPII coat components (Sar1, Sec23, Sec24AB, Sec24CD, and Sec13) (Figure 4A). In contrast, other proteins implicated in secretory trafficking (e.g., coiled-coil tethering proteins) were not required for GPAT4 targeting to LDs (Figure 4A).

Depletion of ERES components from cells that expressed endogenously tagged GPAT4 with additional dsRNA designs showed they are required for GPAT4 targeting to LDs, unlike coiled-coil tethering proteins (Figures 4B and 4C). This effect was specific to late ERTOLD targeting (Ldsdh1 and HSD17B11; Figures S5A-D) and did not affect LD targeting of early ERTOLD cargoes (LDAH and Ubxd8; Figure S5E) or CYTOLD proteins (Lsd1, CGI-58, and CCT1; Figure S5F). Depletion of Sec16 or Tango1 (but not of controls LacZ or seipin) also reduced abundance of GPAT4 purified with LDs in subcellular fractionation experiments, unlike LDAH or CCT1 (Figure 4D). 


\section{ER exit site proteins localize to LDs}

To test if ERES are involved in late ERTOLD, we analyzed the localization of Tangol and Sec16 with respect to LD maturation by immunofluorescence. Many ERES were not localized to LDs, presumably because they operate in canonical protein export from the ER to the Golgi apparatus (Figures 4E and 4F). However, some ERES localized to apparent contact sites of the ER and LDs. Importantly, the association between ERES and LDs increased significantly and transiently around the time of late ERTOLD, approximately 4 hours after initiating oleic acid treatment. This suggests that ERES function in both the export of secretory proteins to the Golgi apparatus and late ERTOLD targeting to LDs. In agreement with a direct role of ERES at LDs, overexpressed Sec16 (fused with mCherry) localized around LDs and recruited endogenous Tangol (fused with EGFP) to LDs (Figure 4G), indicating that Sec16 may act upstream of Tangol at LDs. Additionally, expression of a tagged dominant-negative version of Sar1 (the GDP-restricted T34N mutant) formed ring-like signals around LDs and impaired targeting of endogenously tagged GPAT4 to LDs (Figures S2B and S2C).

The transiently increased association of LDs and Sec16 and Tango1 was accompanied by an increase in the number of ERES per cell at 4 hours after initiating oleic acid treatment (Figures 4E-F and S5G). This suggests a role for ERES at LDs, independent of the canonical secretory pathway. To better understand how the different ERES components organize around LDs, we depleted cells of the key component Tango1 and tested the association of other ERES components with LDs by mass spectrometry. Strikingly, abundance of ERES components Sec12, Sar1, Sec16, and Sec23 was robustly increased in LD fractions from cells depleted of Tangol compared with LacZ control (Figure 4H). Consistent with this, immunofluorescence microscopy showed increases in Sec16 puncta association with LDs upon Tangol RNAi (Figure 4I, two left-most panels). Similarly, Tango1 depletion increased association of the overexpressed constitutively active Sar1 H74G mutant (defective in GTP hydrolysis) and Sec23 with LDs by confocal microscopy (Figure S5H). Thus, depletion of the ERES protein Tango1 appears to increase Sar1, Sec23, and Sec16 localization to ER-LD contact sites.

To assess if Sec16 recruitment to LDs requires other ERES factors, we depleted Sec12, Sar1, or Sec23 on top of Tango1 and tested Sec16 association with LDs. Sec23 depletion did not affect Tango1 depletion-mediated Sec16 recruitment to LDs, but Sec12 or Sar1 depletion (with 
Tango1 depletion) abolished Sec16 recruitment to LDs (Figure 4I). Similarly, localization of overexpressed, tagged Sec16 around LDs required Sec12 and Sar1 but not Sec23 (Figure S5I). This contrasts with the previous finding that Sec16 localization to canonical ERES was independent of Sar1 (Ivan et al., 2008) and suggests differences in the ERES organization for ERTOLD and Golgi protein targeting.

\section{Seipin restricts late ERTOLD cargoes from accessing LDs during their formation}

Late ERTOLD targeting results in an apparent paradox: why do late ERTOLD cargo proteins stay in the ER not binding to LDs when they form? At LD formation sites, seipin forms a large complex with 20-24 transmembrane domains (depending on species) forming a 10-15-nm ring that appears to localize around the budding neck of forming LDs (Arlt et al., 2021; Sui et al., 2018; Yan et al., 2018). This structure suggests that the seipin complex may restrict ER proteins from accessing forming LDs. To test this possibility, we compared targeting kinetics of early and late ERTOLD proteins in cells lacking seipin. Unlike in wildtype cells (Figure 1), all analyzed early (LDAH, Ubxd8) and late ERTOLD proteins (GPAT4, Ldsdh1, HSD17B11) targeted LDs as early as 30 minutes after LD induction in seipin knock-out cells (Figure 5A).

When we depleted one of the ERES or ERTOLD membrane fusion machinery proteins (Sec16, Tango1, Trs20, Rab1, Rint1, Syx5 or Bet1) in seipin knock-out cells, we found that impaired localization of late ERTOLD targeting cargoes was rescued, compared with the defect found in wildtype cells depleted for these factors (Figures 3A-B, 4B-C, and 5B-C). Specifically, late ERTOLD proteins targeted LDs during their formation in the absence of seipin, even when the ERES or ERTOLD membrane fusion machinery proteins were depleted (Figures 5 D and S6A). Importantly, their depletion did not alter the formation of endogenous seipin foci near LDs (Figure S6B). This shows that seipin functions as a negative regulator of protein targeting to forming LDs, restricting the access of specific ERTOLD cargoes. This also indicates that depletion of late ERTOLD machinery does not impair the ability of late ERTOLD cargoes to move to LDs but instead abolishes their path to LDs, and the absence of seipin provides an alternative route for late ERTOLD targeting. 


\section{Systematic identification of late ERTOLD cargoes}

Identification of the machinery for late ERTOLD protein targeting enabled us to systematically identify proteins that depend on this trafficking route to access LDs. For this, we individually depleted members of the ERES or ERTOLD membrane fusion machinery (Tango1, Trs20, Rab1, Rint1, Syx5 or Bet1) from cells, isolated LDs, and analyzed their composition by mass spectrometry-based proteomics. Seipin knock-out cells and RNAi treatment targeting LacZ were included as controls. As expected, protein levels of each factor targeted by RNAi were dramatically reduced (Figure S7A). Filtering the data for the set of LD proteins (Krahmer et al., 2013) with two or four consecutive predicted transmembrane domains that may form membrane-embedded hairpins, we found $\sim 10$ proteins whose abundance in LD fractions was reduced by depletion of late ERTOLD targeting machinery components. These proteins included LPCAT, ACSL5, ReepA, and DHRS7B, in addition to GPAT4 (Figure 6A).

To confirm their targeting and dependence on late ERTOLD membrane fusion machinery, we expressed fluorescently tagged versions of these proteins in cells lacking Sar1, Sec16, Tango1, Rab1, or Syx 5 and compared them with LacZ controls. As with the proteomics results, we found that LD localization of ACSL5, DHRS7B, and LPCAT was strongly impaired by depletion of the late ERTOLD machinery (Figures 6B and 6C). ReepA targeting was not impaired, but it targeted LDs early instead (Figure S7 and S7C). 


\section{DISCUSSION}

Here we addressed a major gap in our understanding of protein targeting in eukaryotic cells: how do proteins localize from the bilayer membrane of the ER to the monolayer of LDs? We delineate two distinct mechanisms for ERTOLD targeting: early ERTOLD targeting with proteins transiting through LDACs during LD formation, and late ERTOLD targeting via independently established membrane bridges that connect the ER with mature LDs. We identified the membrane fusion machinery for late ERTOLD targeting and a requirement for ERES machinery in mediating late ERTOLD targeting. We uncovered a spatial association of LDs with many of these machinery components, including ERES. Additionally, we found numerous cargoes of early and late ERTOLD pathways.

Previously, we and others showed that some artificial ER-embedded hairpins, such as LiveDrop (Wang et al., 2016) or HPos (Kassan et al., 2013), access LDs during their formation. The LDAC component LDAF1, which appears to contain two hairpins, also accesses LDs during formation (Chung et al., 2019). We now find that early ERTOLD targeting occurs for other cellular proteins, including Ubxd8, LDAH, and ReepA. How some ER proteins, but not others, access nascent LDs during their formation is unclear. Current data suggest that the ring of seipin at LDACs restricts some but not all ERTOLD proteins from accessing nascent LDs [Figure 7, leftmost panel; (Arlt et al., 2021; Sui et al., 2018; Yan et al., 2018)].

The barrier between the ER and forming LDs necessitates an alternative pathway for protein targeting to LDs. Studies in Drosophila cells suggested that GPAT4 is excluded from nascent LDs and traffics to LDs via membrane bridges (Wilfling et al., 2013). The estimated speed of GPAT4 targeting to LDs was consistent with diffusion within membranes but was too fast for vesicular trafficking (Wilfling et al., 2014). These findings suggested that cells possess machinery to generate ER-LD membrane bridges, but how the bridges are established was unknown.

By performing an unbiased screen for factors enabling late ERTOLD targeting of GPAT4, we identified components required for each step of membrane fusion, including Rab1, Rint1, Trs20 and specific SNAREs. Rab GTPases act as switches for regulating various steps of intracellular membrane trafficking (Stenmark, 2009). Specifically, Rab1 has been implicated in tethering COPII-coated vesicles from the ER to $c i s$-Golgi by interacting with coil-coiled tether, such as p115 and GM130 (Allan et al., 2000; Beard et al., 2005; Moyer et al., 2001). Given the localization of 
Rab1 on LDs here and by others (Bersuker et al., 2018; Krahmer et al., 2013), we suspect that Rab1 acts as a molecular switch priming the LD membranes for heterotypic fusion with the ER. Alternatively, it may facilitate the extrusion of late ERTOLD cargoes at ERES (Westrate et al., 2020). Whereas p1 15 and GM130 were dispensable for late ERTOLD targeting, we found another membrane tethering complex component Rint1, which was proposed to help in establishing ERLD contacts (Xu et al., 2018), to localize around LDs and be required for late ERTOLD targeting.

Trs20, which is a shared component of different TRAPP complexes (Barrowman et al., 2010), was required for late ERTOLD targeting. TRAPP complexes may act as a GEF or a tethering complex for Rab1 (Kim et al., 2016). In agreement with a role of Trs20 in activating Rab1 in late ERTOLD targeting, expression of a Rab1 dominant-negative mutant (which sequesters TRAPP complexes) abolished GPAT4 targeting to LDs (Figure S2B and S2C). Intriguingly, no other component of TRAPP complexes was required for late ERTOLD targeting, which argues for a specific role of Trs20 in this context. Trs20 for instance may be critical for shaping the ER adjacent to LDs for protein export, as was suggested for its human ortholog Sedlin at ERES during the export of large cargoes, such as procollagen (Brandizzi and Barlowe, 2013; Venditti et al., 2012).

The SNARES we identified as necessary for late ERTOLD targeting constitute components of a putative SNAREpin: Syx5 (Qa SNARE), membrin (Qb), Bet1 (Qc) and Ykt (R). The capacity of this combination to fuse the ER membrane with a LD has not yet been tested, and which of the SNAREs may act on the side of LDs is unclear. Ykt6 is a good candidate as it is anchored to the membrane via a lipid modification (Fukasawa et al., 2004), rather than a transmembrane domain which would be incompatible with localizing to the LD monolayer. Also, Ykt6 was identified as a potential LD protein in systematic studies of LD composition (Bersuker et al., 2018; Krahmer et al., 2018).

Unexpectedly, our screen also identified many ERES components, including Sec12, Sar1, Sec16, and Tangol (Budnik and Stephens, 2009; Liu et al., 2017; Raote et al., 2018), as required for late ERTOLD protein targeting. Consistent with previous observations that ERES localize near LDs (Soni et al., 2009), we found transient association between ERES and LDs around the time late ERTOLD targeting begins. Thus, an ERES analogous domain may function in establishing late ERTOLD targeting bridges. This might explain why ATGL colocalizes with ERES markers 
when the COPI machinery is impaired (Soni et al., 2009). ERES domains functioning in secretory pathway or late ERTOLD targeting may compete for some of the same components since the number of Sec16 and Tango1 puncta increases in response to LD induction and many ERES components re-localize to sites around LDs when the ERES organizing protein Tango1 is depleted.

Arfl/COPI coatomer proteins are required for LD targeting of GPAT4 and ATGL (Beller et al., 2008; Soni et al., 2009; Wilfling et al., 2014). A current model for the function of Arf1/COPI proteins posits that they localize directly on LDs, modulating their surface properties (Thiam et al., 2013b; Wilfling et al., 2014). Although we do not know yet if they act before or after SNAREs, these proteins may be needed to modify the LD surface to accommodate fusion factors, such as Rab1 or Ykt6.

An attractive unifying model based on these and other findings (Raote et al., 2017, 2018; Weigel et al., 2021) is that the ER forms tubular carriers at ERES that connect to different target organelles. In the case of secretory trafficking, formation of such tubes or tunnels allows for secretion of large cargoes, such as collagens or lipoproteins (Raote et al., 2018; Santos et al., 2016), to the Golgi apparatus. In our model of late ERTOLD, tubular structures formed at ERES could instead fuse with LDs to form bridges between both organelles (Figure 7, middle panel). The result of the fusion reaction is that the cytosolic leaflet of the ER bilayer becomes contiguous with the LD monolayer surface, allowing membrane-embedded proteins to traverse between the organelles (Figure 7, right-most panel). Late ERTOLD proteins may then accumulate on LDs because this location is energetically favorable over the ER (Olarte et al., 2020).

\section{Limitations of the Study}

We previously reported microscopy evidence showing membrane bridges between the ER and LDs mediating protein targeting (Wilfling et al., 2013, 2014). Although evidence suggests that the identified membrane fusion and ERES proteins act directly at LDs to establish such ER-LD membrane bridges, direct visualization of this reaction is not available. Likely, the fusion reactions are fast, and only a few events are needed to mediate targeting. Moreover, the machinery used in this reaction is shared with other membrane trafficking reactions. Thus, like other membrane trafficking events, the establishment of membrane bridges is difficult to observe, and future work 
will have to focus on the biochemical dissection of the reaction, as well as visualization of membrane bridges.

The pathway of late ERTOLD targeting appear to be evolutionarily conserved between flies and humans, and some of the hits of our screen, such as Arf1/COPI, are required for ERTOLD targeting in both systems (Beller et al., 2008; Soni et al., 2009; Wilfling et al., 2014). It seems likely that late ERTOLD targeting operates in mammalian cells, inasmuch as salient features of cell biology are mostly conserved between organisms. This, however, will require further testing. Importantly, proteins involved in metabolic diseases, such as HSD17B13 (an orthologue of late ERTOLD cargo HSD17B11 in this study), may utilize this pathway, highlighting the importance of understanding the mechanisms of ERTOLD targeting for possible therapeutics. 


\section{ACKNOWLEDGMENTS}

We thank the members of Farese \& Walther laboratory, Drs. Timothy Mitchison (HMS), Norbert Perrimon (HMS, HHMI), and Adrian Salic (HMS) for helpful discussions. We also thank Drs. Mathias Beller (Heinrich Heine Universitat Dusseldorf, Germany), Sally Horne-Badovinac (University of Chicago), Luke Lavis (HHMI), Catherine Rabouille (Hubrecht Institute, Netherlands), and Norbert Perrimon for reagents; Rong Tao, Dr. Jonathan Zirin, Dr. Yanhui Hu, Dr. Donghui Yang-Zhou, Shannon Knight, and Gabriel Amador (DRSC, Department of Genetics, HMS) for technical support with screening; the Nikon Imaging Center (HMS) for imaging support; the Flow Cytometry Core (Department of Immunology, HMS) for the support with cell sorting; and Garry Howard for editorial assistance.

This work was supported by the grants from the National Institutes of Health R01GM097194 (T.C.W), 5TL1TR001101 (J.S.), and T32GM007753 (J.S.). J.S. received support from the American Heart Association Predoctoral Fellowship and the Aramont Fund for Emerging Science Research. T.C.W. is a Howard Hughes Medical Institute investigator. A.M. is a Helen Hay Whitney Foundation Postdoctoral Fellow. DRSC is supported by NIGMS P41 GM132087.

\section{AUTHOR CONTRIBUTIONS}

J.S., R.V.F., and T.C.W. conceived the project. J.S., R.V.F., and T.C.W. designed the screen, and S.M. and M.C. provided additional input. M.C. and J.S. built the pipeline for screen image analysis. J.S. performed and analyzed the screen. J.S. performed and analyzed most of the experiments. A.M. created Tango1 knock-in cell line. C-W.L. performed co-expression of LDAH and GPAT4 in cells. Z.W.L. performed mass spectrometry analyses. C-H.L. performed spatial analysis of LDs and ERES. J.S., R.V.F., and T.C.W. wrote the manuscript. All authors discussed the results and contributed to the manuscript.

\section{DECLARATION of INTRESTS}

The authors declare no competing interests. 


\section{FIGURE LEGENDS}

Figure 1. ER proteins target LDs early (early ERTOLD) or late (late ERTOLD) after LD induction

(A) ER proteins LDAH and GPAT4 target LDs early or late, respectively, upon LD biogenesis. Confocal imaging of live Drosophila S2 R+ cells stably overexpressing EGFP-GPAT4 transfected with a LDAH-mScarlet-I(mSi) encoding construct at given timepoints after $1 \mathrm{mM}$ oleic acid treatment. LDs were stained with LipidTOX Deep Red Neutral Lipid Stain. Scale bar, 5 and $1 \mu \mathrm{m}$ (inlay).

(B) Ubxd8 targets LDs early, and Ldsdh1 and HSD17B11 target LDs late upon LD biogenesis. Confocal imaging of live wildtype cells transiently transfected with EGFP tagged constructs at given timepoints after $1 \mathrm{mM}$ oleic acid treatment. LDs were stained with monodansylpentane (MDH). Representative images are shown. Scale bar, 5 and $1 \mu \mathrm{m}$ (inlay).

(C) Bar graph showing percentage of cells with LD targeting over time from the imaging experiment in (B), except LDAH-EGFP and EGFP-GPAT4 (not shown). For HSD17B11, cells with LD targeting were defined as those with $>2$ LDs with protein targeting in the imaging plane (see Figures S1A\&B). Mean \pm SD, $n=3$ independent experiments (10-16 cells each). One-way ANOVA, ${ }^{*} \mathrm{p}<0.05,{ }^{*} \mathrm{p}<0.01,{ }^{*} * \mathrm{p}<0.001, \# \mathrm{p}<0.0001$.

Figure 2. Genome-scale imaging screen reveals that the membrane-fusion machinery is required for GPAT4 targeting to LDs

(A) Overview of genome-scale imaging screen

(B) Histogram of targeting ratios of screen controls $(n=528$ for LacZ; $n=132$ for $\beta C O P$, Arf79F, and Seipin). Dotted lines indicate median values for each control.

(C) Histogram of all targeting ratios in the screen $(n=50,688)$. Median of all targeting ratios is indicated in black. Targeting ratios of select screen hits are indicated in different colors. 
(D) Heatmap of robust Z-scores for different classes of membrane fusion machinery (Rabs, tethering complexes, and SNAREs) from the imaging screen. Genes of which knockdown results in robust Z-score $<-2.5$ are highlighted in red.

Figure 3. Membrane-fusion regulator, tether, and SNAREs are required for late ERTOLD targeting

(A) Depletion of specific Rab, membrane-tethering complex components, and SNAREs abolishes endogenous GPAT4 targeting to LDs. Confocal imaging of live EGFP-GPAT4 endogenous knockin cells upon RNAi of membrane-fusion machinery components, followed by a 20-hr incubation in oleate-containing medium (except for $0 \mathrm{~h}$ timepoint for LacZ RNAi). LDs were stained with MDH. Representative images are shown. Scale bar, 5 and $1 \mu \mathrm{m}$ (inlay).

(B) Bar graph showing targeting ratios from the imaging experiment in (A) and Figure S2A. Mean $\pm \mathrm{SD}, \mathrm{n}=18-45$ cells from 2-3 independent experiments. Red color highlights knockdowns that abolish GPAT4 targeting to LDs on imaging. One-way ANOVA, **p $<0.01, * * * \mathrm{p}<0.001$, $\# \mathrm{p}<0.0001$, compared to LacZ unless otherwise indicated.

(C) Depletion of specific Rab, membrane-tethering complex components, and SNAREs reduces GPAT4 amount in LD fractions. Western blot analysis of fractions of wildtype cells upon RNAi, followed by a $20-\mathrm{hr}$ incubation in oleate-containing medium. Indicated on the left-hand side of the blot are protein targets of the primary antibodies, and on the right-hand side are ladder positions. Input $=$ whole-cell lysate, $M=$ membranes, $S=$ soluble fraction. Intensities of GPAT4 bands in LD fractions relative to LacZ control (1.00) were: $\operatorname{Trs} 20^{\#}(0.34 \pm 0.06), \operatorname{Rab}^{\#}(0.28 \pm 0.03)$, Rint $1^{\#}$ $(0.37 \pm 0.04), \operatorname{Syx}^{\#}(0.35 \pm 0.03)$, and $\operatorname{Bet}^{\#}(0.38 \pm 0.04)$ (mean $\pm \mathrm{SD}, \mathrm{n}=3$ independent experiments). One-way ANOVA, \#p<0.0001, compared to LacZ.

(D) Depletion of specific Rab, membrane-tethering complex components, and SNAREs impairs targeting of Ldsdh1 (late ERTOLD) but not of LDAH (early ERTOLD) or Lsd1 (CYTOLD). Confocal imaging of live wildtype cells upon RNAi of fusion machinery, followed by transient transfection of EGFP tagged constructs and a $20-\mathrm{hr}$ incubation in oleate-containing medium. Scale bar, 5 and $1 \mu \mathrm{m}$ (inlay). 
(E) Bar graph showing targeting ratios from the imaging experiment in (D). Mean $\pm \mathrm{SD}, \mathrm{n}=35-$ 50 cells from 3 independent experiments. One-way ANOVA, ${ }^{*} p<0.05, \# p<0.0001$, compared to LacZ.

(F) Localization of transiently transfected mCherry-Rab1 or EGFP-Rint1 with respect to LDs. Scale bar, 5 and $1 \mu \mathrm{m}$ (inlay).

Figure 4. ERES organizers associate with LDs and are required for late ERTOLD targeting (A) Heatmap of robust Z-scores for ER exit site organizers and coiled-coil tethers from the imaging screen. Genes of which knockdown results in robust Z-score $<-2.5$ are highlighted in red.

(B) Depletion of ERES components abolishes endogenous GPAT4 targeting to LDs. Confocal imaging of live EGFP-GPAT4 endogenous knock-in cells upon RNAi of ERES components, followed by a 20-hr incubation in oleate-containing medium. LDs were stained with MDH. Representative images are shown. Scale bar, 5 and $1 \mu \mathrm{m}$ (inlay).

(C) Bar graph showing targeting ratios from the imaging experiment in (B), including select coiledcoil tethers (images not shown). Mean $\pm \mathrm{SD}, \mathrm{n}=15-20$ cells from 2-3 independent experiments. One-way ANOVA, \#p<0.0001, compared to LacZ.

(D) Depletion of ERES components reduces GPAT4 amount in LD fractions. Western blot analysis of fractions of wildtype Drosophila S2 R+ cells upon RNAi, followed by a 20-hr incubation in oleate-containing medium. Indicated on the left-hand side of the blot are protein targets of the primary antibodies, and on the right-hand side are ladder positions. Input = wholecell lysate, sol = soluble fraction. Quantifications of GPAT4 bands in LD fractions relative to LacZ control are indicated (mean, $\mathrm{n}=3$ independent experiments). One-way ANOVA, **p<0.01, compared to LacZ.

(E) ERES components Sec16 and Tango1 associate spatially with LDs 4 hours after LD induction. Immunofluorescence of Sec16 and Tango 1 in wildtype cells at given timepoints after $1 \mathrm{mM}$ oleic acid treatment. Scale bar, 5 and $1 \mu \mathrm{m}$ (inlay).

(F) Bar graph showing percentages of Sec16 or Tangol puncta in association with LDs over time, calculated in 3-dimensional space per cell from the imaging experiment in $(\mathrm{E})$. Mean $\pm \mathrm{SD}, \mathrm{n}=$ 35-40 cells from 2 independent experiments. One-way ANOVA, $* * * p<0.001, \# p<0.0001$. 
(G) Overexpressed Sec16 localizes around LDs and recruits endogenous Tango1 to LDs. Confocal imaging of live Tango1-EGFP endogenous knock-in cells upon transient transfection of mCherry or mCherry-Sec 16 constructs, followed by a 20 -hr incubation in oleate-containing medium. Scale bar, 5 and $1 \mu \mathrm{m}$ (inlay).

(H) ERES components enrich in LD fractions upon Tangol depletion. Heatmap for abundance of ERES organizers in LD fractions upon LacZ vs. Tango1 RNAi, as measured by mass spectrometry and normalized to LacZ control.

(I) Sec16 strongly co-localizes around LDs upon Tango1 depletion. Immunofluorescence of Sec16 in wildtype cells upon RNAi of Tango1 or Tango1 plus another ERES component, followed by a 20-hr incubation in oleate-containing medium. Scale bar, 5 and $1 \mu \mathrm{m}$ (inlay).

\section{Figure 5. Seipin depletion allows for late ERTOLD targeting in the absence of fusion machinery or ERES components}

(A) Late ERTOLD proteins target LDs early in absence of seipin. Confocal imaging of live Seipin knockout cells transiently transfected with EGFP-tagged constructs at given timepoints after $1 \mathrm{mM}$ oleic acid treatment. LDs were stained with MDH. Representative images are shown. Percentage of cells with LD targeting are indicated (mean, $\mathrm{n}=3$ independent experiments, 8-13 cells each). Scale bar, 5 and $1 \mu \mathrm{m}$ (inlay).

(B) Absence of seipin provides an alternative pathway for LD targeting of late ERTOLD proteins. Confocal imaging of live wildtype or Seipin knock-out cells upon RNAi of ERES or fusionmachinery components, followed by transient transfection with EGFP-tagged constructs and a 20$\mathrm{hr}$ incubation in oleate-containing medium. Scale bar, 5 and $1 \mu \mathrm{m}$ (inlay).

(C) Bar graph showing targeting ratios from the imaging experiment in (B). Mean $\pm \mathrm{SD}, \mathrm{n}=35-$ 50 cells from 3 independent experiments. One-way ANOVA, $* * p<0.01, * * * p<0.001$, compared to LacZ.

(D) Bar graph showing percentages of cells with LD targeting after a $0.5-\mathrm{hr}$ incubation in oleatecontaining medium. Representative images are shown in Figure S6A.

\section{Figure 6. LD proteomics reveal additional late ERTOLD cargoes}


(A) Heatmap of abundance of potential ERTOLD proteins in LD fractions upon depletion of the late ERTOLD machinery components or seipin (compared to LacZ control), as measured by mass spectrometry.

(B) LPCAT, ACSL5, and DHRS7B require ERES or fusion-machinery components for LD targeting. Confocal imaging of live wildtype cells upon RNAi of ERES or fusion-machinery components, followed by transient transfection with EGFP-tagged constructs and a 20-hr incubation in oleate-containing medium. LDs were stained with MDH. Scale bar, 5 and $1 \mu \mathrm{m}$ (inlay).

(C) Bar graph showing targeting ratios from the imaging experiment in (B). Mean $\pm \mathrm{SD}, \mathrm{n}=30$ 50 cells from 3 independent experiments. One-way ANOVA, \#p<0.0001, compared to LacZ.

\section{Figure 7. Model of ERTOLD targeting}

Early cargoes can access forming LDs from the ER through the LDACs, whereas late cargoes cannot. A process mediated by the membrane-fusion machinery, including a Rab protein, membrane tethers and SNAREs, at ERES forms an ERTOLD bridge, which then allows LD targeting of late cargoes, such as GPAT4 and LPCAT, that are crucial for lipid metabolism on LD surfaces. 


\section{SUPPLEMENTAL FIGURE LEGENDS}

Figure S1. HSD17B11 targeting to LDs and an imaging screen to identify factors required for GPAT4 targeting to LDs, related to Figures 1 and 2

(A) Bar graph showing percentage of cells for a given number of LDs with HSD17B11-EGFP targeting over time after $1 \mathrm{mM}$ oleic acid treatment. Representative images are shown in Figure $1 \mathrm{~B}$.

(B) Representation of (A) with respect to time in oleate-containing medium.

(C) Schematic diagram for the calculation of targeting ratios in the imaging screen. Sample images from a well containing LacZ control are shown. Machine learning-based segmentation methods were used to segment individual cells and regions of LDs from the nuclear and LD stains, which are superimposed on EGFP-GPAT4 channel to calculate LD targeting ratio for each cell. Median of the targeting ratios from all segmented cells in eight different fields of the well is reported as the final readout.

(D) Representative images for screen controls. LacZ RNAi has no effect on GPAT4 targeting to LDs. Depletion of Arf79F or $\beta C O P$ reduces GPAT4 targeting to LDs. Depletion of seipin increases GPAT4 targeting to LDs. Scale bar, $10 \mu \mathrm{m}$.

(E) Genome-scale screen results are reproducible. Scatter plot showing targeting ratios from 2 independent genome-scale screen experiments. Linear regression line is shown in grey. R and R2 values are indicated.

(F) Protein complexes enriched among hits required for GPAT4 targeting to LDs (defined as robust Z-score < -2.5) using COMPLEAT (Vinayagam et al., 2013). Node color: Blue to red (lowest to highest robust Z-scores), grey (non-hits, robust Z-score > 2.5). Line type: solid (known interaction), dashed (known interaction among orthologs in another species). $\mathrm{p}$-value $<0.01$ for all complexes shown.

Figure S2. Specific membrane-fusion regulator, tether, and SNAREs are required for GPAT4 targeting to LDs, related to Figure 3

(A) Depletion of specific Rab, tethering-complex components, and SNAREs abolishes LD targeting to LDs. Confocal imaging of live EGFP-GPAT4 endogenous knock-in cells upon RNAi 
of membrane fusion machinery components, $20 \mathrm{~h}$ after $1-\mathrm{mM}$ oleic acid treatment (except for $0 \mathrm{~h}$ timepoint for LacZ RNAi). LDs were stained with MDH. Representative images are shown. Scale bar, 5 and $1 \mu \mathrm{m}$ (inlay). Quantification of targeting ratios is shown in Figure 3B.

(B) Effect of Rab1 depletion on LD targeting of GPAT4 is rescued by wildtype Rab1 expression, and the expression of dominant-negative Sar1, Rab1, Syx5, and NSF mutants impairs GPAT4 targeting to LDs. Confocal imaging of live EGFP-GPAT4 endogenous knock-in cells upon RNAi and/or overexpression of Halo tagged constructs. $\mathrm{H}=$ Halo tag. Scale bar, 5 and $1 \mu \mathrm{m}$ (inlay).

(C) Bar graph showing targeting ratios from the imaging experiment in (B). Mean $\pm \mathrm{SD}, \mathrm{n}=40$ 60 cells from 3 independent experiments. One-way ANOVA, $\# p<0.0001$.

Figure S3. Membrane-fusion regulator, tether, and SNAREs are required specifically for late ERTOLD targeting, related to Figure 3

(A). Western blot analysis of fractions of wildtype cells upon RNAi of fusion machinery components, followed by a $20-\mathrm{hr}$ incubation in oleate-containing medium. GPAT4 amount increases in membrane fractions but decrease in LD fractions upon depletion of membrane-fusion machinery components. Indicated on the left-hand side of the blot are protein targets of the primary antibodies, and on the right-hand side are ladder positions. I or Input $=$ whole-cell lysate, $\mathrm{S}=$ soluble fraction. Intensities of GPAT4 bands in membrane fractions relative to LacZ control (1.00) were: Trs20 (2.25 \pm 0.58$), \operatorname{Rab}^{*}(2.62 \pm 1.04)$, Rint1 $(2.11 \pm 0.25)$, Syx $^{* *}(3.07 \pm 0.40)$, and Bet1 $(2.17 \pm 0.28)\left(\right.$ mean $\pm \mathrm{SD}, \mathrm{n}=3$ independent experiments). One-way ANOVA, ${ }^{*} \mathrm{p}<0.05,{ }^{*} \mathrm{p}<0.01$ compared to LacZ.

(B) HSD17B11 requires membrane-fusion machinery components for targeting from the ER to LDs. Confocal imaging of live wildtype cells transiently transfected with HSD17B11-EGFP upon RNAi of fusion machinery, followed by a 20 -hr incubation in oleate-containing medium. Scale bar, 5 and $1 \mu \mathrm{m}$ (inlay).

(C) Bar graph showing percentage of cells with LD targeting (defined as those with $>2$ LDs with protein targeting) from the imaging experiment in (B). Mean $\pm \mathrm{SD}, \mathrm{n}=3$ independent experiments (12-17 cells each). One-way ANOVA, \#p<0.0001, compared to LacZ. 
(D) Bar graph showing percentage of cells for a given number of LDs with HSD17B11-EGFP targeting upon RNAi of membrane-fusion machinery. Representative images are shown in (B).

(E) Representation of (D) with respect different RNAi.

(F) Depletion of specific Rab, membrane-tethering complex components, and SNAREs does not impair targeting of Ubxd8 (early ERTOLD) or CGI-58 and CCT1 (CYTOLD). Confocal imaging of live wildtype cells transiently transfected with EGFP- or mCherry-tagged constructs upon RNAi of fusion machinery, followed by a 20 -hr incubation in oleate-containing medium. Scale bar, 5 and $1 \mu \mathrm{m}$ (inlay).

(G) Bar graph showing targeting ratios from the imaging experiment in $(\mathrm{G})$. Mean $\pm \mathrm{SD}, \mathrm{n}=30$ 60 cells from 3 independent experiments. For mCherry-CCT1, nuclear signal was excluded from the calculation. One-way ANOVA, \#p<0.0001, compared to LacZ.

Figure S4. Trs20 and specific SNAREs associate with LDs, related to Figure 3

(A) Trs20 forms punctate localizations around LDs when highly overexpressed. Localization of transiently transfected Trs20-EGFP with respect to LDs. "Low" and "high" indicate the degree of overexpression, based on fluorescence intensity. Scale bar, 5 and $1 \mu \mathrm{m}$ (inlay).

(B) Overexpressed Rint1 recruits Trs20 to LDs. Localization of transiently co-transfected Trs20EGFP and mCherry-Rint1 with respect to LDs. Scale bar, 5 and $1 \mu \mathrm{m}$ (inlay).

(C) Specific SNAREs are enriched in the LD fraction of murine fatty liver [data mined from nafldorganellemap.org; (Krahmer et al., 2018)]. In this study, mice were subjected to 12 weeks of highfat diet, their livers were harvested and separated into 22 fractions using a sucrose gradient, and proteomes of the fractions were analyzed with mass spectrometry. First row shows the organellar migration pattern for LDs based on protein correlation profiling. SNAREs are classified according to their classes, and the predicted orthologs of SNAREs required for late ERTOLD targeting (Syx5, membrin, Bet1, and Ykt6) are highlighted in red.

Figure S5. ERES increase in number upon LD induction and are specifically required for late ERTOLD targeting, related to Figure 4 
(A) Sec16 and Tango 1 are required for LD targeting of Ldsdh1. Confocal imaging of live wildtype cells upon RNAi of ERES components, followed by transient transfection with Ldsdh1-EGFP and a $20-$ hr incubation in oleate-containing medium. Scale bar, 5 and $1 \mu \mathrm{m}$ (inlay). Bar graph shows targeting ratios calculated from the images. Mean $\pm \mathrm{SD}, \mathrm{n}=40-50$ cells from 3 independent experiments. One-way ANOVA, \#p<0.0001, compared to LacZ.

(B) Sec16 and Tango1 are required for LD targeting of HSD17B11. Confocal imaging of live wildtype cells upon RNAi of ERES components, followed by transient transfection with HSD17B11-EGFP and a 20-hr incubation in oleate-containing medium. Scale bar, 5 and $1 \mu \mathrm{m}$ (inlay). Bar graph shows percentage of cells with LD targeting (defined as those with $>2$ LDs with protein targeting). Mean $\pm \mathrm{SD}, \mathrm{n}=3$ independent experiments (14-17 cells each). One-way ANOVA, \#p<0.0001, compared to LacZ.

(C) Bar graph showing percentage of cells for a given number of LDs with HSD17B11-EGFP targeting upon RNAi of ERES components. Representative images are shown in (B).

(D) Representation of (C) with respect different RNAis.

(E-F) Sec16 and Tango1 are dispensable for LD targeting of LDAH and Ubxd8 (early ERTOLD) and of Lsd1, CGI-58, and CCT1 (CYTOLD). Confocal imaging of live wildtype cells upon RNAi of fusion machinery, followed by transient transfection of EGFP or mCherry tagged constructs and a $20-\mathrm{hr}$ incubation in oleate-containing medium. Scale bar, 5 and $1 \mu \mathrm{m}$ (inlay). Bar graph shows targeting ratios calculated from the images. For mCherry-CCT1, nuclear signal was excluded from the calculation. Mean $\pm \mathrm{SD}, \mathrm{n}=30-50$ cells from 3 independent experiments. Oneway ANOVA, *p<0.05, compared to LacZ.

(G) LD induction transiently increases the number of Sec16 and Tango1 puncta. Bar graph showing the number of Sec16 or Tango1 puncta in 3-dimensional space per cell over time in oleatecontaining medium. Representative images are shown in Figure 4E. Mean $\pm \mathrm{SD}, \mathrm{n}=35-40$ cells from 2 independent experiments. One-way ANOVA, ***p $<0.001, \# p<0.0001$.

(H) Overexpressed Sar1-H74G and Sec23 accumulate around LDs upon Tango1 depletion. Confocal imaging of live wildtype cells upon RNAi of LacZ or Tango1, followed by transient transfection of EGFP tagged ERES components and a 20-hr incubation in oleate-containing medium. Scale bar, 5 and $1 \mu \mathrm{m}$ (inlay). 
(I) Localization of Sec16 around LDs and its recruitment of endogenous Tango1 require Sec12 and Sar1 but not Sec23. Confocal imaging of live Tango1-EGFP endogenous knock-in cells upon RNAi of ERES components followed by transient transfection with an mCherry-Sec16 construct and a 20 -hr incubation in oleate containing medium. Scale bar, 5 and $1 \mu \mathrm{m}$ (inlay).

\section{Figure S6. Seipin-mediated ER-LD contacts are independent of late ERTOLD pathway, related to Figure 5}

(A) Seipin depletion allows for early targeting of late ERTOLD cargoes even in the absence of late ERTOLD machinery. Confocal imaging of live wildtype or Seipin knock-out cells upon RNAi of ERES or fusion machinery components, followed by transient transfection with EGFP tagged constructs and a $0.5-\mathrm{hr}$ incubation in oleate-containing medium. Scale bar, 5 and $1 \mu \mathrm{m}$ (inlay). Quantification is shown in Figure 5D.

(B) Depletion of late ERTOLD machinery does not affect association of seipin puncta with LDs. Confocal imaging of live GFP-Seipin endogenous knock-in cells upon RNAi of ERES or fusion machinery components, followed by a 20 -hr incubation in oleate-containing medium. Scale bar, 5 and $1 \mu \mathrm{m}$ (inlay).

\section{Figure S7. LD proteomics reveal additional late ERTOLD cargoes, related to Figure 6}

(A) Heatmap of abundance of ERES and fusion-machinery components and seipin in LD fractions upon their depletion by RNAi (or gene deletion for Seipin) compared to LacZ control, as measured by mass spectrometry.

(B) REEPA targets LDs early, and LPCAT, ACSL5, and DHRS7B target LDs late upon LD induction. Confocal imaging of live wildtype cells transiently transfected with EGFP-tagged constructs at given timepoints after $1 \mathrm{mM}$ oleic acid treatment. LDs were stained with MDH. Representative images are shown. Scale bar, 5 and $1 \mu \mathrm{m}$ (inlay).

(C) Bar graph showing percentage of cells with LD targeting over time from the imaging experiment in (B). Mean $\pm \mathrm{SD}, \mathrm{n}=3$ independent experiments (10-20 cells each). One-way ANOVA, $* * p<0.01, \# p<0.0001$. 


\section{METHODS}

- KEY RESOURCES TABLE

- RESOURCE AVAILABILITY

○ Lead Contact

- Materials Availability

- Data and Code Availability

- EXPERIMENTAL MODEL AND SUBJECT DETAILS

- Cell lines and cell culture

- METHOD DETAILS

- Special reagents

- Genome-scale RNAi imaging screen

- Plasmid construction

- Transfection

- In vitro double-stranded RNA synthesis

○ RNA interference

- Generation of a stable cell line

- Generations of cell lines using CRISPR-Cas9

- Immunofluorescence

- Fluorescence microscopy

- Fractionation of cells

- Immunoblotting

- Mass Spectrometry

- QUANTIFICATION AND STATISTICAL ANALYSIS

- Statistical analysis

- Analysis of genome-scale imaging screen

- Quantification of fluorescence images

- Spatial association between ERES and LDs

- Quantification of immunoblots

- Analysis of mass spectrometry data 


\section{KEY RESOURCES TABLE}

\begin{tabular}{|c|c|c|}
\hline REAGENT or RESOURCE & SOURCE & IDENTIFIER \\
\hline \multicolumn{3}{|l|}{ Antibodies } \\
\hline Rabbit anti-Drosophila GPAT4 & (Wilfling et al., 2013) & $\mathrm{N} / \mathrm{A}$ \\
\hline Rat anti-Drosophila LDAH & (Thiel et al., 2013) & $\mathrm{N} / \mathrm{A}$ \\
\hline Rabbit anti-Drosophila CCT1 & (Krahmer et al., 2011) & $\mathrm{N} / \mathrm{A}$ \\
\hline Mouse anti-Drosophila CNX99A & $\begin{array}{l}\text { (Riedel et al., 2016), } \\
\text { available on } \\
\text { Developmental } \\
\text { Studies Hybridoma } \\
\text { Bank }\end{array}$ & Cat\# Cnx99A 6-2-1 \\
\hline Mouse anti-a-tubulin & Sigma Aldrich & Cat\# T5168 \\
\hline Rabbit anti-Drosophila Sec16 & (Ivan et al., 2008) & N/A \\
\hline Guinea pig anti-Drosophila Tango1 & (Lerner et al., 2013) & $\mathrm{N} / \mathrm{A}$ \\
\hline Mouse monoclonal anti-rabbit IgG-HRP & $\begin{array}{l}\text { Santa Cruz } \\
\text { Biotechnology }\end{array}$ & Cat\# sc-2357 \\
\hline Mouse anti-lgG kappa binding protein-HRP & $\begin{array}{l}\text { Santa Cruz } \\
\text { Biotechnology }\end{array}$ & Cat\# sc-516102 \\
\hline Goat anti-rat IgG H\&L-HRP & Abcam & Cat\# ab97057 \\
\hline Alexa Fluor 647 goat anti-rabbit IgG & Thermo Scientific & Cat\# A-21244 \\
\hline Alexa Fluor 488 goat anti-guinea pig IgG & Thermo Scientific & Cat\# A-11073 \\
\hline \multicolumn{3}{|l|}{ Bacterial and virus strains } \\
\hline One Shot $^{\text {TM }}$ TOP10 Chemically Competent E. coli & $\begin{array}{l}\text { Thermo Fisher } \\
\text { Scientific }\end{array}$ & Cat\# C404003 \\
\hline \multicolumn{3}{|l|}{ Chemicals, peptides, and recombinant proteins } \\
\hline Oleic Acid & Sigma-Aldrich & Cat\# 01008 \\
\hline AUTOdot Autophagy Visualization Dye & Abgent & Cat\# SM1000b \\
\hline HCS LipidTOX Deep Red Neutral Lipid Stain & $\begin{array}{l}\text { Thermo Fisher } \\
\text { Scientific }\end{array}$ & Cat\# H34477 \\
\hline Effectene Transfection Reagent & Qiagen & Cat\# 301425 \\
\hline Concanavalin A & Sigma-Aldrich & Cat\# C5275 \\
\hline Benzonase Nuclease & Millipore & Cat\# E1014 \\
\hline $\begin{array}{l}\text { cOmplete, Mini, EDTA-free Protease } \\
\text { Inhibitor Cocktail }\end{array}$ & Roche & 11836170001 \\
\hline \multicolumn{3}{|l|}{ Critical commercial assays } \\
\hline $\mathrm{pENTR}^{\mathrm{TM}} / \mathrm{D}-\mathrm{TOPO}{ }^{\mathrm{TM}}$ Cloning Kit & Invitrogen & Cat\# K240020 \\
\hline Gateway $^{\mathrm{TM}}$ LR Clonase ${ }^{\mathrm{TM}}$ II Enzyme mix & Invitrogen & Cat\# 11791020 \\
\hline NucleoSpin Gel and PCR Clean-up Kit & Macherey-Nagel & Cat\# 740609.250 \\
\hline MEGAscript $^{\mathrm{TM}}$ T7 Transcription Kit & Invitrogen & AMB13345 \\
\hline $\begin{array}{l}\text { QuikChange II XL Site-Directed } \\
\text { Mutagenesis Kit }\end{array}$ & Agilent Technologies & Cat\# 200521 \\
\hline Pierce BCA Protein Assay Kit & $\begin{array}{l}\text { Thermo Fisher } \\
\text { Scientific }\end{array}$ & Cat\# 23225 \\
\hline SuperSignal West Pico & $\begin{array}{l}\text { Thermo Fisher } \\
\text { Scientific }\end{array}$ & Cat\# 34580 \\
\hline \multicolumn{3}{|l|}{ Deposited data } \\
\hline Published dataset: murine fatty liver organellar proteome & (Krahmer et al., 2018) & $\begin{array}{l}\text { www.nafld- } \\
\text { organellemap.org }\end{array}$ \\
\hline Screen images/analysis results & This paper & www.Lipiddroplet.org \\
\hline
\end{tabular}




\begin{tabular}{|c|c|c|}
\hline Screen quantification pipeline (MATLAB-based) & This paper & $\begin{array}{l}\text { https://doi.org/10.79 } \\
\text { 10/DVN/NKJDWS }\end{array}$ \\
\hline Lipid droplet fraction proteomics & This paper & $\begin{array}{l}\text { ProteomeXchange } \\
\text { Consortium, dataset } \\
\text { identifier } \\
\text { PXD027283 }\end{array}$ \\
\hline \multicolumn{3}{|l|}{ Experimental models: Cell lines } \\
\hline D. melanogaster: Cell line S2: S2R+ & $\begin{array}{l}\text { Laboratory of Norbert } \\
\text { Perrimon (Harvard } \\
\text { Medical School, } \\
\text { HHMI) }\end{array}$ & $\begin{array}{l}\text { FlyBase ID: } \\
\text { FBtc0000150; RRID: } \\
\text { CVCL_Z831 }\end{array}$ \\
\hline \multicolumn{3}{|l|}{ Oligonucleotides } \\
\hline $\begin{array}{l}\text { Please see Table S2 and Table S3 for primer } \\
\text { sequences used for cloning plasmids and double- } \\
\text { stranded RNA synthesis }\end{array}$ & This paper & $\mathrm{N} / \mathrm{A}$ \\
\hline \multicolumn{3}{|l|}{ Recombinant DNA } \\
\hline $\begin{array}{l}\text { Please see Table S2 for all plasmids used and cloned in } \\
\text { this study }\end{array}$ & This paper & $\mathrm{N} / \mathrm{A}$ \\
\hline pmScarlet-i_C1 & $\begin{array}{l}\text { (Bindels et al., 2017), } \\
\text { available on Addgene }\end{array}$ & Plasmid \#85044 \\
\hline pAc5-STABLE-Puro $^{R}$ & (González et al., 2011) & $\mathrm{N} / \mathrm{A}$ \\
\hline \multicolumn{3}{|l|}{ Software and algorithms } \\
\hline MATLAB R2017a & MathWorks & $\begin{array}{l}\text { www.mathworks.co } \\
\text { m }\end{array}$ \\
\hline NIS-Elements & NiKon & $\mathrm{N} / \mathrm{A}$ \\
\hline Fiji & $\begin{array}{l}\text { (Schindelin et al., } \\
\text { 2012) }\end{array}$ & https://fiji.sc/ \\
\hline DiAna & (Gilles et al., 2017) & $\mathrm{N} / \mathrm{A}$ \\
\hline GraphPad Prism 8 & GraphPad & www.graphpad.com \\
\hline MaxQuant & (Cox and Mann, 2008) & www.maxquant.org \\
\hline
\end{tabular}




\section{RESOURCE AVAILABILITY}

\section{Lead Contact}

Further information and requests for resources and reagents should be directed to and will be fulfilled by the Lead Contact, Tobias C. Walther (twalther@hsph.harvard.edu).

\section{Materials Availability}

All unique/stable reagents used in this study are available from the Lead Contact with a completed Materials Transfer Agreement in accordance with the Harvard T.H. Chan School of Public Health policies.

\section{Data and Code Availability}

Original screen images and quantification results will be available at the Lipid Droplet Knowledge Portal [http://lipiddroplet.org/; (Mejhert et al., 2021)]. All original code (used for quantification of screen images) has been deposited at Harvard Dataverse and is publicly available. DOIs are listed in the key resources table.

The mass spectrometry proteomics data have been deposited to the ProteomeXchange Consortium via the PRIDE (Perez-Riverol et al., 2019) partner repository with the dataset identifier PXD027283. 


\section{EXPERIMENTAL MODEL and SUBJECT DETAILS}

\section{Cell lines and cell culture}

The Drosophila cells used in this study belong to the $\mathrm{S} 2 \mathrm{R}+$ cell line (sex: male) and were provided by Dr. Norbert Perrimon (Harvard Medical School). Cells were cultured at $26^{\circ} \mathrm{C}$ in Schneider's Drosophila Medium (Gibco, \#21720001) supplemented with 10\% fetal bovine serum (Gibco), 25 units $/ \mathrm{ml}$ penicillin, and $25 \mu \mathrm{g} / \mathrm{ml}$ streptomycin. Cells were maintained by splitting 1:6-1:12 every 3-4 days. Where noted, cells were incubated with $1 \mathrm{mM}$ oleic acid complexed with essentially fatty acid-free BSA to induce LDs. 


\section{METHODS DETAILS}

\section{Special reagents}

Janelia Fluor 646 HaloTag Ligand (JF646) was a kind gift from Dr. Luke Lavis (Janelia Research Campus, USA). Anti-dmLDAH used for western blot experiments (Thiel et al., 2013) was a gift from Dr. Mathias Beller (Heinrich Heine Universitat Dusseldorf, Germany). Anti-dmSec16 used for immunofluorescence experiments (Ivan et al., 2008) was a gift from Dr. Catherine Rabouille (Hubrecht Institute, Netherlands). Anti- $d m$ Tango1 used for immunofluorescence experiments (Lerner et al., 2013) was a gift from Dr. Sally Horne-Badovinac (University of Chicago, USA).

$10 \mathrm{mM}$ oleic acid was prepared by dissolving $1.98 \mathrm{~g}$ of essentially fatty acid-free BSA in $10 \mathrm{~mL}$ PBS, adding $31.74 \mu \mathrm{L}$ oleic acid drop-by-drop, and shaking at $37^{\circ} \mathrm{C}$ for $1 \mathrm{hr}$. Solution was sterile-filtered $(0.22 \mu \mathrm{m})$ before use. All oleic acid treatments were performed with $1 \mathrm{mM}$ final concentration.

\section{Genome-scale RNAi imaging screen}

Drosophila S2 R+ cells stably overexpressing EGFP-GPAT4 were subjected to a genome-scale library of dsRNA in imaging-compatible 384-well plates (PerkinElmer, \#6057300) two times, prepared by the HMS Drosophila RNAi Screening Center (DRSC 2.0 genome-wide screening library). The library targets approximately 13,900 genes 1 2 times and consists of 66 384-well plates with $250 \mathrm{ng}$ of double-stranded RNA (dsRNA) in $5 \mu \mathrm{L}$ per well. Confluent cells were resuspended from plates to $60 \times 10^{4}$ cells $/ \mathrm{mL}$ in Schneider's Drosophila Medium (Gibco, \#21720001) without serum supplementation. $10 \mu \mathrm{L}$ of the cell suspension was dispensed into the dsRNA plates using the Thermo Scientific Matrix WellMate Microplate Dispenser. After mixing the contents gently, plates were sealed with parafilm and placed in a 'wet chamber' (airtight container with wet paper towels) in a $26^{\circ} \mathrm{C}$ incubator for $50 \mathrm{~min} .30 \mu \mathrm{L}$ of Schneider's Drosophila Medium supplemented with $10 \%$ fetal bovine serum, 100 units $/ \mathrm{mL}$ of penicillin, and $100 \mu \mathrm{g} / \mathrm{mL}$ of streptomycin was added to each well, and plates were sealed with parafilm and placed in the wet chamber for 3.75 days.

After RNAi, 6uL of $10 \mathrm{mM}$ OA solution and $14 \mu \mathrm{L}$ of fresh media was dispensed to each well, and the plates were sealed with parafilm and placed in the wet chamber for $20 \mathrm{hr}$. Next day, 
wells were washed once with $50 \mu \mathrm{L}$ of PBS and about half the liquid was carefully aspirated using vacuum aspirator to avoid disrupting cells at the bottom of the plate, leaving $\sim 50 \mu \mathrm{L}$. $50 \mu \mathrm{L}$ of freshly prepared 8\% paraformaldehyde in PBS solution was dispensed to each well and incubated at room temperature for $25 \mathrm{~min}$. Again with careful aspiration, wells were washed with $70 \mu \mathrm{L}$ of PBS three times. $17 \mu \mathrm{L}$ of $1 \mu \mathrm{M}$ SiR-DNA nuclear stain (Spirochrome, \#SC007), and $133 \mu \mathrm{M}$ monodansylpentane LD stain (AUTOdot; Abcepta, \#SM1000b) in PBS was added to each well (final concentration $0.25 \mu \mathrm{M}$ SiR-DNA \& $33.3 \mu \mathrm{M}$ AUTOdot) and incubated for 35 min. Finally, each well was washed with $70 \mu \mathrm{L}$ of PBS three times, and $25 \mu \mathrm{L}$ of PBS was added (final volume $\sim 75 \mu \mathrm{L}$ ) for imaging.

For automated confocal imaging, GE IN Cell Analyzer 6000 Cell Imaging System with robotics support for automated plate loading. Using the IN Cell Analyzer software, three channel images (FITC for EGFP-GPAT4, Cy5 for nuclei, and DAPI for LDs) were taken in eight fields per well at the manually determined offset from auto-focusing for each plate using $60 \mathrm{X}$ objective.

\section{Plasmid construction}

PCR of the insert was performed using PfuUltra II Fusion Hotstart DNA Polymerase (Agilent Technologies, \#600672), following the manufacturer's protocol. Purified PCR product was first cloned into an entry vector using the pENTR/D-TOPO Cloning Kit (Invitrogen, \#K240020) and then into a destination vector from the Drosophila Gateway vector collection system (Murphy Laboratory, Carnegie Mellon University) using the Gateway LR clonase Enzyme mix (Invitrogen, \#11791019).

Halo destination vectors were created by replacing the EGFP sequence of pAGW and pAWG from the Drosophila Gateway vector collection system with Halo sequence using restriction-ligation (EcoRV \& AgeI and SacI \& AgeI, respectively).

For mutagenesis of constructs, mutations were made using the QuikChange II XL SiteDirected Mutagenesis Kit (Agilent, \#200521) in an entry vector, which was then cloned into a destination vector to avoid undetected mutations.

All final plasmids were verified by restriction analysis and sequencing of the insert region. All information about PCR template and primers are provided in Table S2.

\section{Transfection}


Cells were transfected with the Effectene Transfection Reagent (Qiagen, \#301425), following the manufacturer's protocol. When co-transfecting with more than one plasmid, equal amount (in $\mu \mathrm{g}$ ) of the plasmids were used. Any further treatments took place $26 \mathrm{hr}$ after transfection.

\section{In vitro double-stranded RNA synthesis}

Genomic DNA of the cells was isolated using the DNeasy Blood \& Tissue Kit (Qiagen, \#69504). PCR was performed using primers containing the T7 promoter sequence (on both forward and reverse primers) with PfuUltra II Fusion Hotstart DNA Polymerase (Agilent Technologies, \#600672). PCR products with the expected size was separated using 1\% agarose gel. Purified PCR products were used as a template for RNA transcription using the MEGAscript T7 Transcription Kit (Invitrogen, \#AM1334), which was then purified using the RNeasy Mini Kit (Qiagen, \#74104). Sizes and quality of synthesized dsRNA were confirmed using 1\% agarose gel before they were used for RNAi. PCR primer sequences are provided in Table S3.

\section{RNA interference}

Cells were spun down at 300g for 5 min and resuspended with Schneider's Drosophila Medium (Gibco, \#21720001) without serum supplementation at $60 \times 10^{4}$ cells $/ \mathrm{mL}$. Cells were plated first and dsRNA was added at $20 \mathrm{ng} / \mu \mathrm{L}$. After carefully shaking the plate to mix the contents, plates were sealed with parafilm and placed in a 'wet chamber' (airtight container with wet paper towels) inside $26^{\circ} \mathrm{C}$ incubator to prevent evaporation for $50 \mathrm{~min}$. After $50 \mathrm{~min}$, serum-supplemented medium with three volumes of initial cell suspension were added carefully to avoid detaching cells. After sealing with parafilm, the plate was incubated in the wet chamber for 3.5-4 days before further treatments. In transfection, cells were transferred onto a new plate before following the transfection protocol.

\section{Generation of a stable cell line}

A stable cell line overexpressing EGFP-GPAT4 was created by transfecting cells with pActinEGFP-GPAT4-T2A-Puro ${ }^{\mathrm{R}}$. Information on PCR template and primers used for cloning the construct is provided in Table S2. Selection was started 3 days after transfection with $10 \mu \mathrm{g} / \mathrm{mL}$ puromycin. 5 days later when most control cells $(>75 \%)$ have died, transfected cells were 
recovered in medium without puromycin for 5 days. This selection and recovery were repeated one more time before cells were sorted.

For cell sorting, cells were suspended in sterile PBS supplemented with $1 \%$ fetal bovine serum. Using FACSAria-561 with $100 \mu \mathrm{m}$ gating, EGFP+ cells (488 nm laser) were sorted into a 96-well plate (100 cells/well) containing conditioned medium (medium collected from cells growing at exponential phase, combined with equal volume of fresh Schneider's medium supplemented with $20 \%$ fetal bovine serum). After 2 weeks, cells were expanded and subjected to microscopy and western blot for verification of the cell line.

\section{Generations of cell lines using CRISPR-Cas9}

Knock-out and knock-in cell lines were created using CRISPR-Cas9, following protocols published by Housden et al. (Housden and Perrimon, 2016; Housden et al., 2016). Guide RNA sequence and PCR primer sequences for donor construct cloning are provided in Table S2. 1 week after transfection, cells were suspended in sterile PBS supplemented with $1 \%$ fetal bovine serum and single-cell sorted into a 96-well plate containing conditioned medium (medium collected from cells growing at exponential phase, combined with equal volume of fresh Schneider's medium supplemented with 20\% fetal bovine serum), using FACSAria-561 with 100- $\mu$ m gating. After 2 3 weeks, viable single-cell colonies were expanded and subjected to microscopy, western blot, and sequencing for verification of correct genome-editing.

\section{Immunofluorescence}

Cells were plated to a 96-square well clear bottom plates (Perkin Elmer) in 1:1 dilution with fresh media (100 $\mu \mathrm{L}$ of $80 \sim 90 \%$ confluent cell suspension $+100 \mu \mathrm{L}$ of fresh medium). After $1 \mathrm{hr}, 22.2$ $\mu \mathrm{L}$ of $10 \mathrm{mM}$ oleic acid was added. At a given OA timepoint, $100 \mu \mathrm{L}$ of liquid was removed (leaving $\sim 100 \mu \mathrm{L}$, careful not to dry the well or disrupt the cells at the bottom of the well). Wells were washed 2 times with $200 \mu \mathrm{L}$ of PBS. $200 \mu \mathrm{L}$ of $6 \%$ paraformaldehyde (Polysciences 1881410) in PBS was added to each well and incubated for $10 \mathrm{~min}$, followed by washing with $200 \mu \mathrm{L}$ of PBS 4 times. Cells were permeabilized with $200 \mu \mathrm{L}$ of $0.15 \%$ triton X-100 and $0.15 \%$ BSA in PBS for 3 min, washed 4 times with $200 \mu \mathrm{L}$ of PBS, blocked with $200 \mu \mathrm{L}$ of $7.5 \%$ normal goat serum (Cell Signaling 5425S) in PBS for $1 \mathrm{hr}$. After removing $200 \mu \mathrm{L}$ from the well (leaving $\sim 100 \mu \mathrm{L}$ ), $50 \mu \mathrm{L}$ of antibody solution for the final concentration of 1:1500 rabbit anti- $d m \mathrm{Sec} 16$ (Ivan et al., 
2008 ) or guinea pig anti- $d m$ Tangol (Lerner et al., 2013) in 5\% normal goat serum in PBS was added and incubated for $1.5 \mathrm{hr}$. After removing $50 \mu \mathrm{L}$ from the well (leaving $\sim 100 \mu \mathrm{L}$ ), and wells were washed with $0.2 \%$ BSA in PBS solution 4 times with incubation for 5 min with each wash. Wells were washed once with $200 \mu \mathrm{L}$ of $5 \%$ normal goat serum in PBS. $50 \mu \mathrm{L}$ of secondary antibody solution for the final concentration of 1:1000 (Alexa Fluor 488 goat anti-guinea pig IgG, Thermo Scientific A-11073; Alexa Fluor 647 goat anti-rabbit IgG, Thermo Scientific A-21244) in $5 \%$ normal goat serum in PBS was added and incubated for $1.5 \mathrm{hr}$. After removing $50 \mu \mathrm{L}$ from the well (leaving $\sim 100 \mu \mathrm{L}$ ), wells were washed with $0.2 \%$ BSA in PBS solution 4 times with incubation for $5 \mathrm{~min}$ with each wash, followed by washing with $200 \mu \mathrm{L}$ of PBS 4 times. Finally, $0.10 \mu \mathrm{L}$ AutoDot (Abcepta SM1000b) in $200 \mu \mathrm{L}$ of PBS was added for LD staining before imaging.

\section{Fluorescence microscopy}

Cells that have undergone transfection or RNAi in 24-well plates were resuspended in the old medium and combined with equal volume of fresh medium to a 35-mm dish with 14-mm No. 1.5 coverslip bottom (MatTek Life Sciences, \#P35G-1.5-14-C) coated manually with $0.1 \mathrm{mg} / \mathrm{mL}$ Concanavalin A. Cells were allowed to settle for $1 \mathrm{hr}$ at $26^{\circ} \mathrm{C}$ before further treatments, such as with $1 \mathrm{mM}$ oleic acid (OA). Unless otherwise indicated, cells were imaged $20 \mathrm{hr}$ after OA treatment. LDs were stained with $100 \mu \mathrm{M}$ monodansylpentane (AUTOdot; Abcepta, \#SM1000b) or 1:1000 HCS LipidTOX Deep Red Neutral Lipid Stain (Thermo Fisher Scientific, H34477), 10 min before imaging. For JF646 treatment, cells were incubated with the Halo ligand $1 \mathrm{hr}$ before imaging and washed once with PBS before resupplying medium (or medium with OA).

Nikon Eclipse Ti inverted microscope, featuring CSU-X1 spinning disk confocal (Yokogama) and Zyla 4.2 PLUS scientific complementary metal-oxide semiconductor (sCMOS) (Andor, UK), was used for spinning disk confocal microscopy. NIS-elements software (Nikon) was used for acquisition control. Plan Apochromat VC 100X oil objective (Nikon) with 1.40 NA was used, resulting in 0.065- $\mu \mathrm{m}$ pixel size. Solid state excitation lasers - $405 \mathrm{~nm}$ (blue; Andor), $488 \mathrm{~nm}$ (green; Andor), $560 \mathrm{~nm}$ (red; Cobolt), and $637 \mathrm{~nm}$ (far-red; Coherent) — shared quad-pass dichroic beam splitter (Di01-T405/488/568/647, Semrock), whereas emission filters were FF01452/45, FF03-525/50, FF01-607/36, and FF02-685/40 (Semrock), respectively. 


\section{Fractionation of cells}

Cells were resuspended from plates and washed once with PBS, which was then placed on ice for all subsequent steps. Cell pellets were suspended in $1 \mathrm{~mL}$ of $250 \mathrm{mM}$ sucrose buffer containing 200 mM Tris- $\mathrm{HCl}$ (pH 7.4), 1 mM MgCl 2 (pH 7.4), and cOmplete Mini EDTA-protease inhibitor cocktail (Roche, \#4693159001) and broken by passing through 25G syringe 30 times. 1unit/ $\mu \mathrm{L}$ of benzonase nuclease (Millipore, \#E1014) was added and incubated on ice for $10 \mathrm{~min}$. 5\% of the total volume was taken at this stage for whole-cell lysate ('input') analysis. For the rest, unbroken cells and nuclei were fractionated by centrifuging for $5 \mathrm{~min}, 1,000 \mathrm{~g}$ at $4^{\circ} \mathrm{C}$. Top lipid layer and the supernatant were moved to the 5-mL, Open-Top Thinwall Ultra-Clear Tube, 13x51mm (Beckman Coulter, \#344057), where additional $1.5 \mathrm{~mL}$ of the $250 \mathrm{mM}$ sucrose buffer was added. $2.5 \mathrm{~mL}$ of $50 \mathrm{mM}$ sucrose containing $200 \mathrm{mM}$ Tris- $\mathrm{HCl}$ (pH 7.4), $1 \mathrm{mM} \mathrm{MgCl}_{2}$ (pH 7.4), and cOmplete Mini EDTA-protease inhibitor cocktail was layered on top. The two-step sucrose gradient was centrifuged for 16-20 hr, 100,000g, at $4^{\circ} \mathrm{C}$ using the SW 55 Ti Swinging Bucket rotor (Beckman Coulter, 342194).

Top of the tube $(\sim 5 \mathrm{~mm} ; 500 \mu \mathrm{L})$ was sliced using the Beckman Coulter tube slicer, the content of which was taken as 'LD fraction'. Supernatant was taken as 'soluble fraction', and the pellet resuspended in $500 \mu \mathrm{L}$ of $250 \mathrm{mM}$ sucrose buffer was taken as 'membrane fraction'.

For further analysis with immunoblotting or mass spectrometry, proteins from the fractions were precipitated. Briefly, $1 \mathrm{~mL}$ of methanol and $250 \mu \mathrm{L}$ of chloroform was sequentially added to $500 \sim 750 \mu \mathrm{L}$ of aqueous fractions with vigorous mixing after every addition. After centrifuging for $10 \mathrm{~min}, 14,000 \mathrm{~g}$, at $4^{\circ} \mathrm{C}$, top layer was aspirated out. $1.7 \mathrm{~mL}$ of methanol was added and vigorously mixed. Precipitated proteins were then pelleted by centrifuging for $15 \mathrm{~min}, 18,000 \mathrm{~g}$, at $4^{\circ} \mathrm{C}$. All liquid was aspirated, and after allowing the pellet to dry for $5 \mathrm{~min}$, the pellet was resuspended in $100-250 \mu \mathrm{L}$ of $1.5 \%$ SDS, $50 \mathrm{mM}$ Tris- $\mathrm{HCl}(\mathrm{pH} 7.4)$ buffer.

\section{Immunoblotting}

Protein concentrations were measured using the Pierce BCA Protein Assay Kit (Thermo scientific, \#23225), and the amounts indicated in respective figure legends were mixed with 5X Laemmli buffer for the final concentration of $1 \mathrm{X}$ Laemmli buffer (2\% SDS, 10\% glycerol, $50 \mathrm{mM}$ Tris- $\mathrm{HCl}$ (pH 6.8), $\beta$-mercaptoethanol $100 \mathrm{mM}, 0.02 \%$ bromophenol-blue). After running samples in 4-15\% gradient polyacrylamide gel (Bio-Rad, \#4561084) at 100V for $90 \mathrm{~min}$ in $1 \mathrm{X}$ Tris/glycine/SDS 
buffer (Bio-Rad, \#161-0772), proteins were transferred to a 0.2- $\mu \mathrm{m}$ pore size nitrocellulose membrane (Bio-Rad, \#1620112) in 1X Tris/glycine buffer (Bio-Rad, \#161-0771) at 70V for 90 min in the cold room $\left(4^{\circ} \mathrm{C}\right)$. Membrane was blocked by incubating in 5\% non-fat dry milk (Santa Cruz Biotechnology, \#sc-2325) in TBS-T buffer (20 mM Tris, pH 7.6, $150 \mathrm{mM} \mathrm{NaCl,} \mathrm{0.1 \%}$ Tween-20) for $30 \mathrm{~min}$ at room temperature. Membrane was incubated with 5\% milk solution containing primary antibody (dilutions are indicated below) overnight in the cold room.

Next day, membranes are washed three times with TBS-T for $10 \mathrm{~min}$ each at room temperature, incubated with 1:5000 secondary antibodies conjugated to horseradish peroxidase (Santa Cruz Biotechnology, \#sc-516102 for primary antibodies from mouse or \#sc-2357 for primary antibodies from rabbit) in 5\% milk solution for $1 \mathrm{~h}$ at room temperature, and washed three times with TBS-T for $10 \mathrm{~min}$ each at room temperature. SuperSignal West Pico PLUS Chemiluminescent Substrate (Thermo Scientific, \#34580) was applied to the membrane, which was imaged using the Biorad Gel Doc XR system for signal acquisition.

For stripping the membrane of antibodies, membrane was washed with distilled water five times for $5 \mathrm{~min}$ each at room temperature and incubated with $100 \mathrm{mM}$ citric acid solution in distilled water for $10 \mathrm{~min}$ at room temperature. The membrane was then re-blocked with 5\% milk solution for $30 \mathrm{~min}$ at room temperature before proceeding with incubation with another primary antibody.

Primary antibodies and their dilutions: rabbit anti-dmGPAT4 [1:1000; (Wilfling et al., 2013)], rabbit anti-dmCCT1 [1:1000; (Krahmer et al., 2011)], mouse anti-dmCNX99A [1:500; DSHB, \#Cnx99A 6-2-1, (Riedel et al., 2016)], mouse anti- $\alpha$-tubulin (1:2000; Sigma, T5168), and anti-dmLDAH [1:2000; (Thiel et al., 2013)].

\section{Mass spectrometry}

Proteins pellets from lipid droplet-enriched fractions were resuspended in $0.1 \mathrm{M} \mathrm{NaOH}$ (SigmaAldrich) and subsequently neutralized using $200 \mathrm{mM}$ HEPES (4-(2-hydroxyethyl)-1piperazineethanesulfonic acid). Solubilized proteins were reduced using $5 \mathrm{mM}$ dithiothreitol

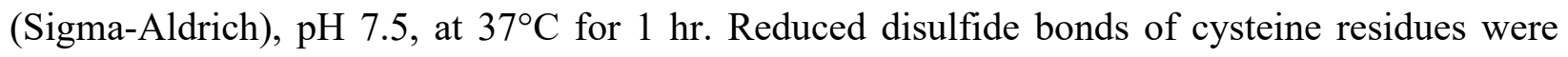
alkylated using $15 \mathrm{mM}$ iodoacetamide (Sigma-Aldrich) for $1 \mathrm{hr}$ in the dark. Excessive iodoacetamide was quenched using $10 \mathrm{mM}$ dithiothreitol. Alkylated protein mixture was diluted sixfold (v/v) using $20 \mathrm{mM}$ HEPES, $\mathrm{pH} 7.5$, and digested for $16 \mathrm{hr}$ at $37^{\circ} \mathrm{C}$ with sequencing grade 
trypsin (Worthington Biochemical) in a 1:100 trypsin to protein ratio. Digested peptides were desalted using self-packed C18 STAGE tips (3M Empore ${ }^{\mathrm{TM}}$ ) (Rappsilber et al., 2003). Desalted peptides were dissolved in $0.1 \%$ (v/v) formic acid and injected onto an Easy-nLC 1000 (Thermo Fisher Scientific), coupled to an Orbitrap Exploris 480 (Thermo Fisher Scientific). Peptide separation was performed on a 500-mm self-packed analytical column using PicoTip ${ }^{\mathrm{TM}}$ emitter (New Objective, Woburn, MA) containing Reprosil Gold 120 C-18, 1.9- $\mu \mathrm{m}$ particle size resin (Dr. Maisch, Ammerbuch-Entringen, Germany). Chromatography separation was carried out using increasing organic proportion of acetonitrile (5-40\% (v/v)) containing $0.1 \%(\mathrm{v} / \mathrm{v})$ formic acid over a $120 \mathrm{~min}$ gradient at a flow rate of $300 \mathrm{~nL} / \mathrm{min}$. 


\section{QUANTIFICATION AND STATISTICAL ANALYSIS}

\section{Statistical analysis}

All statistical analysis was performed using GraphPad Prism 8. Information about significance test is provided in the respective figure legends. All multiple comparisons were performed with the Bonferroni multiple comparisons correction. Statistically significant differences are denoted as follows: ${ }^{*} \mathrm{p}<0.05,{ }^{*} \mathrm{p}<0.01, * * * \mathrm{p}<0.001, \# \mathrm{p}<0.0001$.

\section{Analysis of genome-scale imaging screen}

A custom Matlab analysis pipeline was built to analyze screen images. Nuclei, cell, and LD compartments were obtained using supervised machine-learning methods, specifically Random Forest pixel classifiers (http://github.com/HMS-IDAC/PixelClassifier). Three different models were trained, one for each compartment, using separate sets of annotated images (about seven images per model). Nuclei and cells were segmented from the Cy5 channel, and LDs formed the DAPI channel. Nuclei mask was used for segmenting cells as markers in a watershed algorithm. LD masks were post-processed by selecting only the intersection with cell masks. LD objects were then associated with cell objects, depending on the area of intersection. Finally, the signal in the FITC channel was corrected for auto-fluorescence by subtracting the mean value of control images and was quantified inside and outside the LD mask in each segmented cell. From these measurements, we calculated LD targeting ratio for each segmented cell, defined as the ratio of the mean intensity of EGFP-GPAT4 signal inside the LD mask to that of EGFP-GPAT4 signal outside LD mask within the cell mask. Median LD targeting ratio from all of the segmented cells from the 8 fields of the same well (with a unique dsRNA) was determined and employed as the final readout for the well. Batch patch processing of screen images (total 1,216,512 images) through the custom analysis pipeline was performed using the Harvard O2 cluster.

For the calculation of robust Z-scores, each median LD targeting ratio from the duplicate screen experiment was considered as a separate value. Robust Z-scores for median LD targeting ratios $(\mathrm{X})$ was calculated using the formula below. In our screen, median $=2.147287$ and median absolute deviation $=0.113917$.

$$
\text { Robust } Z-\text { score }=\frac{X_{i}-\operatorname{median}(X)}{1.4826 * \text { median absolute deviation }(X)}
$$




\section{Where Median absolute deviation $=$ median $\left(\left|X_{i}-\operatorname{median}(X)\right|\right)$}

\section{Quantification of fluorescence images}

Confocal images were quantified using the FIJI software (Schindelin et al., 2012) to calculate LD targeting ratios. Cell boundaries were drawn manually based on fluorescence from protein channels, such as EGFP-GPAT4 (Mask 1) and LD regions, were distinguished by applying an automatic threshold (Otsu method) to the monodansylpentane channel within Mask 1, which was then dilated by 1 pixel to include LD surfaces (Mask 2). LD targeting ratios were calculated by dividing the mean intensity of the fluorescent protein channel image in Mask 2 divided by that in (Mask 1 - Mask 2). For CCT1, nuclei were distinguished by manually drawing the nuclear boundary from mCherry-CCT1 channel (Mask 3), which was excluded from Mask 1.

\section{Spatial association between ERES and LDs}

The ERES-LD association was determined by DiAna, an ImageJ plugin for object-based 3D colocalization analysis (Gilles et al., 2017). The fluorescence signal of ERES punctate (Sec16 or Tango1) and LDs were segmented by intensity thresholding. The intensity threshold of the segmentation was automatically determined by an algorithm. After the thresholding, the ERES and LD were identified as 3D objects, and the number of ERES and the closest distance between the ERES and LD boundaries were determined.

The images were preprocessed by background subtraction and median filter before the segmentation. To exclude the interference from cell debris and non-specific labelling, only the objects with pixel size $>30$ pixels were considered in the analysis. The objects located at the $x, y$ and $\mathrm{z}$ boundaries of the image stack were also excluded from the calculation to prevent the error from the incomplete segmentation of the objects. Zero closest distance between ERES and LDs indicated overlapping boundaries between the two. The ratio of the ERES associated with LD was calculated by dividing the number of ERES with zero closest distance with LDs by the total number of ERES within the cell.

\section{Quantification of immunoblots}

Using the FIJI software (Schindelin et al., 2012), a rectangular ROI was drawn around the band of interest in the control lane (usually LacZ RNAi), and the measure function was used to measure 
total intensity inside the ROI. ROI was then moved to the next lane sequentially for measurements. Another measurement outside the expected band region was measured for background subtraction. The measured intensities (band - background) were normalized to the level in the control lane.

\section{Analysis of mass spectrometry data}

The mass spectrometry analyzer operated in data-dependent acquisition mode with a top 10 method at a mass-over-charge $(\mathrm{m} / \mathrm{z})$ range of 300-2000 Da. Mass spectrometry data were analyzed by MaxQuant software version 1.5.2.8 (Cox and Mann, 2008) using the following setting: oxidized methionine residues and protein $\mathrm{N}$-terminal acetylation as variable modification, cysteine carbamidomethylation as fixed modification, first search peptide tolerance $20 \mathrm{ppm}$, main search peptide tolerance $4.5 \mathrm{ppm}$. Protease specificity was set to trypsin with up to 2 missed cleavages allowed. Only peptides longer than 6 amino acids were analyzed, and the minimal ratio count to quantify a protein is 2 . The false discovery rate was set to $5 \%$ for peptide and protein identifications. Database searches were performed using the Andromeda search engine integrated into the MaxQuant software (Cox et al., 2011) against the UniProt Drosophila melanogaster database containing 20,981 entries (December 2018). "Matching between runs" algorithm with a time window of $0.7 \mathrm{~min}$ was employed to transfer identifications between samples processed using the same nanospray conditions. Protein tables were filtered to eliminate identifications from the reverse database and common contaminants.

To identify proteins regulated by different genotypes, the MaxQuant output files were exported to Perseus 1.5.1.6 (Tyanova et al., 2016). Known contaminant and decoy sequences were removed. Projection and clustering of the dataset was performed using principal component analysis to identify potential sample outlier. The cutoff of potential principal components was set at Benjamini-Hochberg FDR 5\%. After removing poorly clustering replicates in the principal component analysis, intensity values were normalized to the sum of all intensities within each sample. Clustergram analysis was performed using the ComplexHeatmap clustering method on $\mathrm{R}$ (Gu et al., 2016). 


\section{SUPPLEMENTAL TABLE TITLES and LEGENDS}

Supplemental Table 1. Gene nomenclature used in the study

List of gene and protein names used in this study. For some fly genes and proteins without common names besides an annotation symbol, names of their predicted human orthologs (based on FlyBase.org and Marrvel.org) were used instead. For ortholog predictions, comma ',' denotes aliases for the same protein and semi-colon ';' denotes more than one possible ortholog. For ReepA, ReepA-RE isoform sequence used in the study for expression.

Supplemental Table 2. Plasmid construction for transient transfection or cell line generation List of primer sequences, PCR template, and backbone information for the construction of plasmids used for transient transfection (first tab) or for the generation of cell lines (second tab) used in the study.

Supplemental Table 3. Oligonucleotide sequences used for the synthesis of double-stranded RNA List of primer sequences for generating PCR templates used in in vitro transcription. All primers were flanked by $\mathrm{T} 7$ promoter sequence (TAATACGACTCACTATAGGG) at the 5' end. 


\section{REFERENCES}

Abul-Husn, N.S., Cheng, X., Li, A.H., Xin, Y., Schurmann, C., Stevis, P., Liu, Y., Kozlitina, J., Stender, S., Wood, G.C., et al. (2018). A protein-truncating HSD17B13 variant and protection from chronic liver disease. New England Journal of Medicine 378, 1096-1106.

Allan, B.B., Moyer, B.D., and Balch, W.E. (2000). Rab1 recruitment of p115 into a cis-SNARE complex: Programming budding COPII vesicles for fusion. Science 289, 444-448.

Arlt, H., Sui, X., Folger, B., Adams, C., Chen, X., Remme, R., Hamprecht, F.A., Dimaio, F., Liao, M., Goodman, J.M., et al. (2021). Seipin forms a flexible cage at lipid droplet formation sites. BioRxiv.

Bannykh, S.I., Rowe, T., and Balch, W.E. (1996). The organization of endoplasmic reticulum export complexes. Journal of Cell Biology 135, 19-35.

Barrowman, J., Bhandari, D., Reinisch, K., and Ferro-Novick, S. (2010). TRAPP complexes in membrane traffic: Convergence through a common Rab. Nature Reviews Molecular Cell Biology 11, 759-763.

BasuRay, S., Wang, Y., Smagris, E., Cohen, J.C., and Hobbs, H.H. (2019). Accumulation of PNPLA3 on lipid droplets is the basis of associated hepatic steatosis. Proceedings of the National Academy of Sciences of the United States of America 116, 9521-9526.

Beard, M., Satoh, A., Shorter, J., and Warren, G. (2005). A Cryptic Rab1-binding Site in the p115 Tethering Protein. Journal of Biological Chemistry 280, 25840-25848.

Beck, R., Ravet, M., Wieland, F.T., and Cassel, D. (2009). The COPI system: Molecular mechanisms and function. FEBS Letters 583, 2701-2709.

Beller, M., Sztalryd, C., Southall, N., Bell, M., Jackle, H., Auld, D.S., and Oliver, B. (2008). COPI Complex Is a Regulator of Lipid Homeostasis. PLoS Biology 6, 2530-2549.

Bersuker, K., Peterson, C.W.H., To, M., Sahl, S.J., Savikhin, V., Grossman, E.A., Nomura, D.K., and Olzmann, J.A. (2018). A Proximity Labeling Strategy Provides Insights into the Composition and Dynamics of Lipid Droplet Proteomes. Developmental Cell 44, 97-112.

Bindels, D.S., Haarbosch, L., van Weeren, L., Postma, M., Wiese, K.E., Mastop, M., Aumonier, S., Gotthard, G., Royant, A., Hink, M.A., et al. (2017). mScarlet: a bright monomeric red fluorescent protein for cellular imaging. Nature Methods 14, 53-56.

Brandizzi, F., and Barlowe, C. (2013). Organization of the ER-Golgi interface for membrane traffic control. Nature Reviews Molecular Cell Biology 14, 382-392.

Budnik, A., and Stephens, D.J. (2009). ER exit sites - Localization and control of COPII vesicle formation. FEBS Letters 583, 3796-3803. 
Chung, J., Wu, X., Lambert, T.J., Lai, Z.W., Walther, T.C., and Farese, R. V (2019). LDAF1 and Seipin Form a Lipid Droplet Assembly Complex. Developmental Cell 51, 551-563.

Cottier, S., and Schneiter, R. (2022). Lipid droplets form a network interconnected by the endoplasmic reticulum through which their proteins equilibrate. Journal of Cell Science 135.

Cox, J., and Mann, M. (2008). MaxQuant enables high peptide identification rates, individualized p.p.b.-range mass accuracies and proteome-wide protein quantification. Nature Biotechnology 26, 1367-1372.

Cox, J., Neuhauser, N., Michalski, A., Scheltema, R.A., Olsen, J. V., and Mann, M. (2011). Andromeda: A peptide search engine integrated into the MaxQuant environment. Journal of Proteome Research 10, 1794-1805.

Dascher, C., Matteson, J., and Balch, W.E. (1994). Syntaxin 5 regulates endoplasmic reticulum to Golgi transport. Journal of Biological Chemistry 269, 29363-29366.

Dhiman, R., Caesar, S., Thiam, A.R., and Schrul, B. (2020). Mechanisms of protein targeting to lipid droplets: A unified cell biological and biophysical perspective. Seminars in Cell and Developmental Biology 108, 4-13.

Eden, E., Navon, R., Steinfeld, I., Lipson, D., and Yakhini, Z. (2009). GOrilla: A tool for discovery and visualization of enriched GO terms in ranked gene lists. BMC Bioinformatics 10 , $1-7$.

Ellong, E.N., Soni, K.G., Bui, Q.T., Sougrat, R., Golinelli-Cohen, M.P., and Jackson, C.L. (2011). Interaction between the triglyceride lipase ATGL and the arf1 activator GBF1. PLoS ONE 6.

Fukasawa, M., Varlamov, O., Eng, W.S., Söllner, T.H., and Rothman, J.E. (2004). Localization and activity of the SNARE Ykt6 determined by its regulatory domain and palmitoylation. Proceedings of the National Academy of Sciences of the United States of America 101, 48154820 .

Gandotra, S., Le Dour, C., Bottomley, W., Cervera, P., Giral, P., Reznik, Y., Charpentier, G., Auclair, M., Delépine, M., Barroso, I., et al. (2011). Perilipin Deficiency and Autosomal Dominant Partial Lipodystrophy. New England Journal of Medicine 364, 740-748.

Gilles, J.F., Dos Santos, M., Boudier, T., Bolte, S., and Heck, N. (2017). DiAna, an ImageJ tool for object-based 3D co-localization and distance analysis. Methods 115, 55-64.

González, M., Martín-Ruíz, I., Jiménez, S., Pirone, L., Barrio, R., and Sutherland, J.D. (2011). Generation of stable Drosophila cell lines using multicistronic vectors. Scientific Reports 1 .

Goo, Y.H., Son, S.H., Kreienberg, P.B., and Paul, A. (2014). Novel lipid droplet-associated serine hydrolase regulates macrophage cholesterol mobilization. Arteriosclerosis, Thrombosis, and Vascular Biology 34, 386-396. 
Gu, Z., Eils, R., and Schlesner, M. (2016). Complex heatmaps reveal patterns and correlations in multidimensional genomic data. Bioinformatics 32, 2847-2849.

Hong, W. (2005). SNAREs and traffic. Biochimica et Biophysica Acta 1744, 120-144.

Housden, B.E., and Perrimon, N. (2016). Design and generation of donor constructs for genome engineering in Drosophila. Cold Spring Harbor Protocols 2016, 789-793.

Housden, B.E., Hu, Y., and Perrimon, N. (2016). Design and generation of Drosophila single guide RNA expression constructs. Cold Spring Harbor Protocols 2016, 782-788.

Ivan, V., de Voer, G., Xanthakis, D., Spoorendonk, K.M., Kondylis, V., and Rabouille, C. (2008). Drosophila Sec16 Mediates the Biogenesis of tER Sites Upstream of Sar1 through an Arginine-Rich Motif. Molecular Biology of the Cell 19, 4352-4365.

Jacquier, N., Choudhary, V., Mari, M., Toulmay, A., Reggiori, F., and Schneiter, R. (2011). Lipid droplets are functionally connected to the endoplasmic reticulum in Saccharomyces cerevisiae. Journal of Cell Science 124, 2424-2437.

Kassan, A., Herms, A., Fernández-Vidal, A., Bosch, M., Schieber, N.L., Reddy, B.J.N., Fajardo, A., Gelabert-Baldrich, M., Tebar, F., Enrich, C., et al. (2013). Acyl-CoA synthetase 3 promotes lipid droplet biogenesis in ER microdomains. Journal of Cell Biology 203, 985-1001.

Kim, J.J., Lipatova, Z., and Segev, N. (2016). TRAPP complexes in secretion and autophagy. Frontiers in Cell and Developmental Biology 4.

Kory, N., Farese, R. V., and Walther, T.C. (2016). Targeting Fat: Mechanisms of Protein Localization to Lipid Droplets. Trends in Cell Biology 26, 535-546.

Kory, N., Grond, S., Kamat, S.S., Li, Z., Krahmer, N., Chitraju, C., Zhou, P., Fröhlich, F., Semova, I., Ejsing, C., et al. (2017). Mice lacking lipid droplet-Associated hydrolase, a gene linked to human prostate cancer, have normal cholesterol ester metabolism. Journal of Lipid Research 58, 226-235.

Krahmer, N., Guo, Y., Wilfling, F., Hilger, M., Lingrell, S., Heger, K., Newman, H.W., SchmidtSupprian, M., Vance, D.E., Mann, M., et al. (2011). Phosphatidylcholine synthesis for lipid droplet expansion is mediated by localized activation of CTP:Phosphocholine cytidylyltransferase. Cell Metabolism 14, 504-515.

Krahmer, N., Hilger, M., Kory, N., Wilfling, F., Stoehr, G., Mann, M., Farese, R. V, and Walther, T.C. (2013). Protein correlation profiles identify lipid droplet proteins with high confidence. Mol. Cell Proteomics 12, 1115-1126.

Krahmer, N., Najafi, B., Schueder, F., Quagliarini, F., Steger, M., Seitz, S., Kasper, R., Salinas, F., Cox, J., Uhlenhaut, N.H., et al. (2018). Organellar Proteomics and Phospho-Proteomics Reveal Subcellular Reorganization in Diet-Induced Hepatic Steatosis. Developmental Cell 47, 205-221. 
Lerner, D.W., McCoy, D., Isabella, A.J., Mahowald, A.P., Gerlach, G.F., Chaudhry, T.A., and Horne-Badovinac, S. (2013). A Rab10-dependent mechanism for polarized basement membrane secretion during organ morphogenesis. Dev Cell 24, 159-168.

Liu, M., Feng, Z., Ke, H., Liu, Y., Sun, T., Dai, J., Cui, W., and Pastor-Pareja, J.C. (2017). Tango1 spatially organizes ER exit sites to control ER export. Journal of Cell Biology 216, 1035-1049.

Liu, Y., Xu, S., Zhang, C., Zhu, X., Hammad, M.A., Zhang, X., Christian, M., Zhang, H., and Liu, P. (2018). Hydroxysteroid dehydrogenase family proteins on lipid droplets through bacteria, C. elegans, and mammals. Biochimica et Biophysica Acta - Molecular and Cell Biology of Lipids 881-894.

Mejhert, N., Gabriel, K.R., Krahmer, N., Kuruvilla, L., Chitraju, C., Boland, S., Jang, D.-K., von Grotthuss, M., Costanzo, M.C., Flannick, J., et al. (2021). The Lipid Droplet Knowledge Portal: A resource for systematic analyses of lipid droplet biology. BioRxiv.

Moyer, B.D., Allan, B.B., and Balch, W.E. (2001). Rab1 interaction with a GM130 effector complex regulates COPII vesicle cis-Golgi tethering. Traffic 2, 268-276.

Olarte, M.J., Kim, S., Sharp, M.E., Swanson, J.M.J., Farese, R. V., and Walther, T.C. (2020). Determinants of Endoplasmic Reticulum-to-Lipid Droplet Protein Targeting. Developmental Cell 54, 471-487.

Olzmann, J.A., and Carvalho, P. (2019). Dynamics and functions of lipid droplets. Nature Reviews Molecular Cell Biology 20, 137-155.

Olzmann, J.A., Richter, C.M., and Kopito, R.R. (2013). Spatial regulation of UBXD8 and p97/VCP controls ATGL-mediated lipid droplet turnover. Proceedings of the National Academy of Sciences of the United States of America 110, 1345-1350.

Pataki, C.I., Rodrigues, J., Zhang, L., Qian, J., Efron, B., Hastie, T., Elias, J.E., Levitt, M., and Kopito, R.R. (2018). Proteomic analysis of monolayer-integrated proteins on lipid droplets identifies amphipathic interfacial $\alpha$-helical membrane anchors. Proceedings of the National Academy of Sciences of the United States of America 115, E8172-E8180.

Payne, F., Lim, K., Girousse, A., Brown, R.J., Kory, N., Robbins, A., Xue, Y., Sleigh, A., Cochran, E., Adams, C., et al. (2014). Mutations disrupting the Kennedy phosphatidylcholine pathway in humans with congenital lipodystrophy and fatty liver disease. Proceedings of the National Academy of Sciences of the United States of America 111, 8901-8906.

Perez-Riverol, Y., Csordas, A., Bai, J., Bernal-Llinares, M., Hewapathirana, S., Kundu, D.J., Inuganti, A., Griss, J., Mayer, G., Eisenacher, M., et al. (2019). The PRIDE database and related tools and resources in 2019: Improving support for quantification data. Nucleic Acids Research 47, D442-D450. 
Prévost, C., Sharp, M.E., Kory, N., Lin, Q., Voth, G.A., Farese, R. v, and Walther, T.C. (2018). Mechanism and Determinants of Amphipathic Helix- Containing Protein Targeting to Lipid Droplets. Developmental Cell 44, 73-86.

Raote, I., Bellido, M.O., Pirozzi, M., Zhang, C., Melville, D., Parashuraman, S., Zimmermann, T., and Malhotra, V. (2017). TANGO1 assembles into rings around COPII coats at ER exit sites. Journal of Cell Biology 216, 901-909.

Raote, I., Ortega-Bellido, M., Santos, A.J.M., Foresti, O., Zhang, C., Garcia-Parajo, M.F., Campelo, F., and Malhotra, V. (2018). TANGO1 builds a machine for collagen export by recruiting and spatially organizing COPII, tethers and membranes. ELife 7, e32723.

Rappsilber, J., Ishihama, Y., and Mann, M. (2003). Stop And Go Extraction tips for matrixassisted laser desorption/ionization, nanoelectrospray, and LC/MS sample pretreatment in proteomics. Analytical Chemistry 75, 663-670.

Riedel, F., Gillingham, A.K., Rosa-Ferreira, C., Galindo, A., and Munro, S. (2016). An antibody toolkit for the study of membrane traffic in Drosophila melanogaster. Biology Open 5, 987-992.

Romeo, S., Kozlitina, J., Xing, C., Pertsemlidis, A., Cox, D., Pennacchio, L.A., Boerwinkle, E., Cohen, J.C., and Hobbs, H.H. (2008). Genetic variation in PNPLA3 confers susceptibility to nonalcoholic fatty liver disease. Nature Genetics 40, 1461-1465.

Rowe, E.R., Mimmack, M.L., Barbosa, A.D., Haider, A., Isaac, I., Ouberai, M.M., Thiam, A.R., Patel, S., Saudek, V., Siniossoglou, S., et al. (2016). Conserved amphipathic helices mediate lipid droplet targeting of perilipins 1-3. Journal of Biological Chemistry 291, 6664-6678.

Santos, A.J.M., Nogueira, C., Ortega-Bellido, M., and Malhotra, V. (2016). TANGO1 and Mia2/cTAGE5 (TALI) cooperate to export bulky pre-chylomicrons/VLDLs from the endoplasmic reticulum. Journal of Cell Biology 213, 343-354.

Satoh, A.K., Tokunaga, F., Kawamura, S., and Ozaki, K. (1997). In situ inhibition of vesicle transport and protein processing in the dominant negative Rab1 mutant of Drosophila. Journal of Cell Science 110, 2943-2953.

Schindelin, J., Arganda-Carreras, I., Frise, E., Kaynig, V., Longair, M., Pietzsch, T., Preibisch, S., Rueden, C., Saalfeld, S., Schmid, B., et al. (2012). Fiji: An open-source platform for biological-image analysis. Nature Methods 9, 676-682.

Schroeder, B., Schulze, R.J., Weller, S.G., Sletten, A.C., Casey, C.A., and Mcniven, M.A. (2015). The Small GTPase Rab7 as a Central Regulator of Hepatocellular Lipophagy. Hepatology 61, 1896-1897.

Schrul, B., and Kopito, R.R. (2016). Peroxin-dependent targeting of a lipid-droplet-destined membrane protein to ER subdomains. Nature Cell Biology 18, 740-751. 
Söllner, T., Whiteheart, S.W., Brunner, M., Erdjument-Bromage, H., Geromanos, S., Tempst, P., and Rothman, J.E. (1993). 1993 SNAP receptors implicated in vesicle targeting and fusion. Nature 362, 318-324.

Soni, K.G., Mardones, G. a, Sougrat, R., Smirnova, E., Jackson, C.L., and Bonifacino, J.S. (2009). Coatomer-dependent protein delivery to lipid droplets. Journal of Cell Science 122, $1834-1841$.

Stenmark, H. (2009). Rab GTPases as coordinators of vesicle traffic. Nature Reviews Molecular Cell Biology 10, 513-525.

Südhof, T.C., and Rothman, J.E. (2009). Membrane fusion: Grappling with SNARE and SM proteins. Science 323, 474-477.

Sui, X., Arlt, H., Brock, K.P., Lai, Z.W., DiMaio, F., Marks, D.S., Liao, M., Farese, R. V., and Walther, T.C. (2018). Cryo-electron microscopy structure of the lipid droplet-formation protein seipin. Journal of Cell Biology 217, 4080-4091.

Tan, R., Wang, W., Wang, S., Wang, Z., Sun, L., He, W., Fan, R., Zhou, Y., Xu, X., Hong, W., et al. (2013). Small GTPase Rab40c Associates with Lipid Droplets and Modulates the Biogenesis of Lipid Droplets. PLoS ONE 8.

Thiam, A.R., Farese, R. V, and Walther, T.C. (2013a). The biophysics and cell biology of lipid droplets. Nature Reviews Molecular Cell Biology 14, 775-786.

Thiam, A.R., Antonny, B., Wang, J., Delacotte, J., Wilfling, F., Walther, T.C., Beck, R., Rothman, J.E., and Pincet, F. (2013b). COPI buds 60-nm lipid droplets from reconstituted waterphospholipid- triacylglyceride interfaces, suggesting a tension clamp function. Proceedings of the National Academy of Sciences of the United States of America 110, 13244-13249.

Thiel, K., Heier, C., Haberl, V., Thul, P.J., Oberer, M., Lass, A., Jäckle, H., and Beller, M. (2013). The evolutionarily conserved protein CG9186 is associated with lipid droplets, required for their positioning and for fat storage. Journal of Cell Science 126, 2198-2212.

Thul, P.J., Tschapalda, K., Kolkhof, P., Thiam, A.R., Oberer, M., and Beller, M. (2017).

Targeting of the Drosophila protein CG2254/Ldsdh1 to a subset of lipid droplets. Journal of Cell Science 130, 3141-3157.

Tyanova, S., Temu, T., Sinitcyn, P., Carlson, A., Hein, M.Y., Geiger, T., Mann, M., and Cox, J. (2016). The Perseus computational platform for comprehensive analysis of (prote)omics data. Nature Methods 13, 731-740.

Ungar, D., and Hughson, F.M. (2003). SNARE Protein Structure and Function. Annual Review of Cell and Developmental Biology 19, 493-517.

Venditti, R., Scanu, T., Santoro, M., Di Tullio, G., Spaar, A., Gaibisso, R., Beznoussenko, G. V., Mironov, A.A., Mironov, A., Zelante, L., et al. (2012). Sedlin controls the ER export of procollagen by regulating the Sar1 cycle. Science 337, 1668-1672. 
Vinayagam, A., Hu, Y., Kulkarni, M., Roesel, C., Sopko, R., Mohr, S.E., and Perrimon, N. (2013). Protein complex-based analysis framework for high-throughput data sets. Science Signaling 6.

Walther, T.C., and Farese, R. v (2012). Lipid droplets and cellular lipid metabolism. Annual Review of Biochemistry 81, 687-714.

Wang, C., Liu, Z., and Huang, X. (2012). Rab32 is important for autophagy and lipid storage in drosophila. PLoS ONE 7.

Wang, H., Becuwe, M., Housden, B.E., Chitraju, C., Porras, A.J., Graham, M.M., Liu, X.N., Thiam, A.R., Savage, D.B., Agarwal, A.K., et al. (2016). Seipin is required for converting nascent to mature lipid droplets. ELife 5.

Weigel, A. V., Chang, C.L., Shtengel, G., Xu, C.S., Hoffman, D.P., Freeman, M., Iyer, N., Aaron, J., Khuon, S., Bogovic, J., et al. (2021). ER-to-Golgi protein delivery through an interwoven, tubular network extending from ER. Cell 184, 2412-2429.

Welte, M.A. (2015). Expanding roles for lipid droplets. Current Biology 25, R470-R481.

Westrate, L.M., Hoyer, M.J., Nash, M.J., and Voeltz, G.K. (2020). Vesicular and uncoated Rab1dependent cargo carriers facilitate ER to Golgi transport. Journal of Cell Science 133.

Whiteheart, S.W., Rossnagel, K., Buhrow, S.A., Brunner, M., Jaenicke, R., and Rothman, J.E. (1994). N-ethylmaleimide-sensitive fusion protein: A trimeric ATPase whose hydrolysis of ATP is required for membrane fusion. Journal of Cell Biology 126, 945-954.

Wilfling, F., Wang, H., Haas, J.T., Krahmer, N., Gould, T.J., Uchida, A., Cheng, J.X., Graham, M., Christiano, R., Fröhlich, F., et al. (2013). Triacylglycerol synthesis enzymes mediate lipid droplet growth by relocalizing from the ER to lipid droplets. Developmental Cell 24, 384-399.

Wilfling, F., Thiam, A.R., Olarte, M.J., Wang, J., Beck, R., Gould, T.J., Allgeyer, E.S., Pincet, F., Bewersdorf, J., Farese, R. v., et al. (2014). Arf1/COPI machinery acts directly on lipid droplets and enables their connection to the ER for protein targeting. ELife 3.

Wu, L., Xu, D., Zhou, L., Xie, B., Yu, L., Yang, H., Huang, L., Ye, J., Deng, H., Yuan, Y.A., et al. (2014). Rab8a-AS160-MSS4 regulatory circuit controls lipid droplet fusion and growth. Developmental Cell 30, 378-393.

Xu, D., Li, Y., Wu, L., Li, Y., Zhao, D., Yu, J., Huang, T., Ferguson, C., Parton, R.G., Yang, H., et al. (2018). Rab18 promotes lipid droplet (LD) growth by tethering the ER to LDs through SNARE and NRZ interactions. Journal of Cell Biology 217, 975-995.

Yan, R., Qian, H., Lukmantara, I., Gao, M., Du, X., Yan, N., and Yang, H. (2018). Human SEIPIN Binds Anionic Phospholipids. Developmental Cell 47, 248-256. 
Yu, J., Zhang, L., Li, Y., Zhu, X., Xu, S., Zhou, X.M., Wang, H., Zhang, H., Liang, B., and Liu, P. (2018). The Adrenal Lipid Droplet is a New Site for Steroid Hormone Metabolism. Proteomics 18.

Zhao, M., Wu, S., Zhou, Q., Vivona, S., Cipriano, D.J., Cheng, Y., and Brunger, A.T. (2015). Mechanistic insights into the recycling machine of the SNARE complex. Nature 518, 61-67. 
FioRxiv preprint doi: https://doi.org/10.1101/2021.09.14.460330; this version posted September 15, 2021. The copyright holder for this preprint
(which was not certified by peer review) is the author/funder. All rights reserved. No reuse allowed without permission.

A

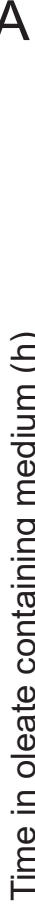
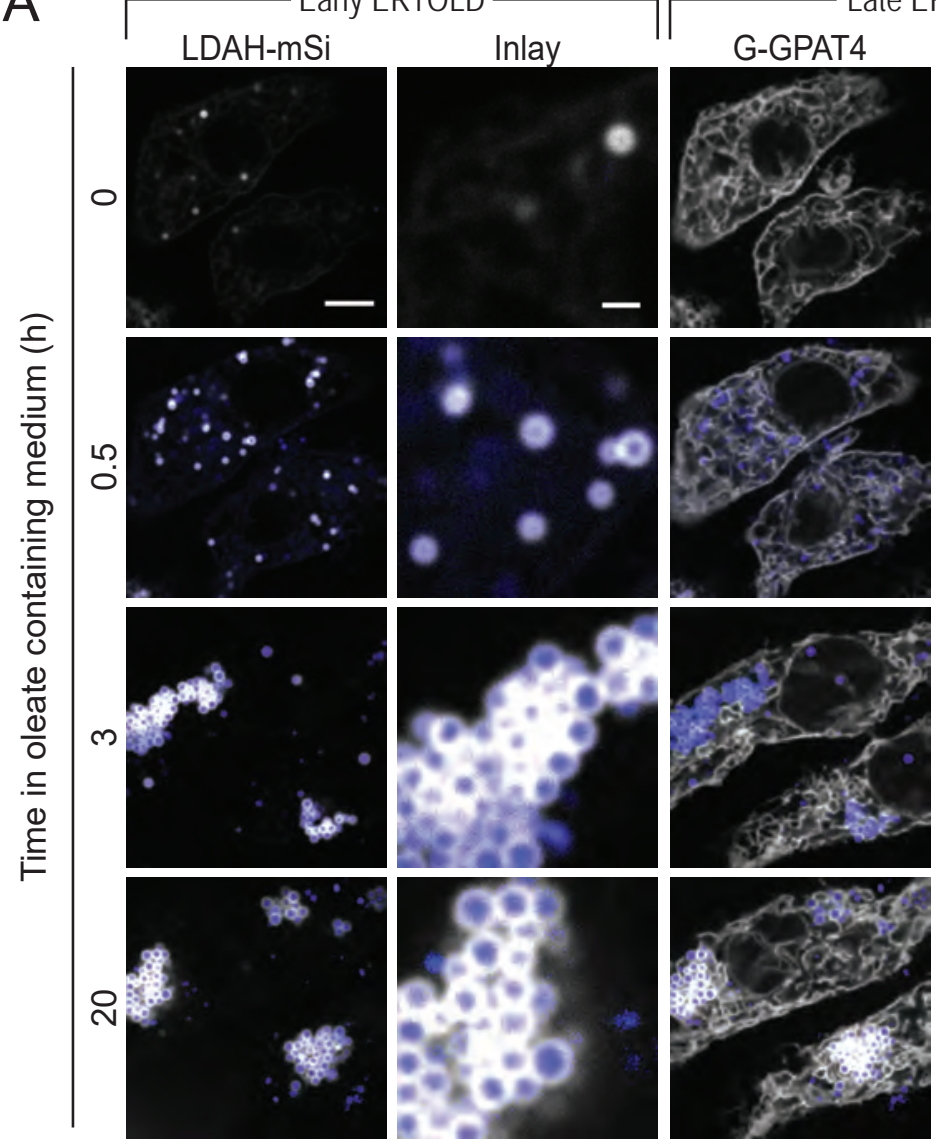

B

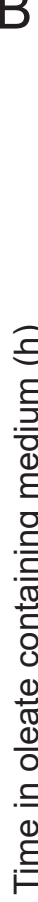
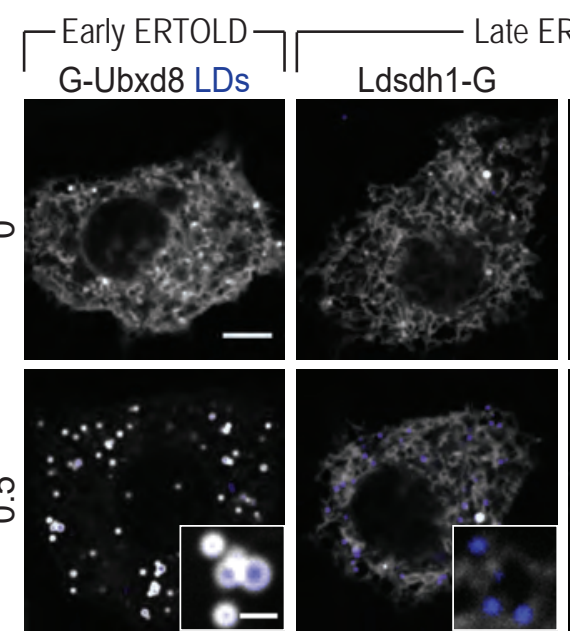
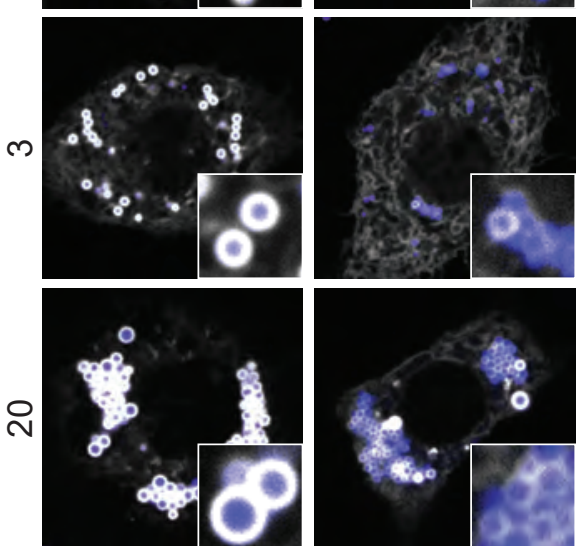

m

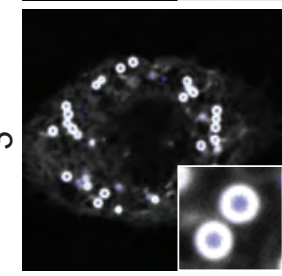

?
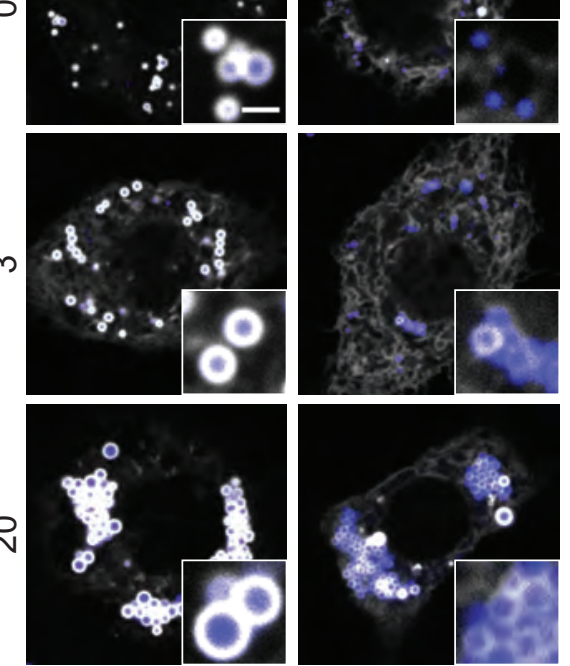
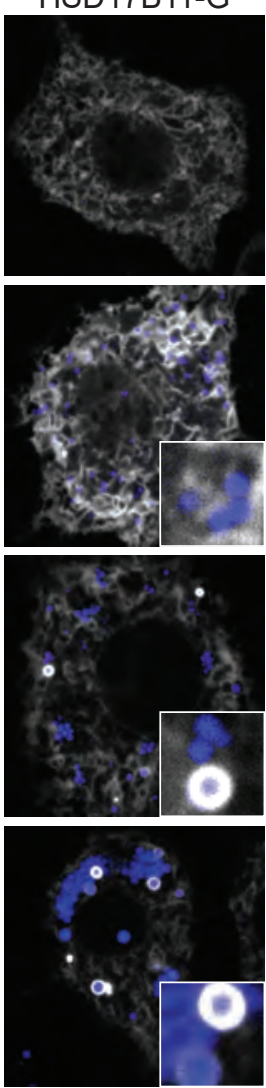
Late ERTOLD

Merged

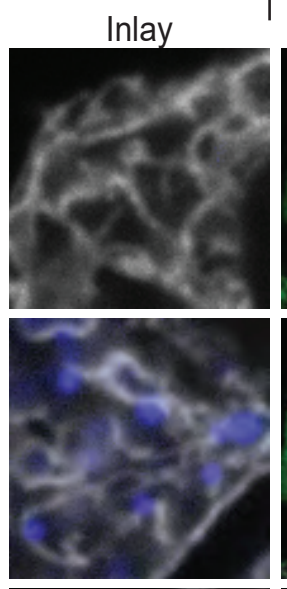

LDAH-mSi G-GPAT4 Inlay
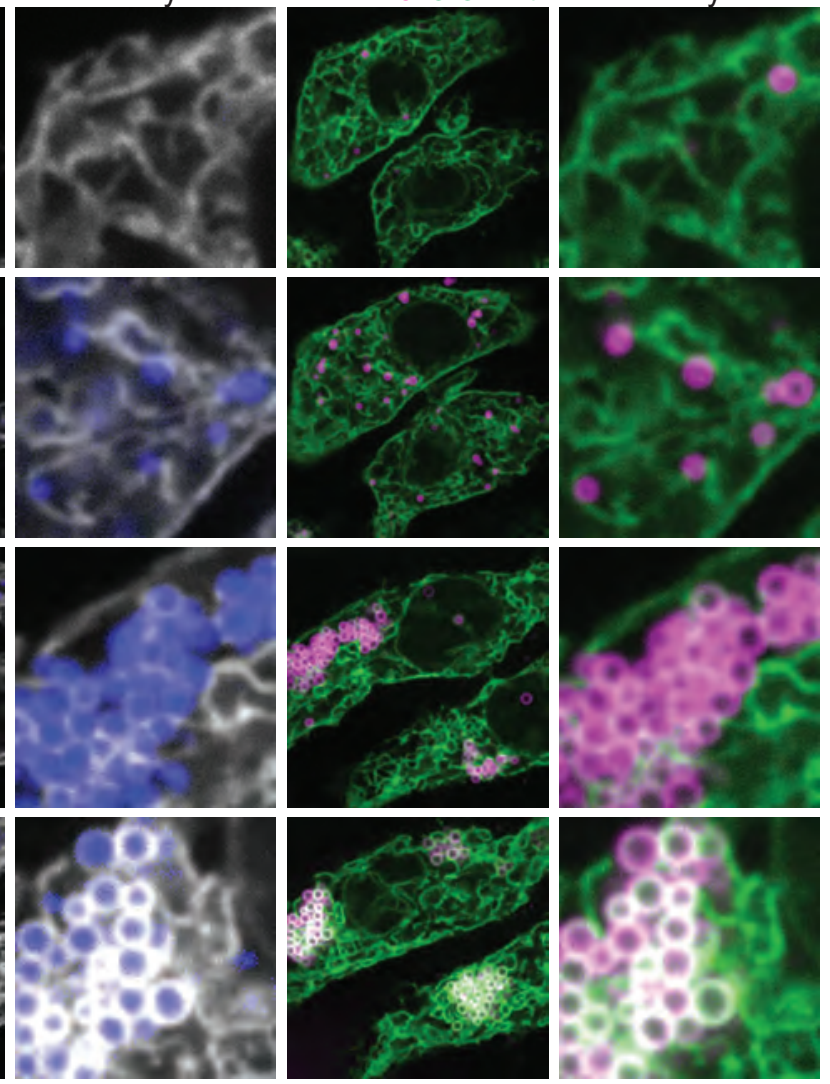

C

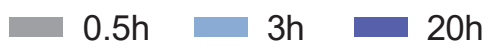

HSD17B11-G

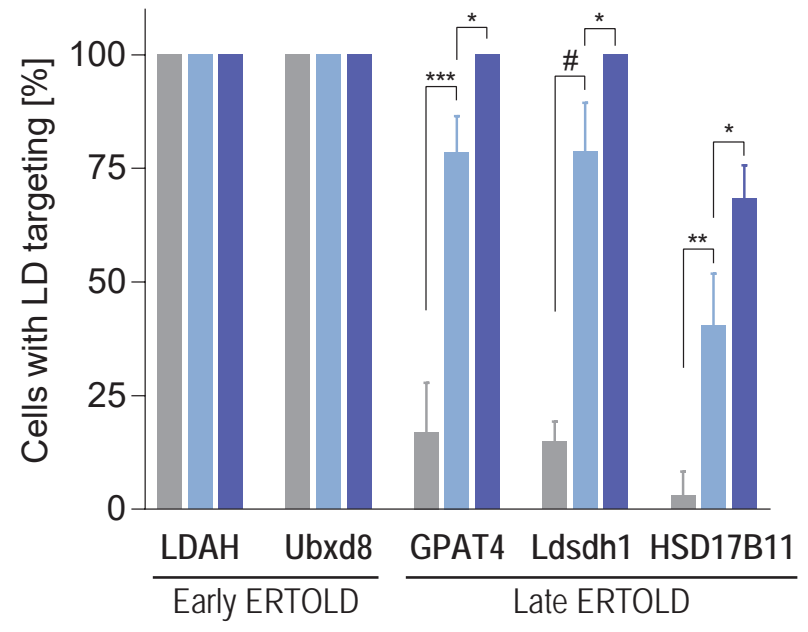




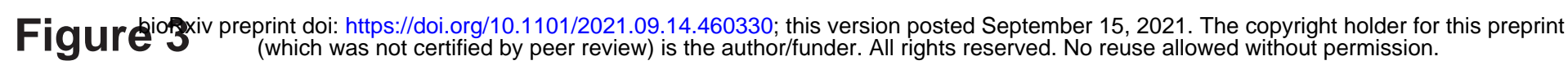

\section{A RNAi:}
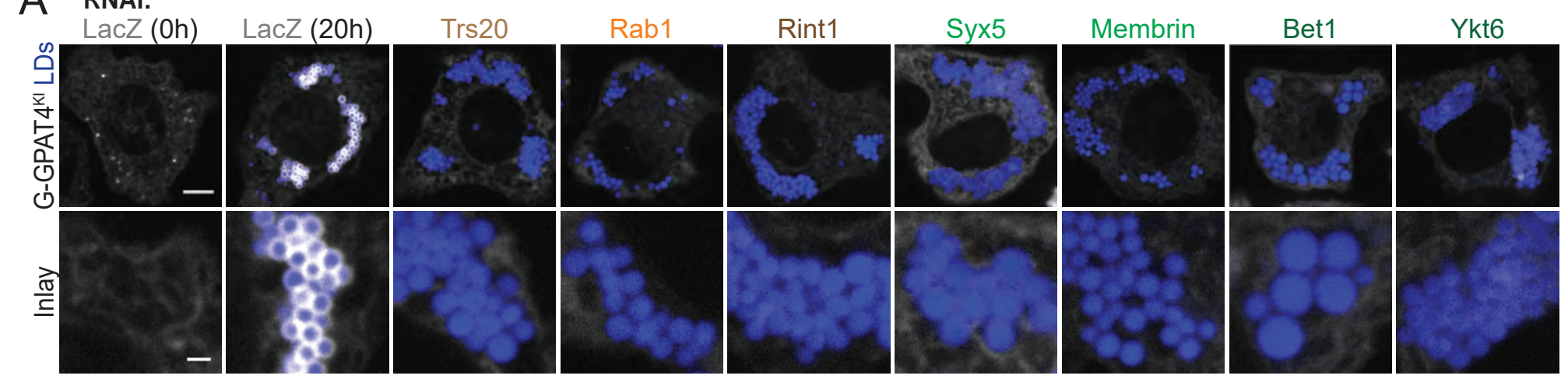

B

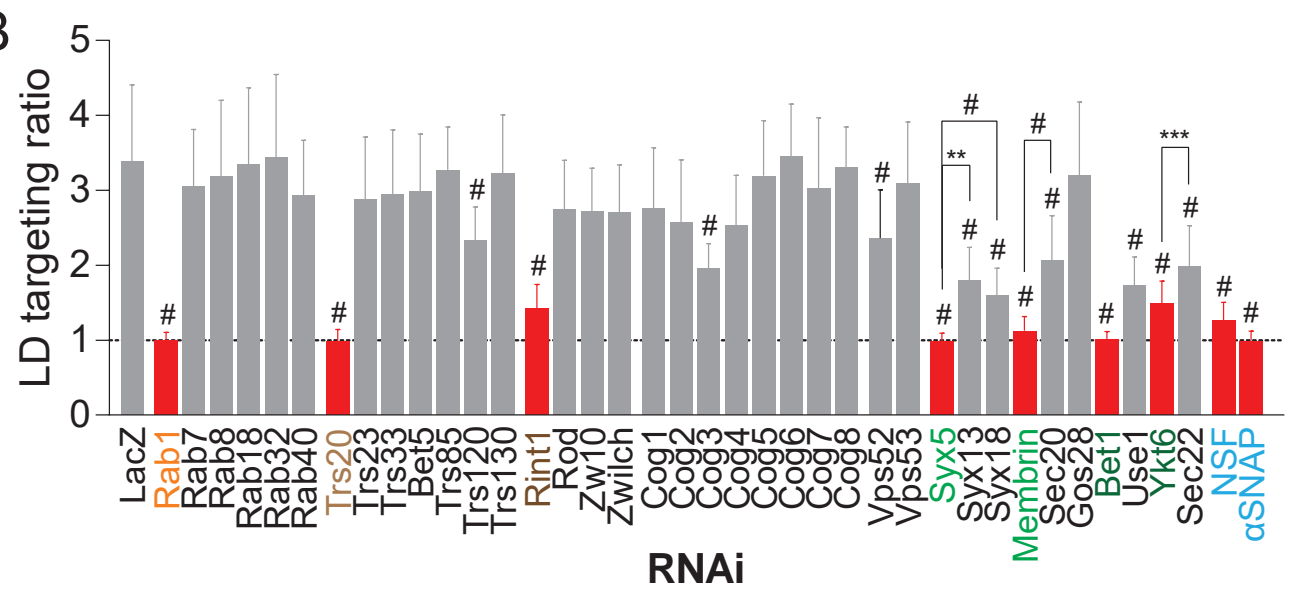

C

D

RNAi: LacZ

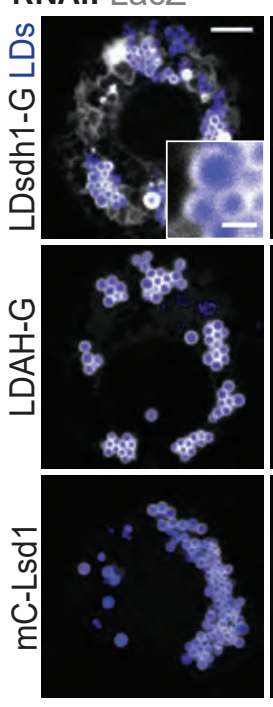

Trs20

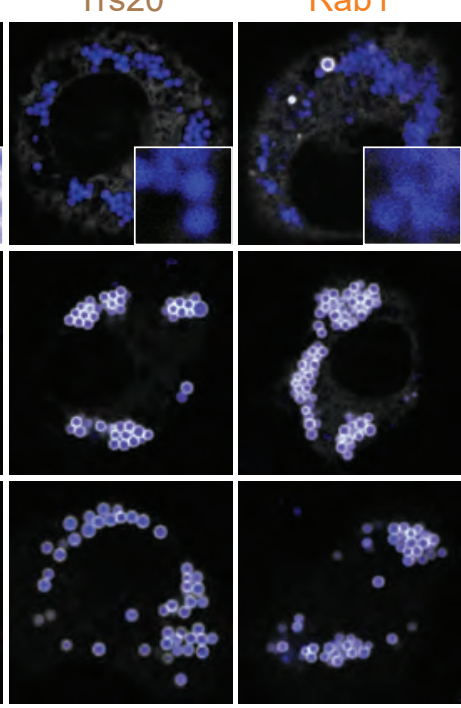

Rint1
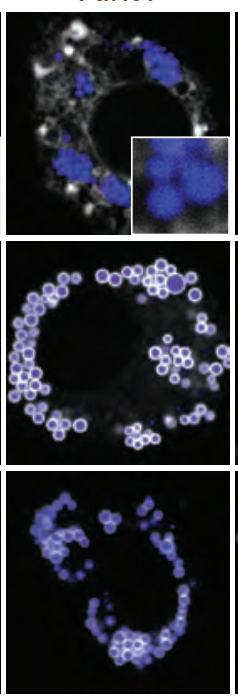

Syx5
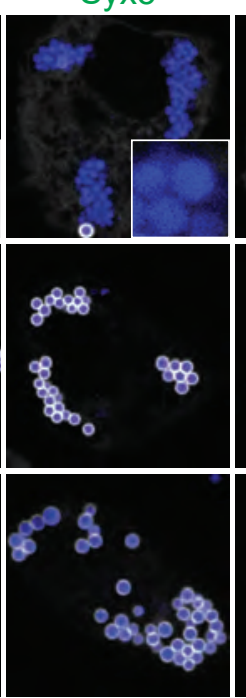

Input

LDs $\quad \mathrm{MS}$

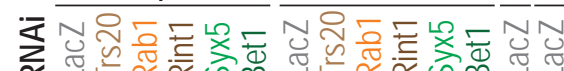

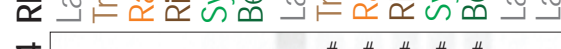

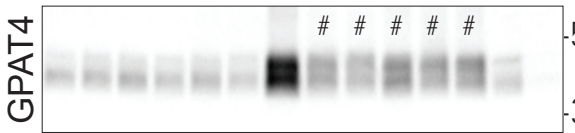

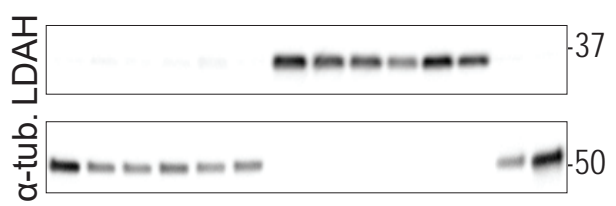

E

$\mathrm{F}$

mCherry-Rab1 LDs

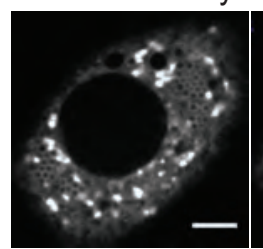

Inlay

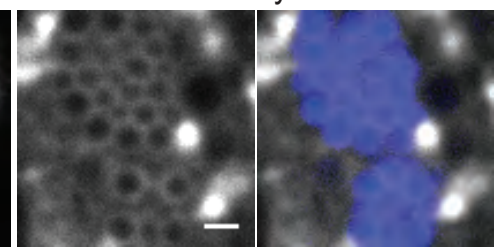

EGFP-Rint1 LDs

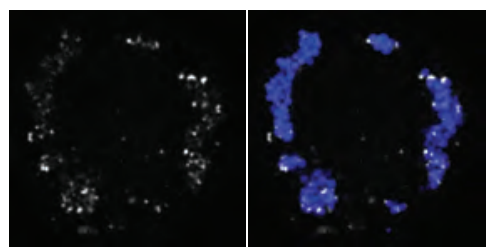

Inlay

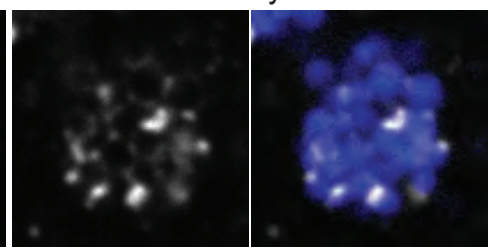


A ER exit site Coiled-coil tethers B

Sec12
Sar1
Sec16
Sec13
Sec31
Sec23
Sec24AB
Sec24CD
Tango1

$\begin{array}{lllll}-6 & -3 & 0 & 3 & 6\end{array}$

$\downarrow$ targeting $\uparrow$

(Robust Z-score)

GCC88
GCC185
GM130
Gmap210
Golgin45
Golgin84
Golgin97
Golgin104
Golgin245
Lva
TMF1
p115
Grasp65
Rbpn-5
Rabip4
$\square$

C

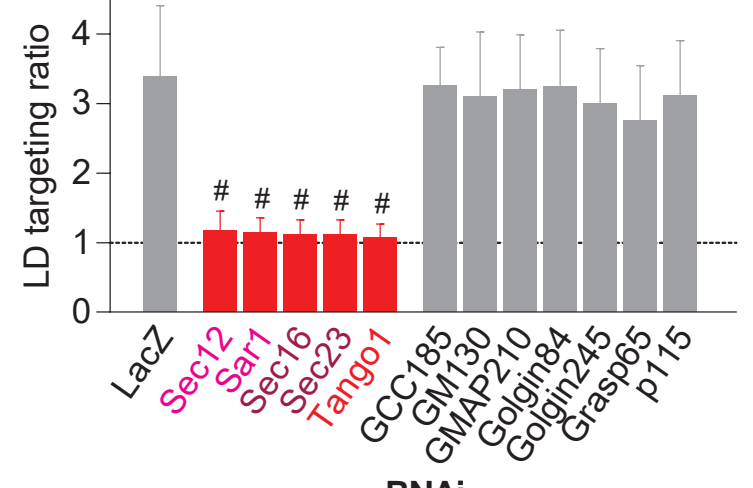

RNAi

E

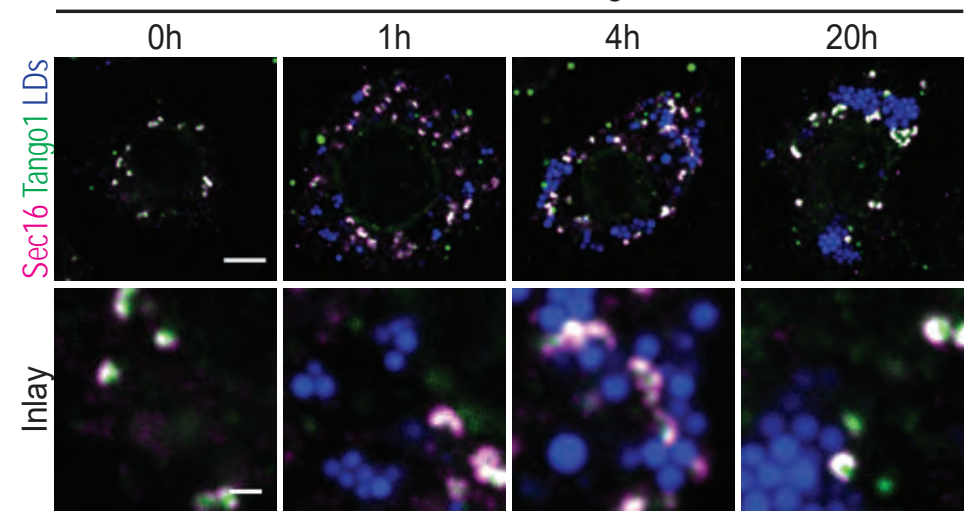

$\mathrm{H}$

Sec12

Sar1

Sec16

Sec13

$\operatorname{Sec} 31(A)$

$\operatorname{Sec} 31$ (B)

Sec23

Sec24AB

Sec24CD

Tango1

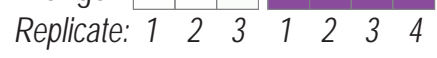

RNAi:

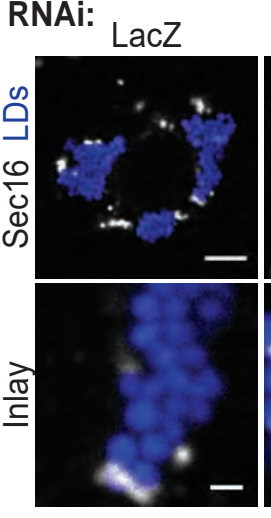

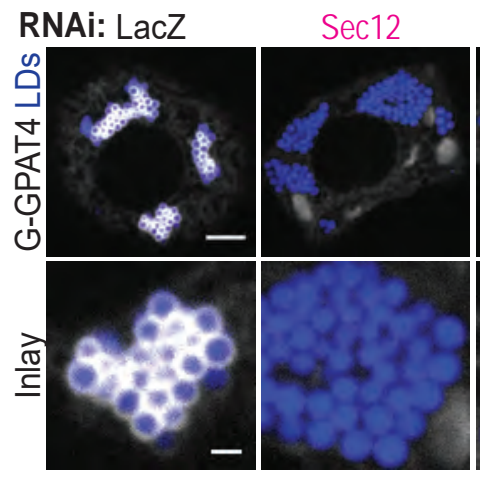
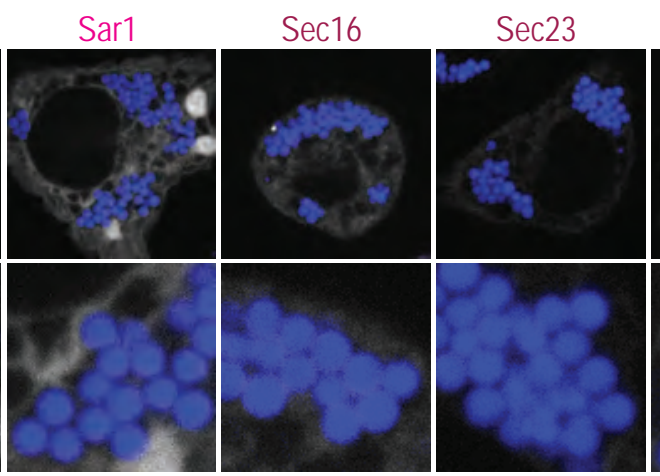

Tango1

D

LDs

Membranes

Sol.

RNAi: LacZ Sec16 Tango1 Seipin LacZ Sec16 Tango1 Seipin LacZ Sec16 Tango1 Seipin LacZ

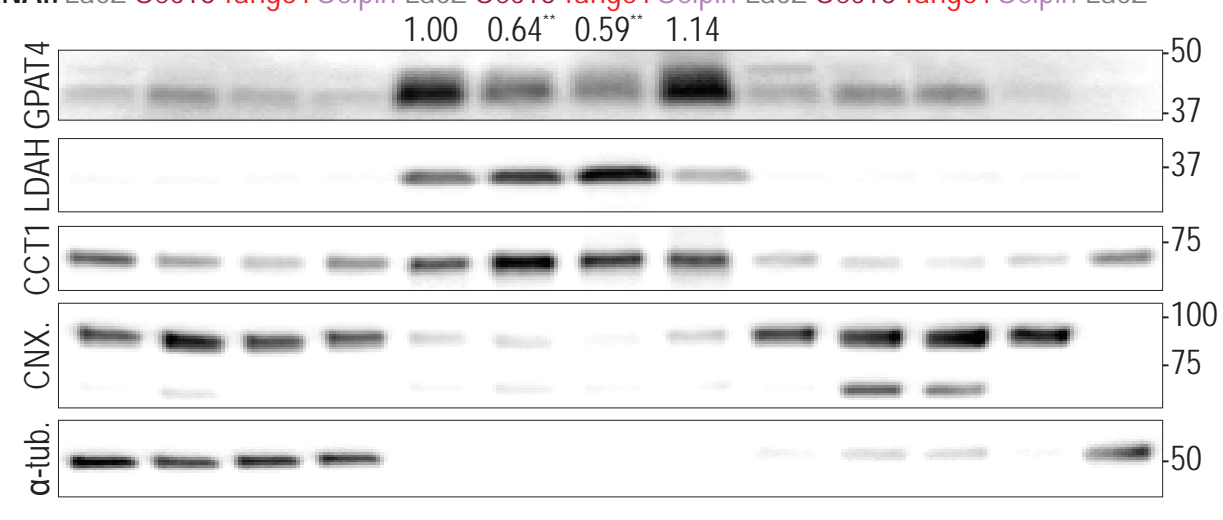

F

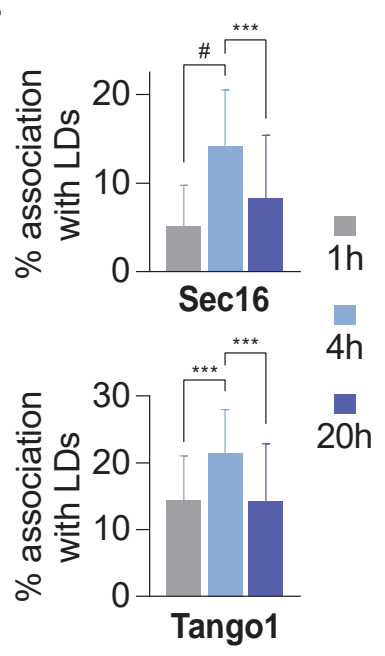

G

OE:

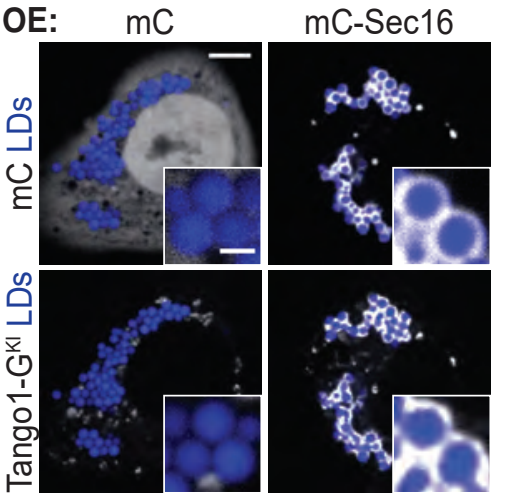

Tango1 +

Tango1

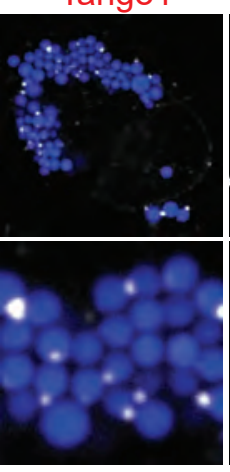

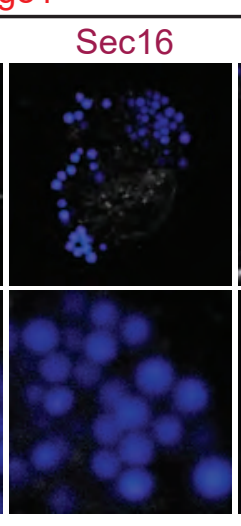

Sec23

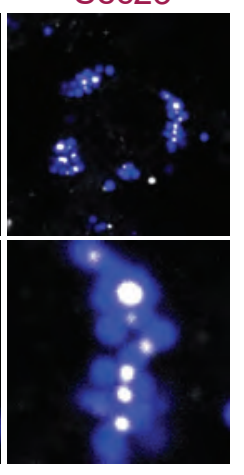




\section{A Seipin KO cells}

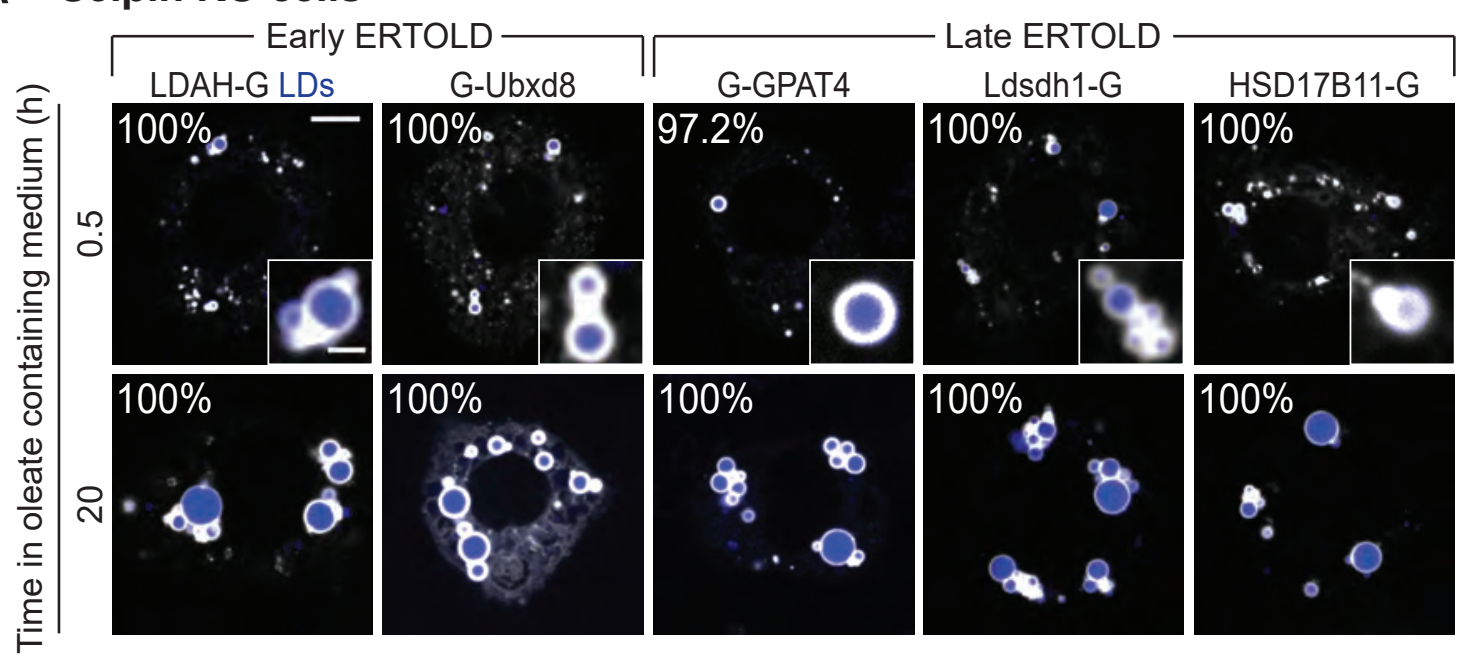

B

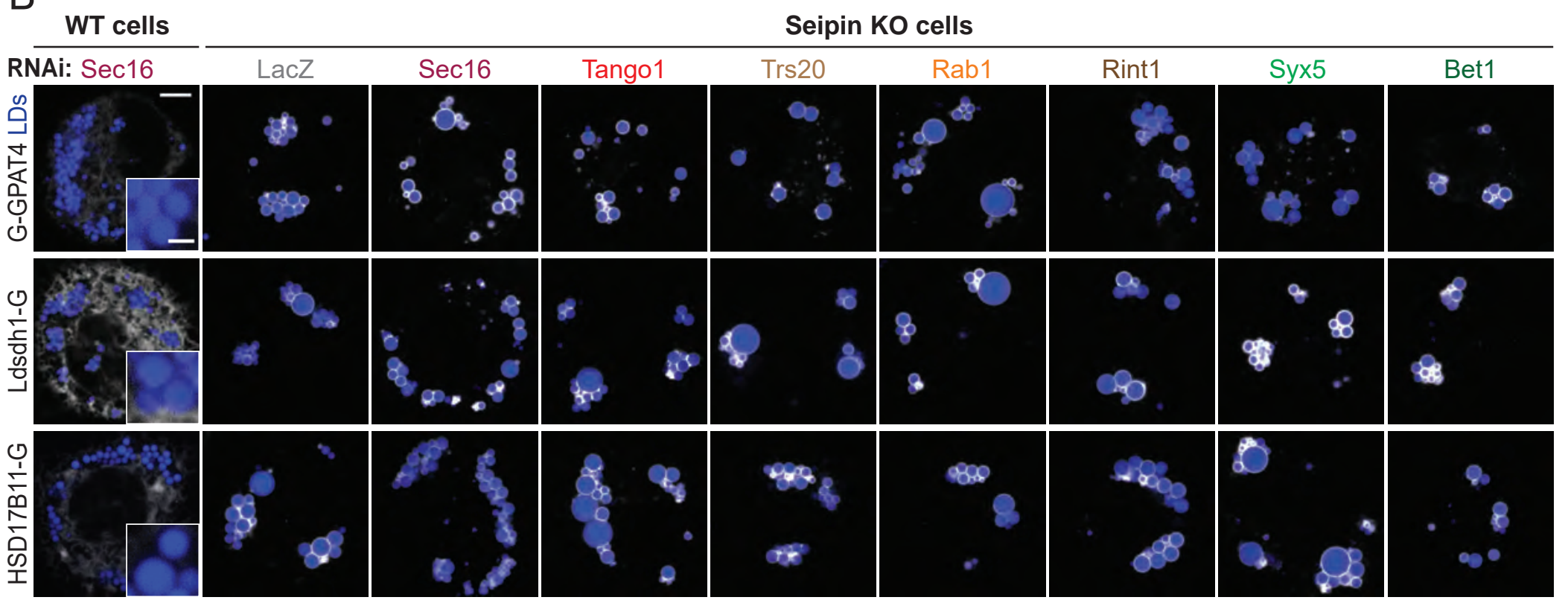

Seipin KO cells: $20 \mathrm{~h}$ in oleate containing medium

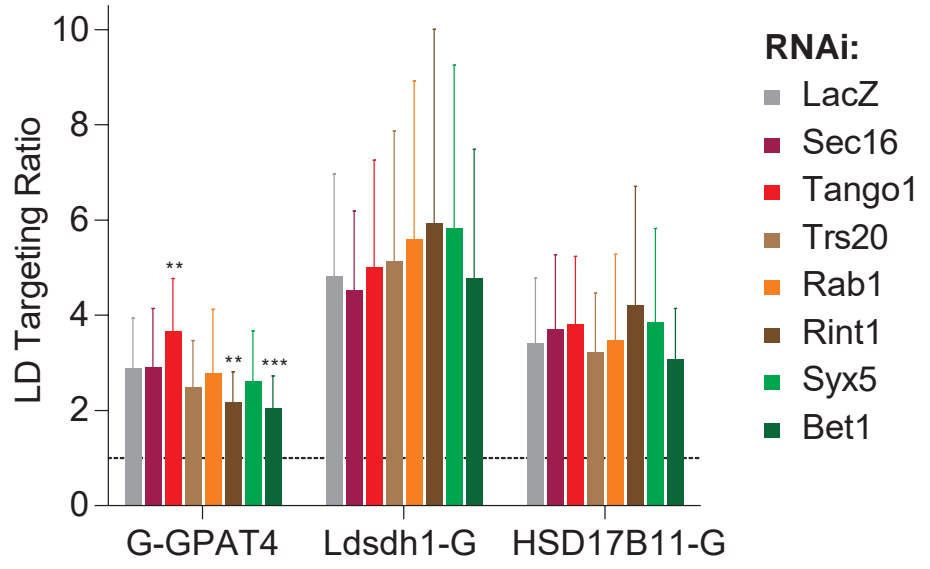

Seipin KO cells: $0.5 \mathrm{~h}$ in oleate containing medium

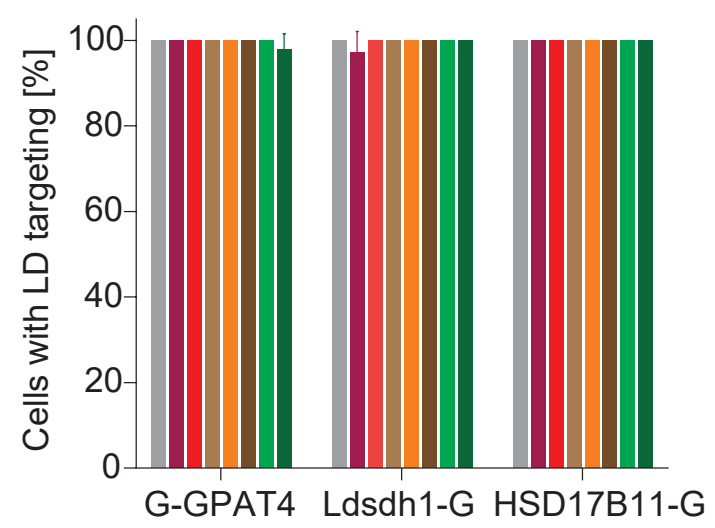



Figure dioxiv preprint doi: https://doi.org/10.1101/2021.09.14.460330; this version posted September 15, 2021. The copyright holder for this preprint
(which was not certified by peer review) is the author/funder. All rights reserved. No reuse allowed without permission.

A

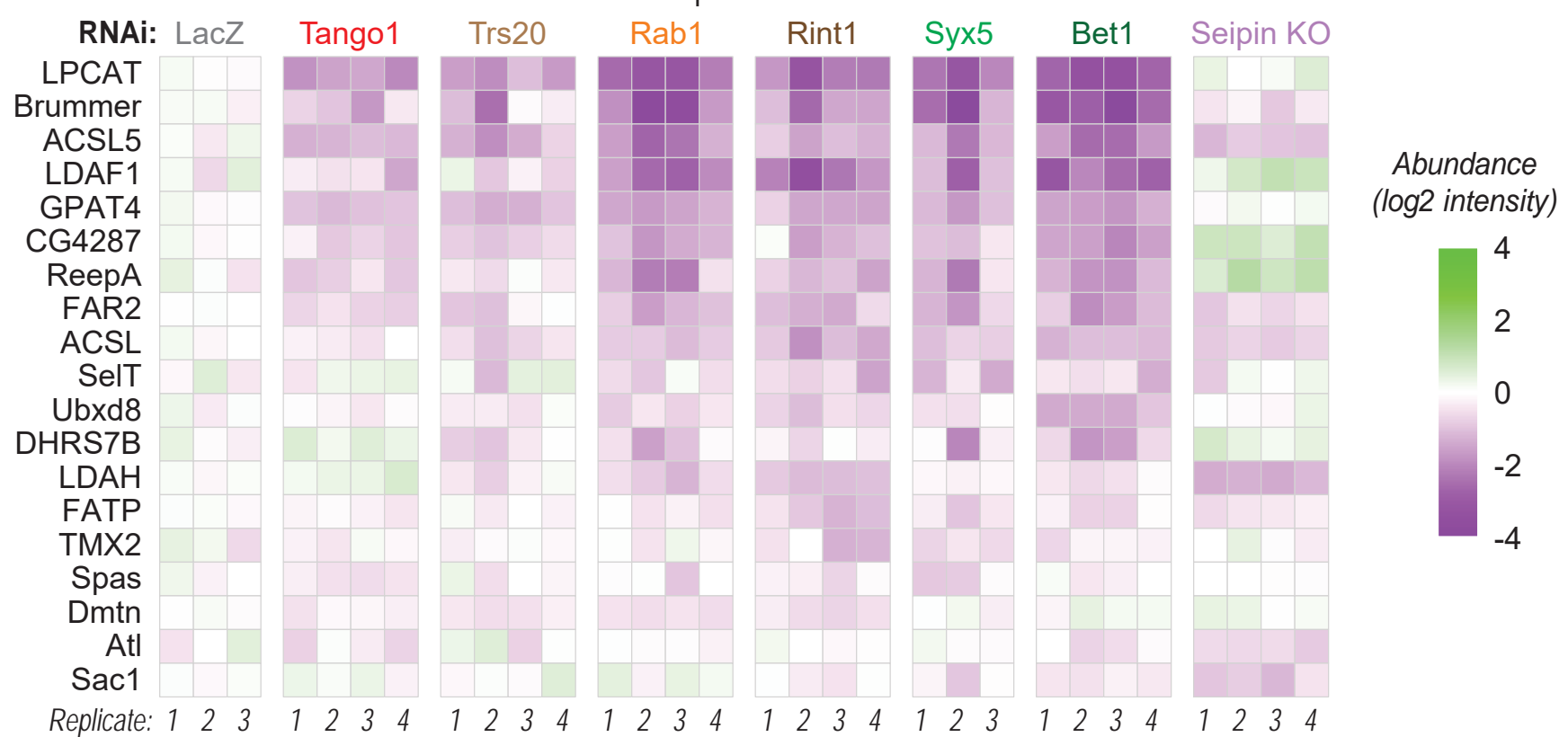

B

RNAi: LacZ
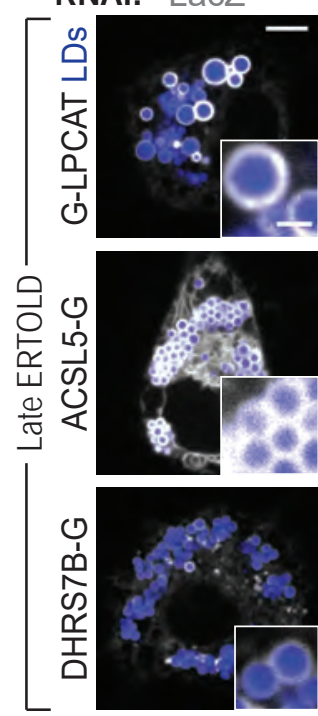

㟧
Sar1
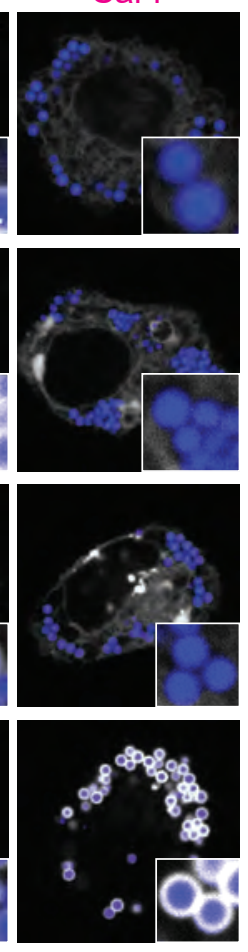
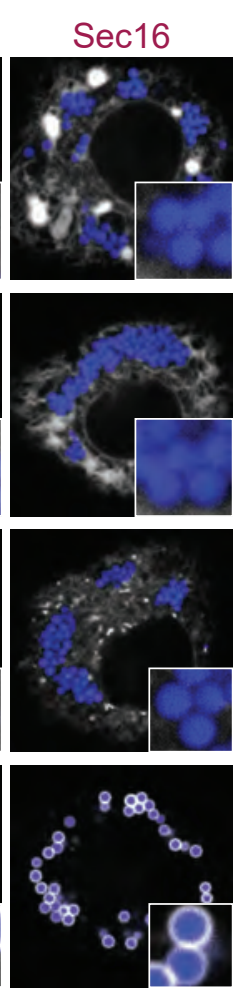

LD proteomics

政
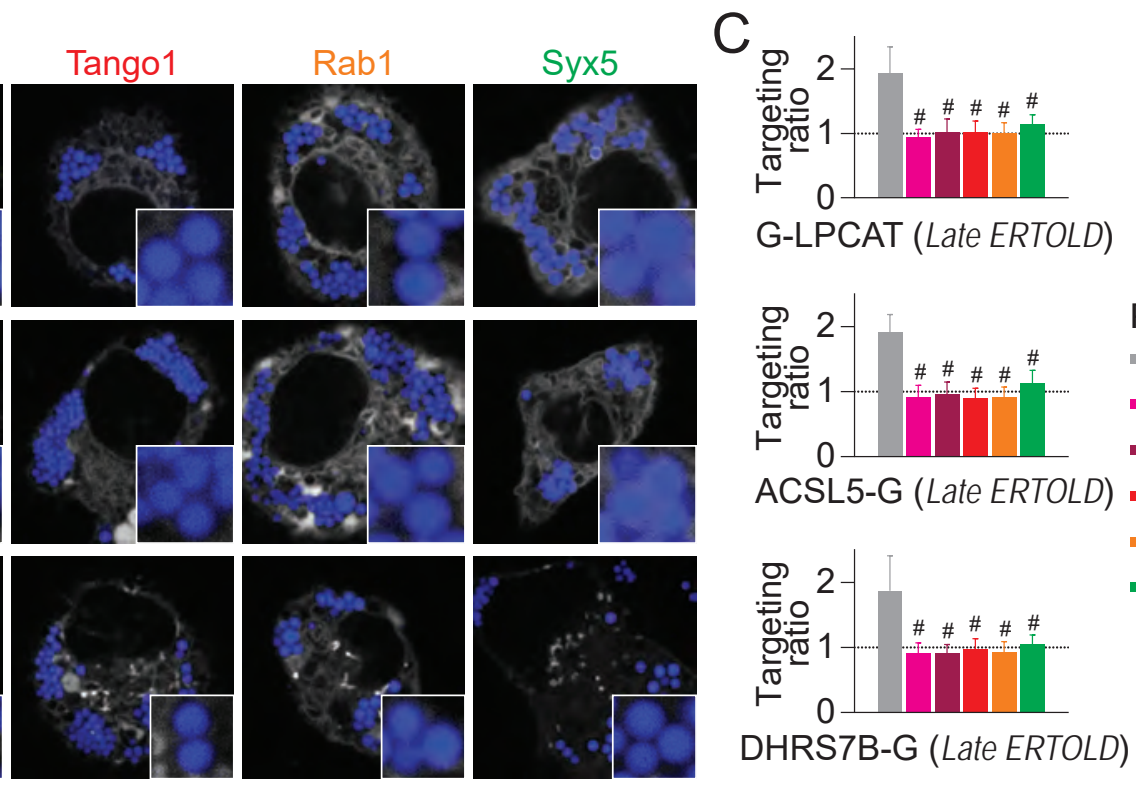

RNAi:

- LacZ

- Sar1

- Sec16

ACSL5-G (Late ERTOLD) - Tango1

DHRS7B-G (Late ERTOLD)
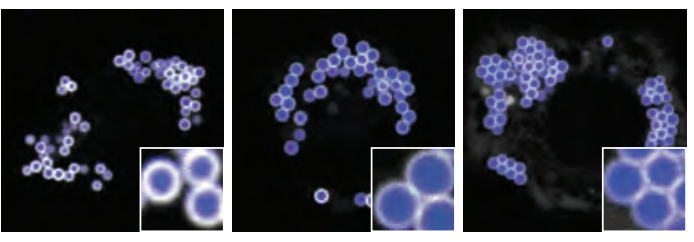

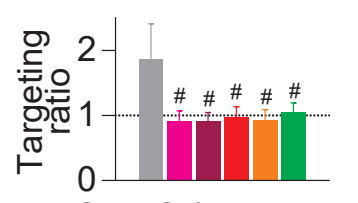

- Rab1

- Syx 5

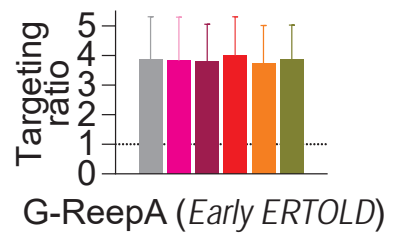




$$
\therefore \rightarrow=0
$$


A

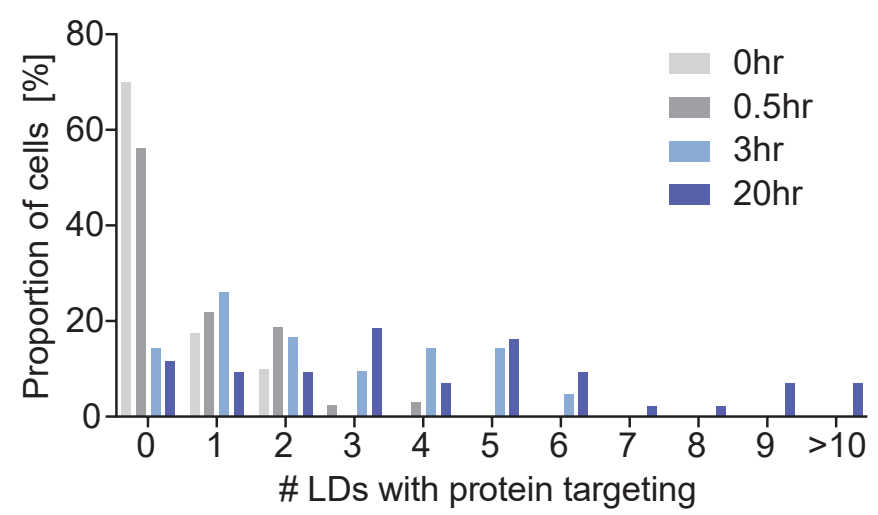

B

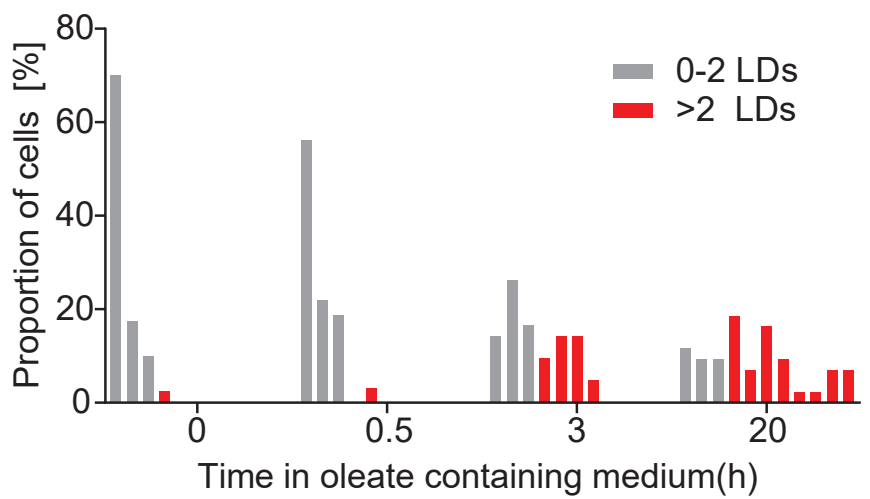

C LacZ RNAi

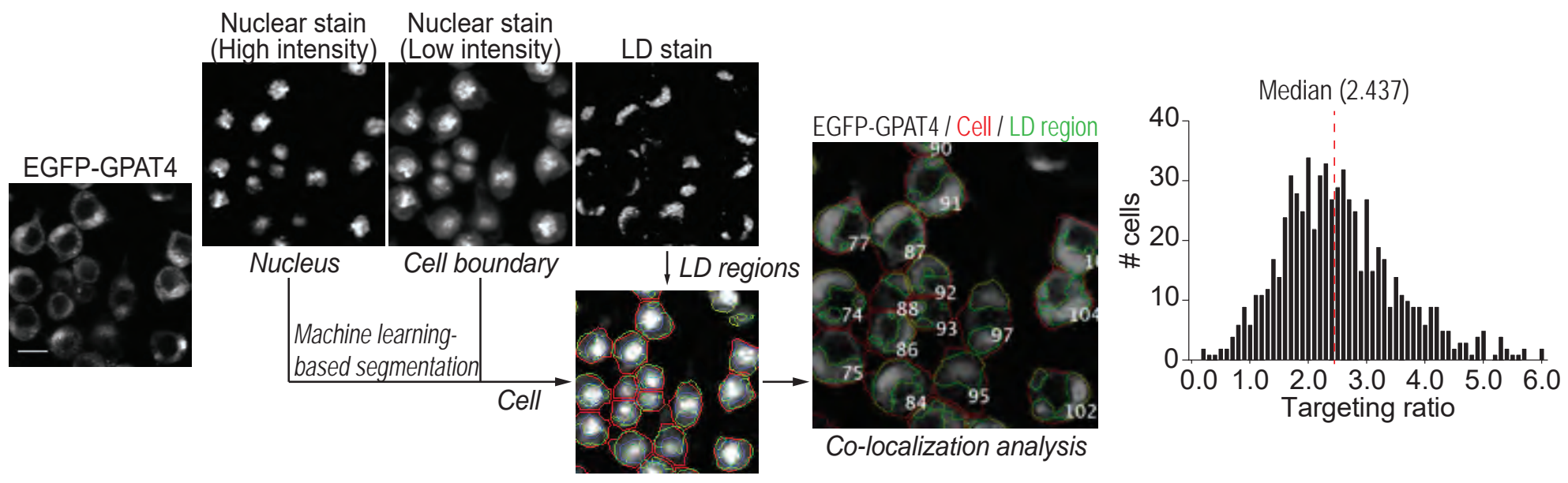

D
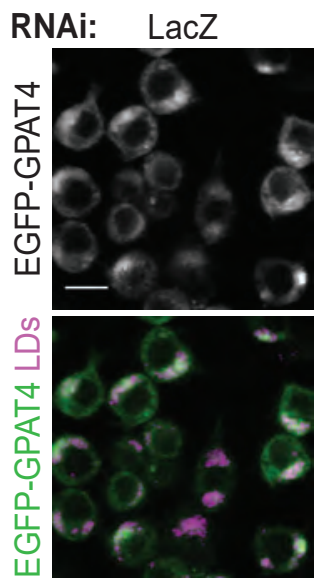

F

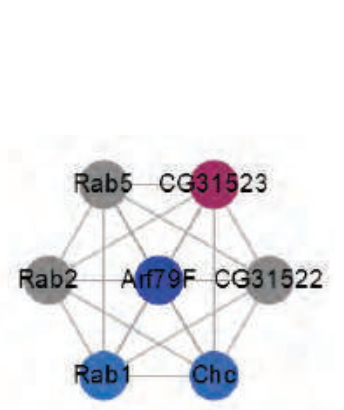

Vesicle endocytosis
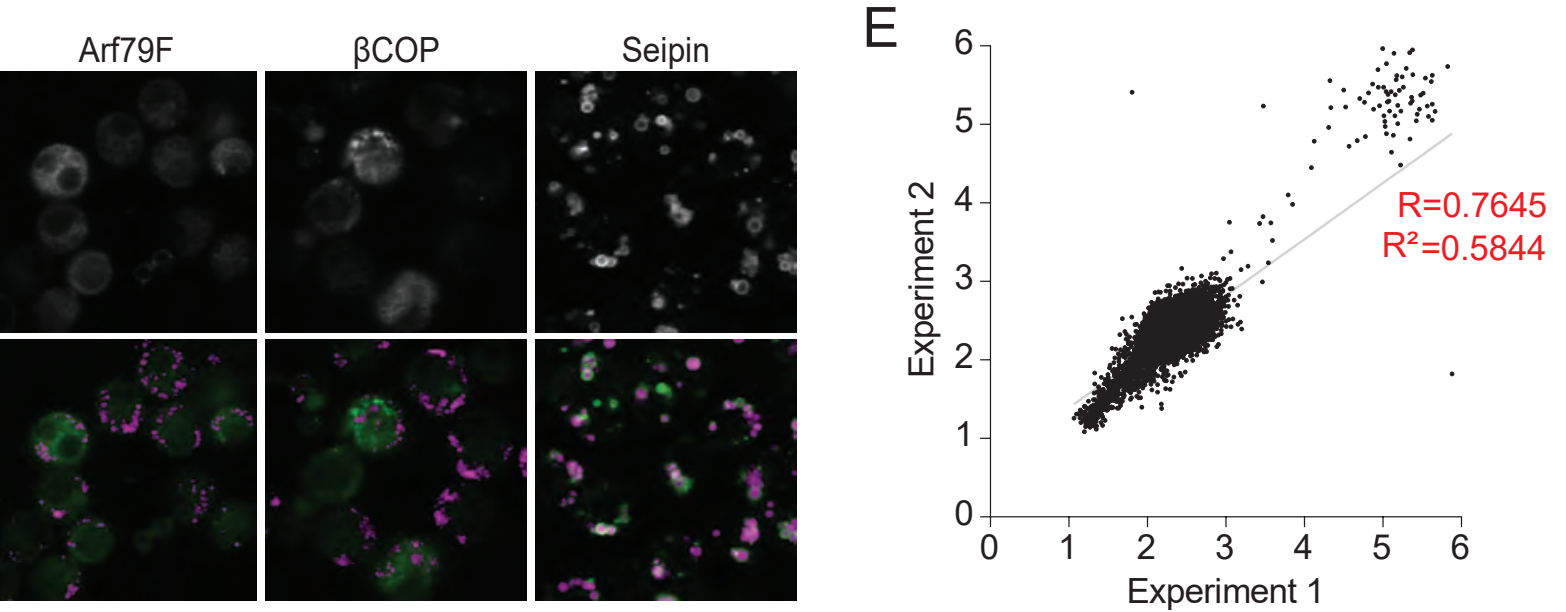

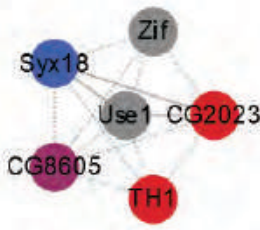

Dsl1p complex

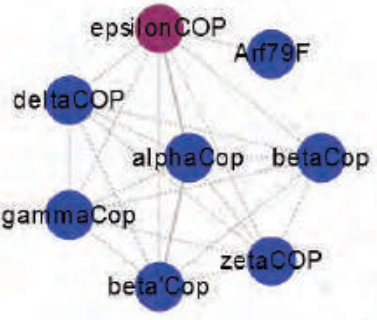

COPI coatomer complex

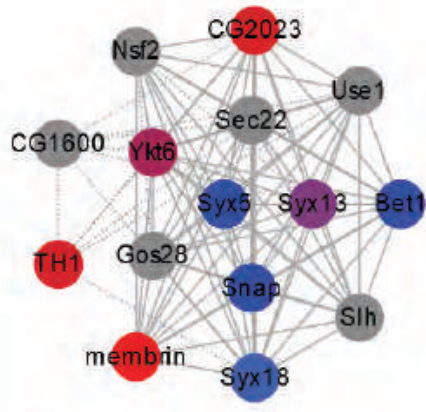

SNARES

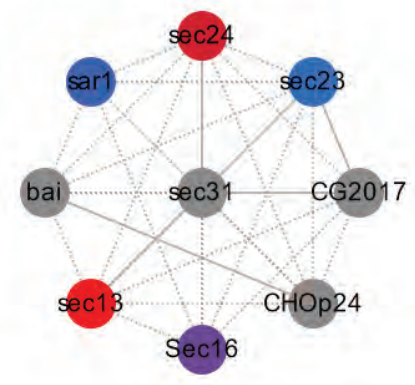

ER exit site 


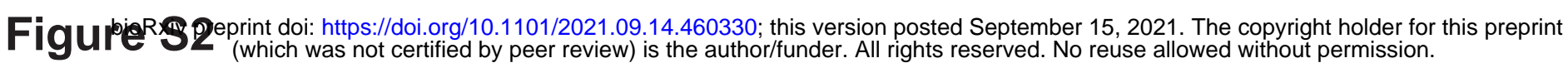

A RNAi:
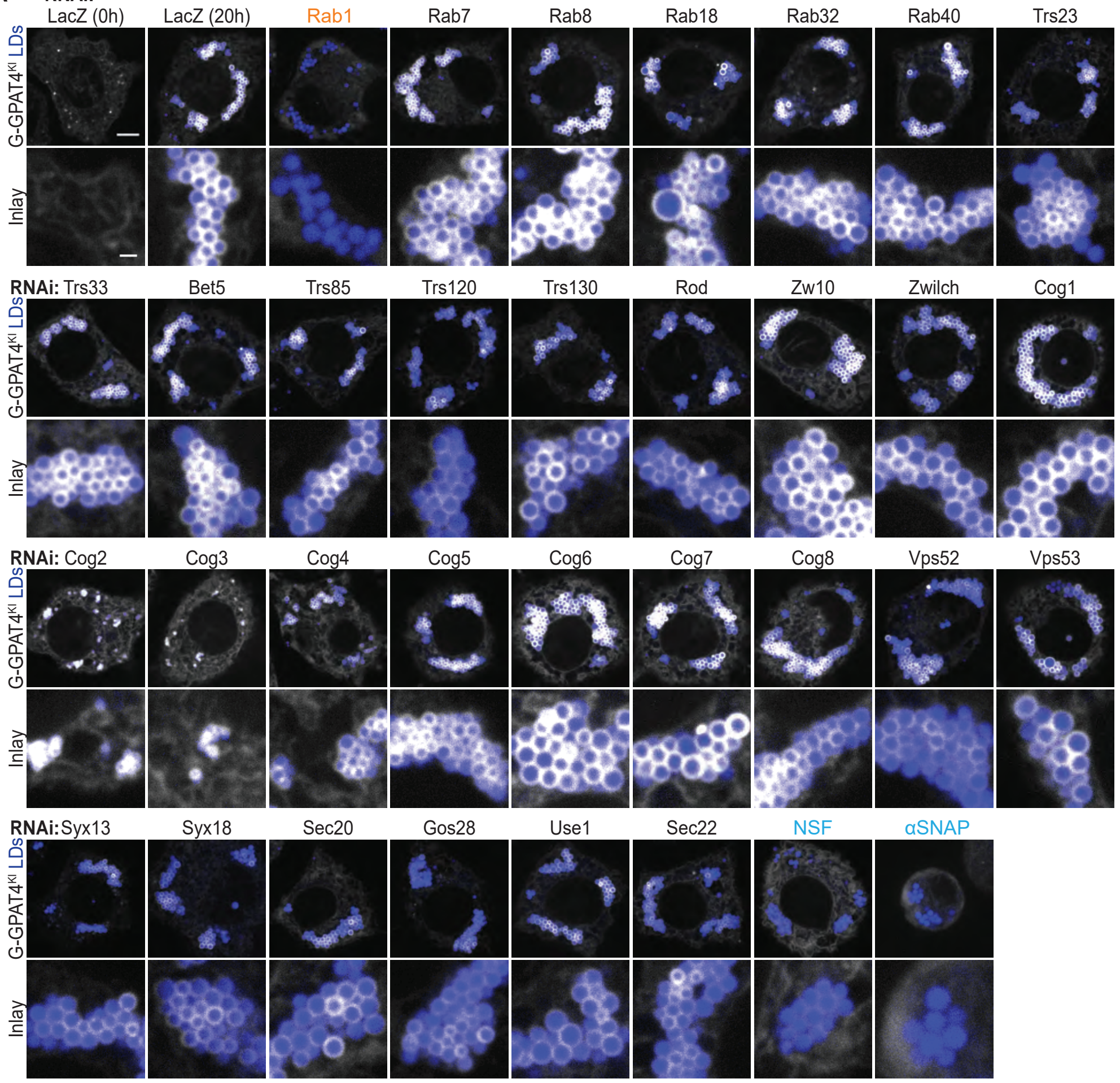

$\mathrm{B}$

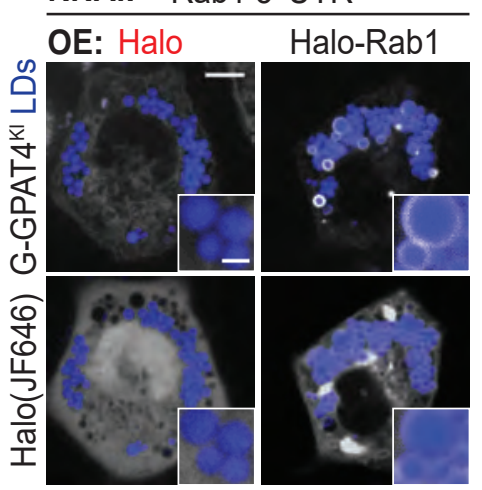

Halo

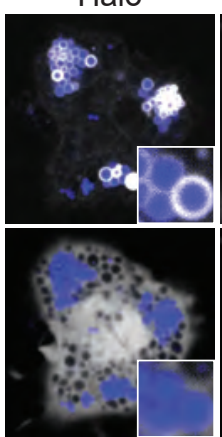

Sar1-T34N-H H-Rab1-N124I H-Syx5-1-445 H-NSF-E329Q

C

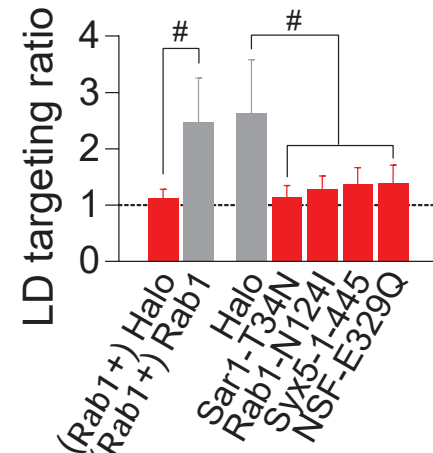

(RNAi +) Overexpression 
A Membranes LDs I S

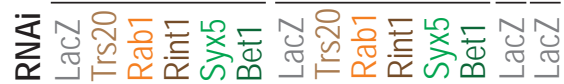

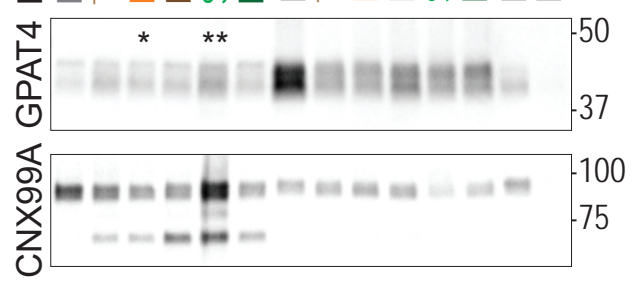

B

RNAi: LacZ

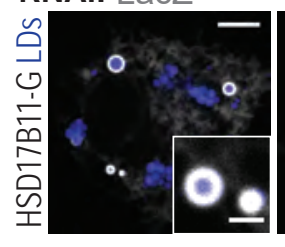

Trs20

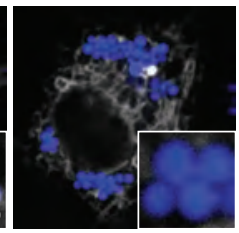

Rab1

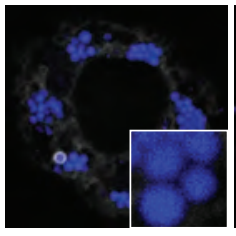

Rint1

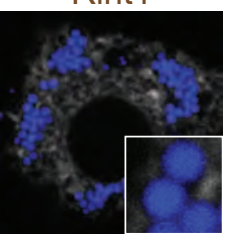

Syx5

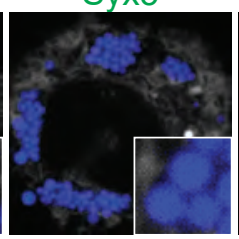

$E$

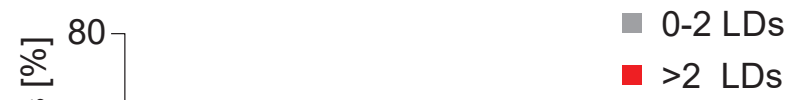

C
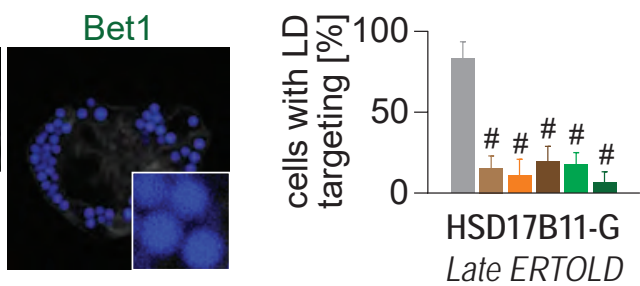

Late ERTOLD

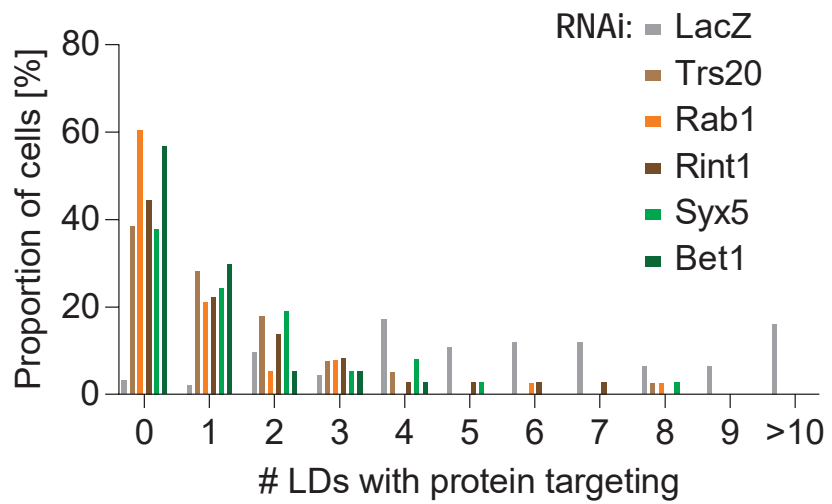

F

RNAi: LacZ

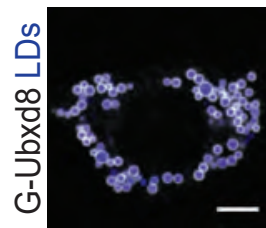

Trs20

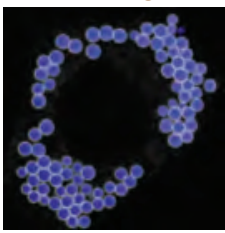

\begin{tabular}{l}
0 \\
है \\
0 \\
0 \\
1 \\
\hline 1 \\
0 \\
0
\end{tabular}

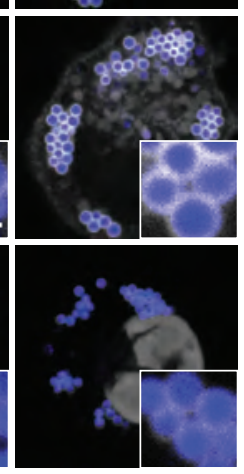

Rab1
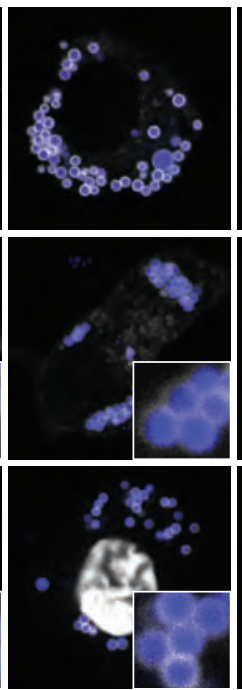

Rint1
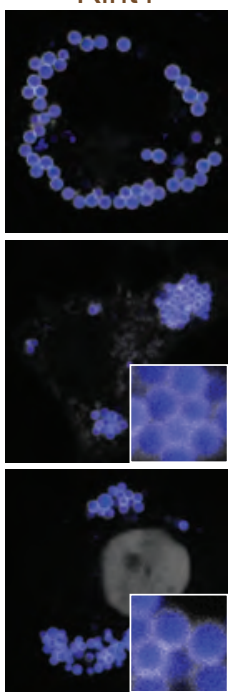

Syx5
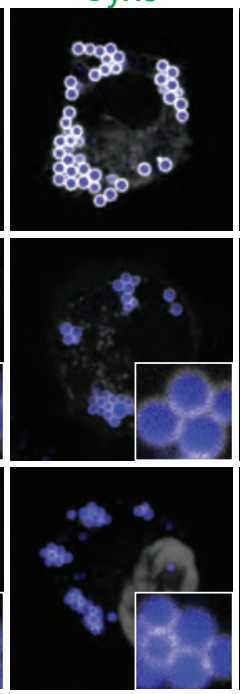

RNAi:

- LacZ
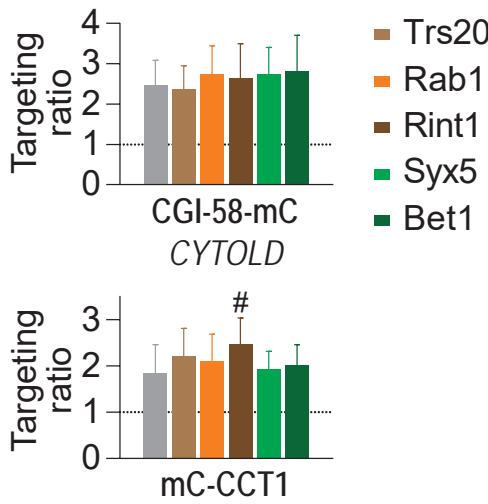

CYTOLD 

Figureateprint doi: https://doi.org/10.1101/2021.09.14.460330; this version posted September 15 , 2021. The copyright holder for this preprint
(which was not certified by peer review) is the author/funder. All rights reserved. No reuse allowed without permission.

A

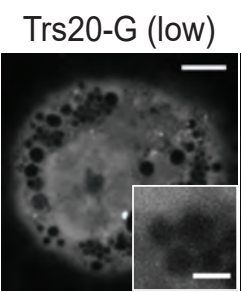

LDs

Trs20-G (high)

LDs
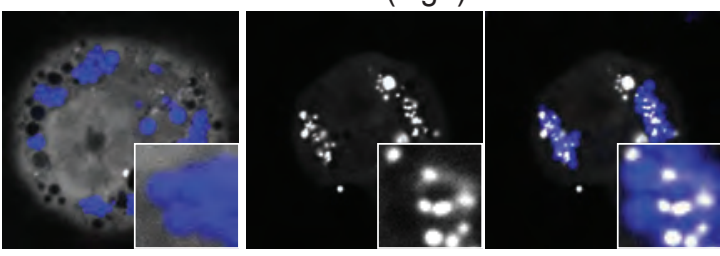

B

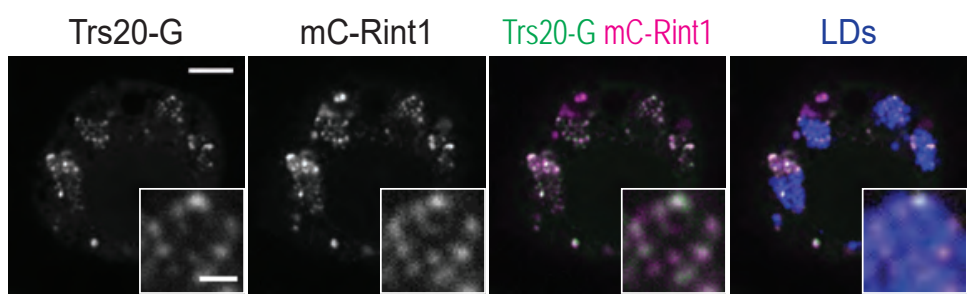

C

Murine liver faction-proteomes after 12 weeks high fat diet (www.nafled-organellemap.org; Krahmer et al., 2018)

0

0.5

1.0

Relative Abundance

Fraction\#: 12234456778910111213141516171819202122

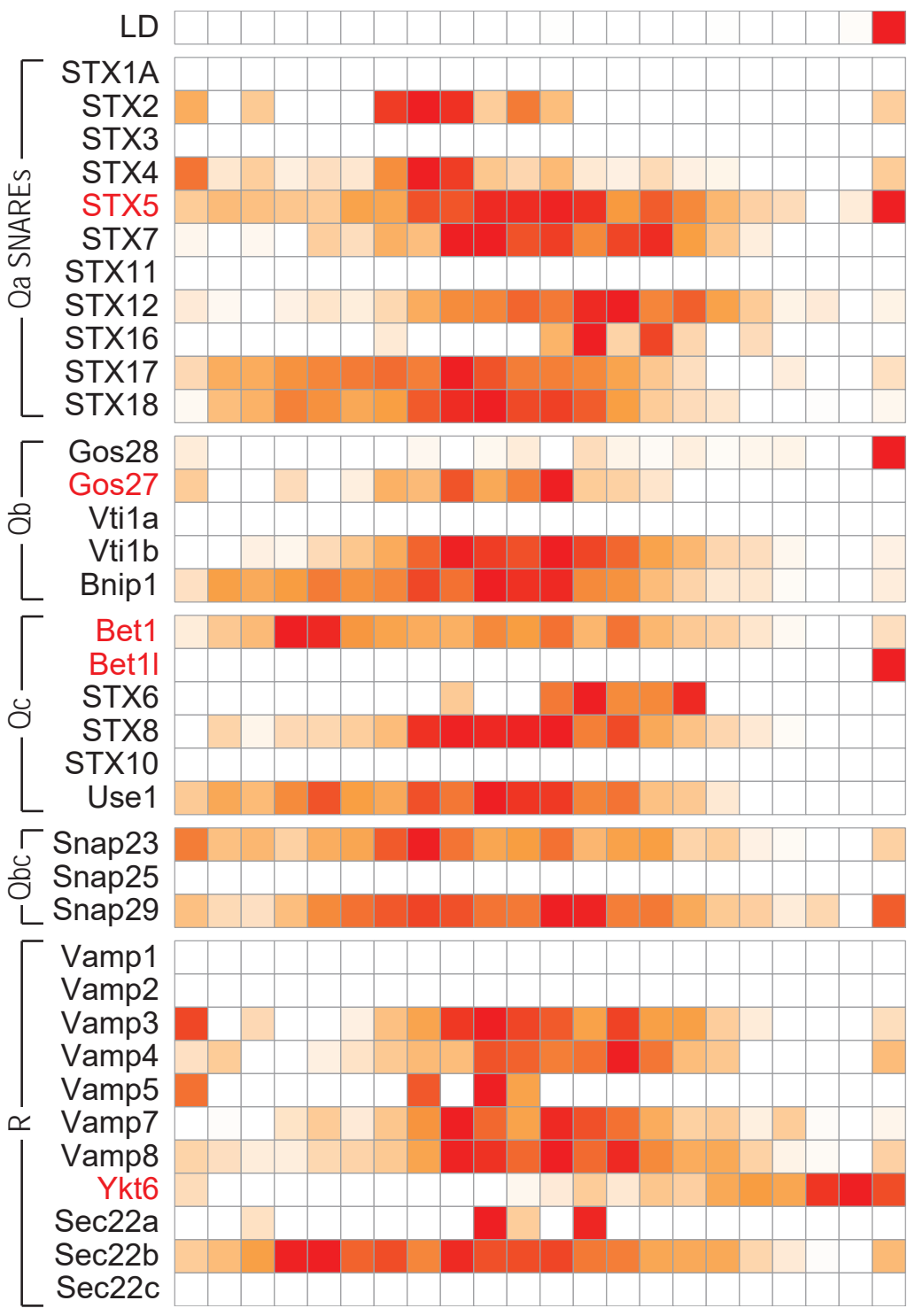


Fig U PeR 35 eprint doi: https://doi.org/10.1101/2021.09.14.460330; this version posted September 15 , 2021. The copyright holder for this preprint
(which was not certified by peer review) is the author/funder. All rights reserved. No reuse allowed without permission.

A Late ERTOLD
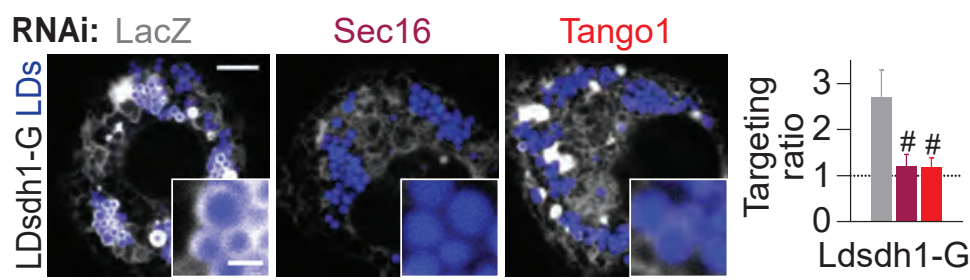

C

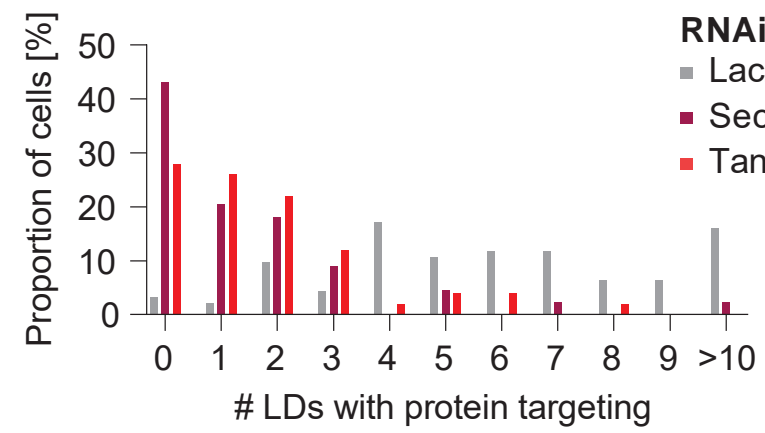

E Early ERTOLD

RNAi: LacZ
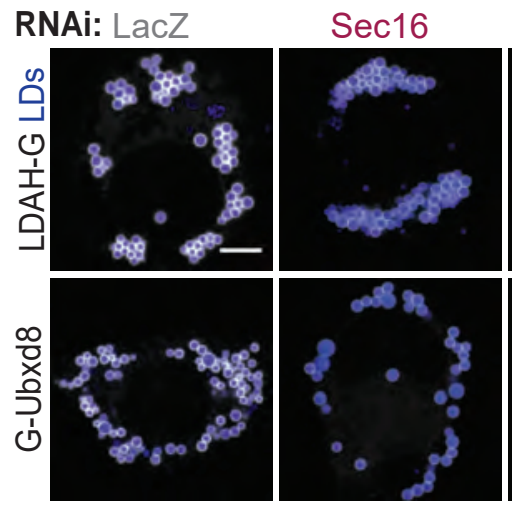

Tango1
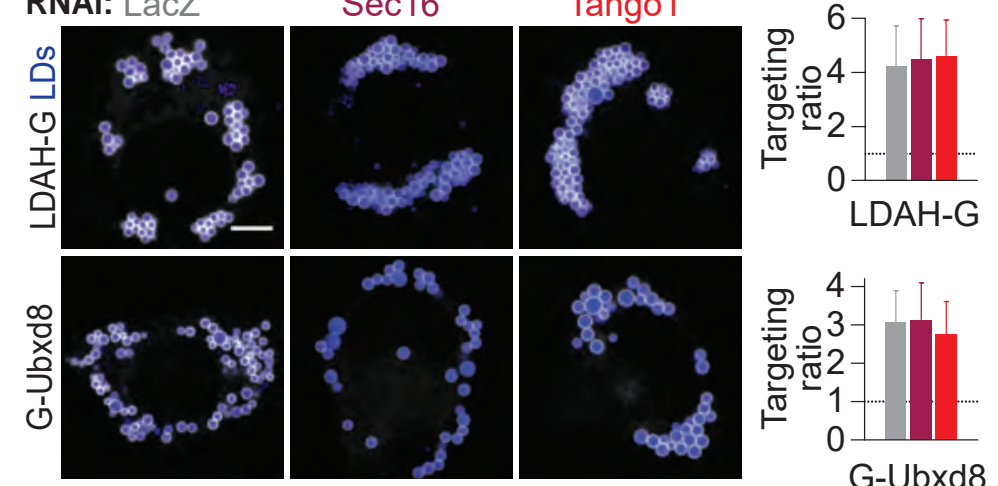

G

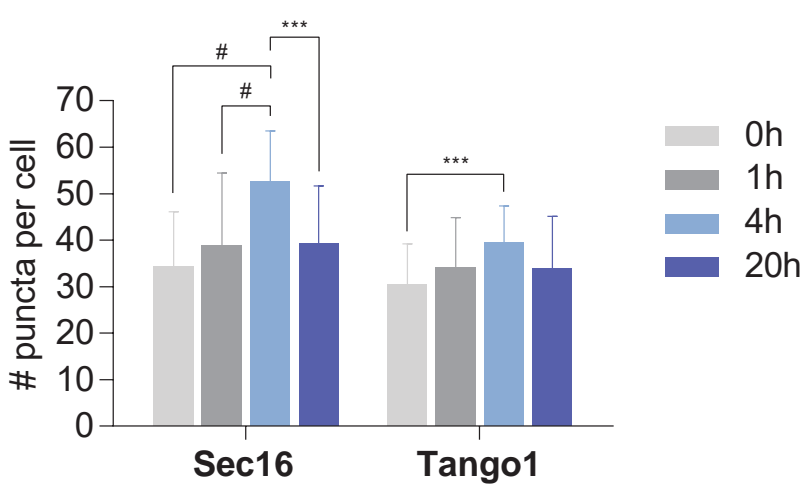

RNAi: LacZ Sec12

Sar1

政
B Late ERTOLD
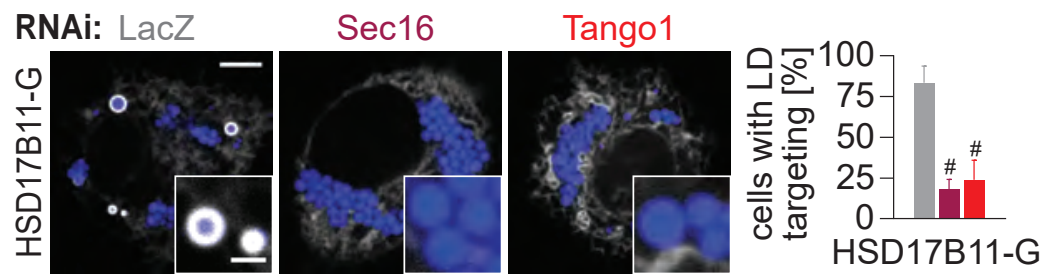

D

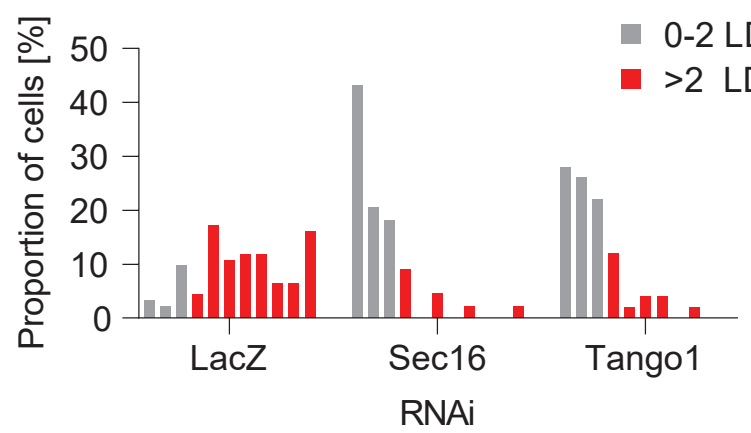

F CYTOLD
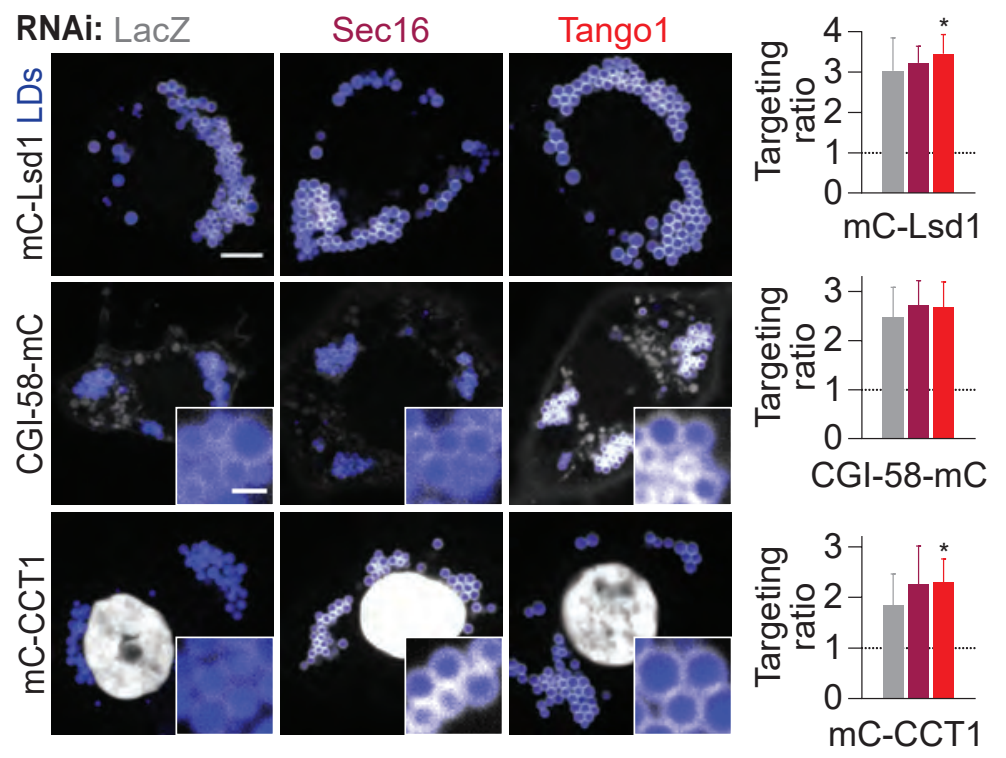

$\mathrm{H}$

OE: Sar1-H74G-EGFP
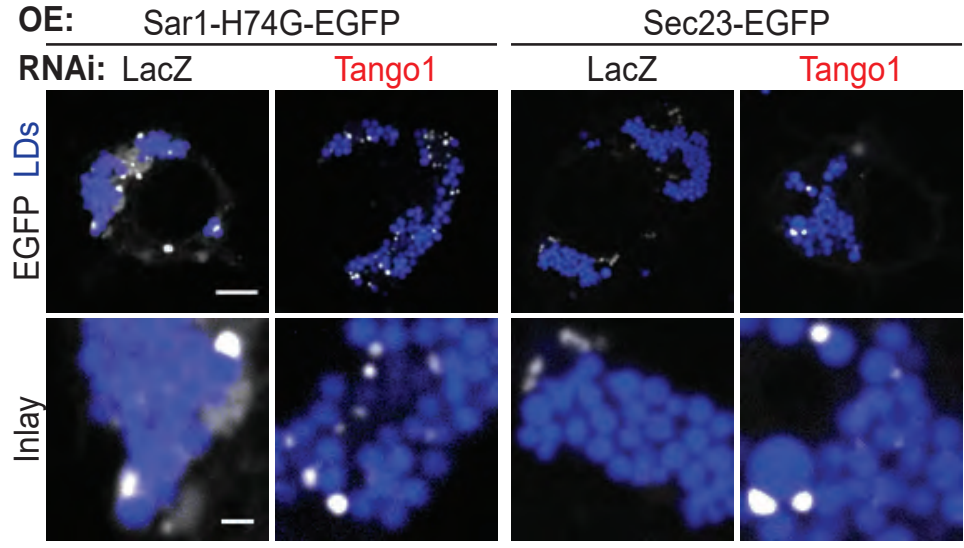


\section{A Seipin KO cells: $\mathbf{0 . 5 h}$ in oleate containing medium}
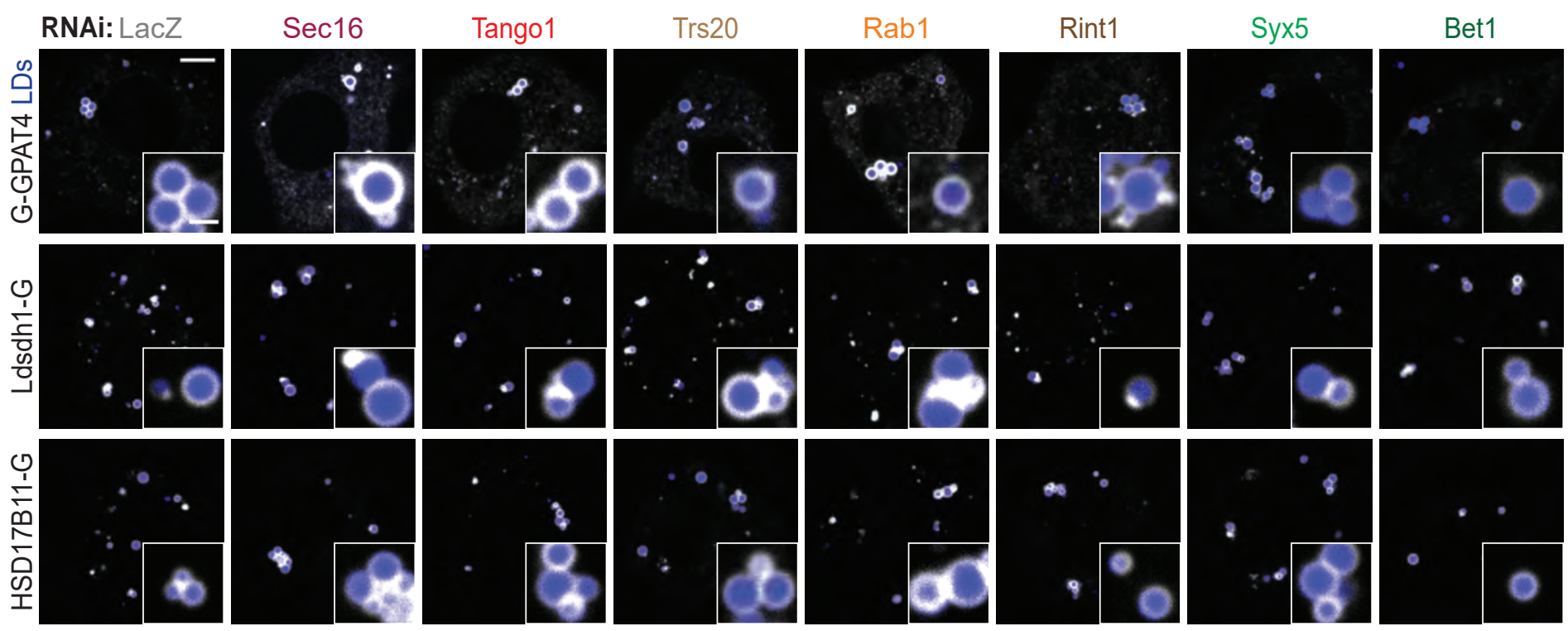

B
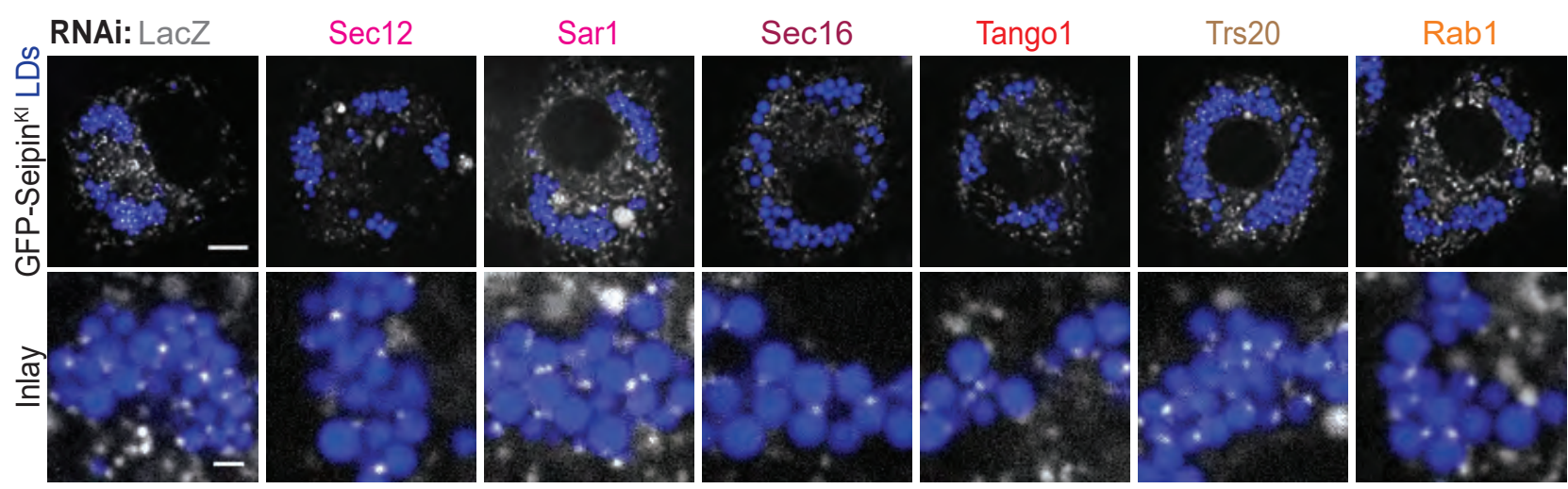

Rint1

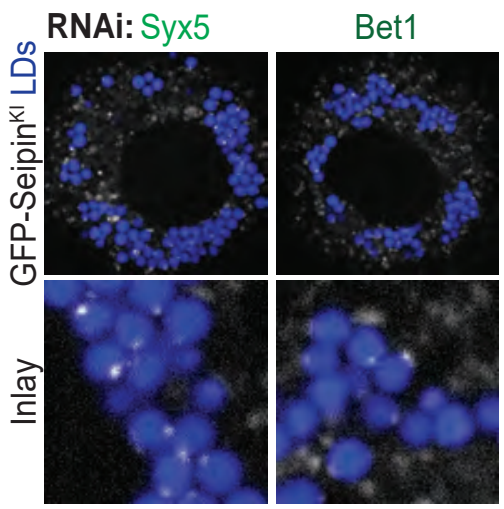

Membrin

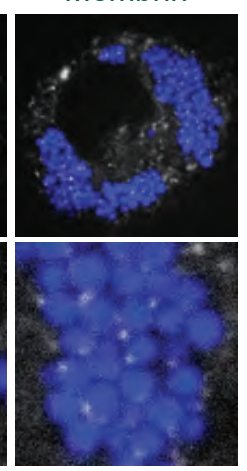


